\title{
Quinine, Whisky, and Sun Helmets: Amateur Medicine in British East and South-Central Africa, 1890-1939
}

\author{
Julia M. Wells
}

\author{
A Thesis Submitted to Victoria University of \\ Wellington in Fulfilment of the Requirements for the \\ Degree of Masters of Arts in History
}


For Nicky and Christina, with love 


\section{Table of Contents}





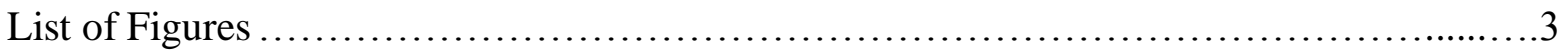

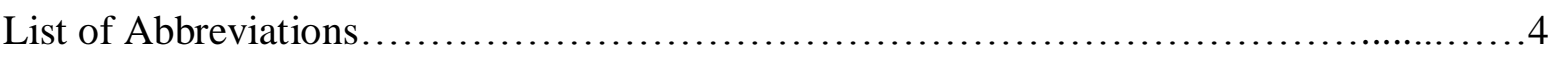

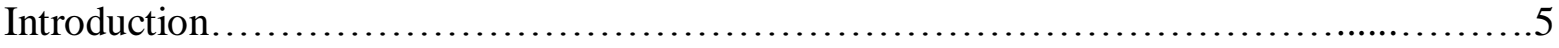

Chapter One

Into the 'White Man's Grave':

Sources of Medical Knowledge and Patterns of Amateur Practice.

Chapter Two

"What an Amount of Quinine we took!":

Amateur Disease Etiologies and Treatment Methods, with a Malaria Case Study....

Chapter Three

Sun Hats and Sundowners:

Managing Bodies and Minds in the Tropical Climate.

Chapter Four

"I was doctor":

Identity, Agency, and the White Woman's Burden

Conclusion.

Bibliography 


\begin{abstract}
Historians have extensively studied colonial doctors in Africa, and the connection between colonial medical services and imperial power. The focus has, however, fallen almost exclusively on medical practice by trained, qualified, and professional doctors and nurses, and neglected amateur treatments carried out by white settlers. This project explores amateur medical treatment in rural parts of British East and South-Central Africa, primarily Kenya and Rhodesia, between 1890 and 1939. It draws upon a range of memoirs, novels, letters, and advice books, most notably the memoirs of white settler women including Karen Blixen, Elspeth Huxley, Hylda Richards, and Alyse Simpson.

The time period is characterised by a marked contrast between the emergence of tropical medicine and hygiene on the one hand, and, on the other, a continuation of nineteenthcentury medical ideas, techniques, and widespread fears of the tropical climate. During the 1890s, tropical medicine and hygiene developed as specialised professional fields of expertise. Yet despite substantial tropical medical advances during and after the 1890s, the disease environment of East and South-Central Africa remained associated with high mortality and morbidity for white settlers. White bodies continued to be viewed, in the popular mind, as profoundly vulnerable to the African environment. Pre-germ theory etiologies of disease and treatment techniques persisted within white settler communities.

This thesis studies the medical skills, ideas, and practices of white settlers in the region. It demonstrates that much of settlers' medical care was performed by other settlers, positioning amateur treatment as crucial to colonial health. The discussion considers advice produced and disseminated through the flourishing print culture of African guidebooks and tropical medical handbooks; tropical outfitting; the translation of popular medical and hygiene advice into white settler practice; and the amateur treatment techniques (most importantly, quinine, alcohol, and disinfectant) and body protection methods that feature in memoirs and letters. Malaria forms a major theme in amateur treatment and prevention. The thesis also examines white settler women's amateur medical practice in African communities, and the shifting patterns of agency and colonial hegemony within these intimate medical encounters. It argues that settlers' medical practice displayed a distinctive set of techniques and ideas that adapted, re-worked, and re-interpreted professional medical advice. It concludes that settlers' amateur medical practice formed an essential element of colonial medicine and bolstered British authority in the region.
\end{abstract}




\section{Acknowledgements}

I would like to thank my supervisor, Charlotte Macdonald, for her guidance and advice throughout this project. Her comments and questions improved this project immensely. Thanks also to Kate Hunter, Nicky Hager, Christina Wells, and Thomas Bevan for reading earlier drafts, and for their insightful feedback.

Thank you to all the people in the master's room, especially Louisa and Evgeniya, for their support, friendship, Friday cake days, and tea time breaks. Thanks to my family and friends for their support, and particular thanks to Thomas for all his kindness and encouragement throughout the year. 


\section{List of Figures}

Figure One.......... The 1952, 1966, 1975, and 1985 editions of .6 Richards' Next Year Will Be Better.

Figure Two

Three tropical advice books that offered 31 medical information to European travellers.

Figure Three.

Graph of instances of amateur doctoring of local people that appear in European memoirs.

Figure Four.

BWC, The Romance of Exploration (London, .96 1934, p.16) in Johnson, 'Tabloid Brand Medicine Chests', 259.

Figure Five.

Harold Copping, The Healer (oil, 1916) in .96 Johnson, 'Tabloid Brand Medicine Chests', 260. 
List of Abbreviations

BWC................ Burroughs Wellcome \& Co.

CMS ................. Church Missionary Society

UMCA................. Universities' Mission to Central Africa 


\section{Introduction}

The ship carrying Hylda Richards and her family to South Africa reached Cape Town at nine o'clock in the evening on Monday, 13 August 1928. ${ }^{1}$ Born in London, Richards and her husband had farmed fifty acres in Kent for eight years, working, she wrote, "from dawn to dusk, seven days a week to make a living". ${ }^{2}$ The couple soon found, however, that "each year began in hope and ended in bitter disappointment" when "crops were either unsaleable or sold at a minimum price." ${ }^{3}$ Richards and her husband decided to migrate to Rhodesia for "another chance". ${ }^{4}$ Richards remained in London with her two young sons while her husband went ahead to Africa; she sailed for Cape Town on 19 July 1928, then travelled by land to Salisbury, Southern Rhodesia. ${ }^{5}$ After training on a farm outside Salisbury for a year, the family moved fifteen miles away to a farm of 2,500 uncultivated acres. ${ }^{6}$

On the farm, Richards found herself socially isolated from other white settlers and financially struggling. She missed cultural pursuits, her family and friends, and "was worried to death" about her children. ${ }^{7}$ The family was crippled by debt for years, and only in the late 1930s did they become more financially secure. Through the 1930s and 1940s, Richards wrote and published humorous poetry under the pseudonym ' $\mathrm{T}$ ', reflecting upon her experiences and hardships in rural Rhodesia. ${ }^{8}$ Annual collections of her verses became, as Adrian Roscoe observes, "something of a Rhodesian institution". ${ }^{9}$ For five weeks Richards also worked as a temporary editor of The Weekly Advertiser, "a little weekly paper" in Salisbury. ${ }^{10}$ In 1952, her memoir Next Year Will Be Better was published in South Africa by the London publishing house Hodder and Stoughton. It enjoyed moderate success, and was reprinted several times

\footnotetext{
${ }^{1}$ Hylda Richards, Next Year Will Be Better (Lincoln: University of Nebraska Press, 1985), first published 1952, 16.

${ }^{2}$ Ibid., 11.

${ }^{3}$ Ibid., 11.

${ }^{4}$ Ibid., 13.

5 Ibid., 15

${ }^{6}$ Ibid., $15-17$.

${ }^{7}$ Ibid., 31-32.

${ }^{8}$ Adrian Roscoe, The Columbia Guide to Central African Literature in English Since 1945 (New York: Columbia University Press, 2008), 67.

${ }^{9}$ Ibid., 68.

${ }^{10}$ Richards, 173.
} 
(figure one). A collection of her poetry, entitled Hurrah for the Life of a Rhodesian Farmer, was published in $1958 .^{11}$
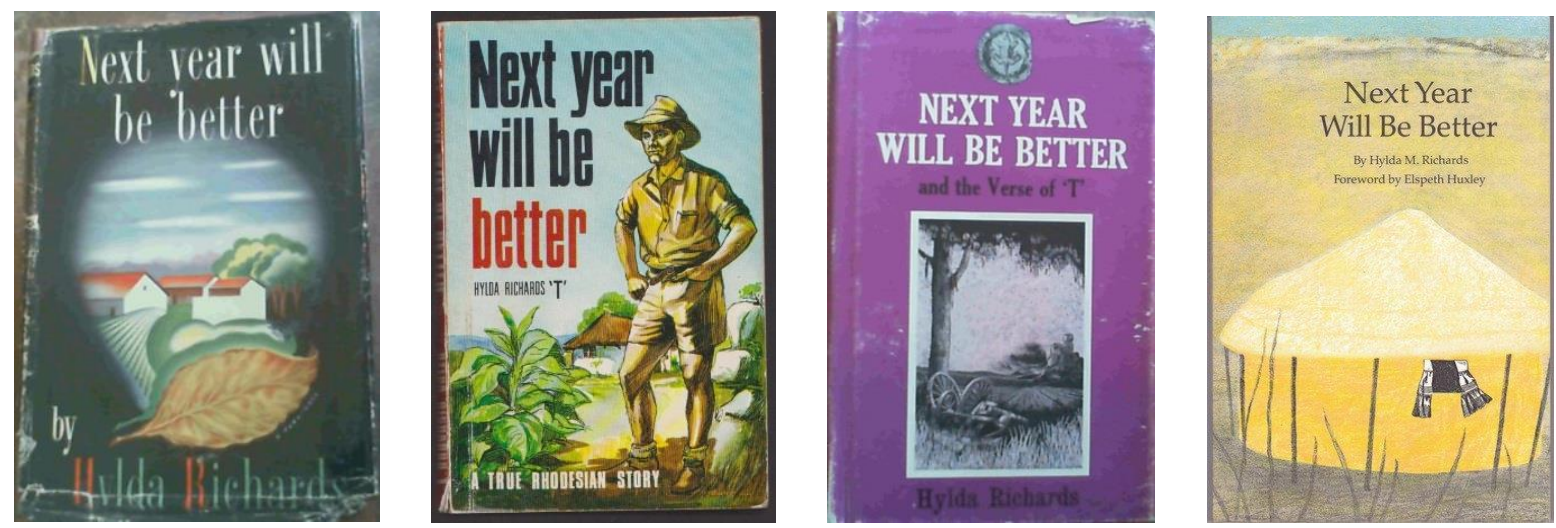

Figure One. The 1952, 1966, 1975, and 1985 editions of Richards' Next Year Will Be Better.

As in the memoirs of many white settlers in British Africa, disease and injuries play a major part in Next Year Will Be Better. Richards suffered from "repeated bilious attacks" that she attributed to sun exposure, dental problems, her "old enemy, tonsillitis", and - after continuous ill health, over-work, and financial strain - was eventually diagnosed as being "on the verge of a serious mental breakdown". ${ }^{12}$ Her sons Bryan and Peter, aged six and three on arrival, also experienced frequent illnesses and injuries, including veldt sores, ringworm, an accidental (and fortunately minor) gunshot wound, pneumonia, bilharzia, German measles, scarlet fever, and chronic, life-threatening asthma. ${ }^{13}$ Medical help was far from their farm and too expensive to consult unless absolutely necessary. ${ }^{14}$ During the rainy season the river often rose, cutting them off from town, telephone access, and so from doctors and the hospital. ${ }^{15}$ Despite living during a time of medical and scientific progress, in which the British press announced triumph after triumph against tropical disease, the Richards family were still profoundly vulnerable to both foreign and familiar illnesses. How did white settlers like Richards treat disease in rural colonial Kenya, Rhodesia, Nyasaland, Uganda, and Tanganyika, living far from recourse to medical professionals?

Richards performed first aid for her children and nursed and treated many of the family's illnesses, relieved only by occasional involvement from doctors and a few periods of

\footnotetext{
${ }^{11}$ Roscoe, 68.

${ }^{12}$ Richards, 31, 81, 88, 112, 137.

13 Ibid., 119, 130, 149-150, 164, 166.

${ }^{14}$ Ibid., 143.

15 Ibid., 142-143.
} 
hospitalisation. ${ }^{16}$ She also provided medical care, somewhat reluctantly, for local people living near her farm. ${ }^{17}$ In the years between 1890 and 1939, most white settlers, missionaries, and officials living in rural areas across British East and South-Central Africa did the same, despite having no formal medical qualifications. Many recorded their experiences of home treatment in letters, diaries, and memoirs, which when read together form a striking testament to the ubiquity of such treatment in rural areas. It is this phenomenon of amateur medical practice by the white residents of rural British East and South-Central Africa, both in their own communities and in local African communities, that is the subject of this study.

Richards and her family were part of the wave of immigrants who entered new territories in British Africa from the Second South African War onwards. The Scramble for Africa (c.18701910), in which European powers rapidly occupied African territory, had ended less than twenty years before Richards' arrival. ${ }^{18}$ By 1905, almost all of the African continent had been divided between Britain, France, Germany, Belgium, Italy, Portugal, and Spain, with Britain seizing by far the largest slice in terms of land, population, and share of sub-Saharan trade. ${ }^{19}$ In East and South-Central Africa, British crown rule was established in Zanzibar in 1890, Nyasaland in 1891, Uganda in 1893, Kenya in 1895, Tanganyika in 1920, and Northern Rhodesia in $1924 .{ }^{20}$ Infrastructure developed rapidly, and railways to carry settlers and commodities spread quickly across the landscape. ${ }^{21}$ Between 1905 and 1914, Kenya's white population tripled. ${ }^{22}$

The two main colonies of white settlement in British tropical Africa were Kenya and Rhodesia. The colonies were unusual as they fell between the two main modes of British colonialism, namely tropical colonies of exploitation and temperate colonies of settlement. ${ }^{23}$ White occupation and the quashing of armed resistance by existing peoples did not allay

\footnotetext{
${ }^{16}$ Ibid., 47, 119, 137, 142-143, 148-149, 166.

${ }^{17}$ Ibid., 83, 125, 144.

18 Johannes Fabian, Out of Our Minds: Reason and Madness in the Exploration of Central Africa (Berkeley: University of California Press, 2000), 5.

19 Andrew Roberts, 'Introduction' in Andrew Roberts (ed.), The Colonial Moment in Africa: Essays on the Movement of Minds and Materials, 1900-1940 (Cambridge: Cambridge University Press, 1990), 3.

${ }^{20}$ Anthony Kirk-Greene, Symbol of Authority: The British District Officer in Africa (London and New York: Tauris, 2006), 3-4.

${ }^{21}$ Roberts, 3.

${ }^{22}$ Dane Kennedy, Islands of White: Settler Society and Culture in Kenya and Southern Rhodesia, 1890-1939 (Durham: Duke University Press, 1987), 42.

${ }^{23}$ Ibid., 2.
} 
official and private concerns within the British community about the place of Europeans in tropical Africa. ${ }^{24}$ In Kenya in particular, public debate continued until the Second World War over its viability as a white settlement colony and the potential dangers of disease and degeneration in tropical climate; in short, whether Kenya could ever become, to use prominent settler Lord Delamere's phrase, a white man's country. ${ }^{25}$ Europeans in Africa shared such concerns with white communities in many other parts of the world. Warwick Anderson, for example, identified anxieties about climate at this time among white communities in Queensland and the Philippines. ${ }^{26}$ In British Africa, whiteness became a central point of identity and social organisation for European settler communities. ${ }^{27}$ Settlers struggled to develop successful export products and it was mineral and land speculation, rather than actual production, which earned fast profits. ${ }^{28}$ Agricultural market collapses during the Great Depression hit the colonies hard, although a minor gold rush in 1930s Kenya provided some alleviation. ${ }^{29}$ Yet despite ongoing doubts over white settler health and periodic economic stagnation, the white populations of Kenya and Rhodesia grew.

White migrants travelled to East and South Central Africa as settlers, missionaries, and officials. White settlers in Kenya and Rhodesia engaged in farming, mining, the professions, and business. Missionaries from many different organisations set up stations in the region. ${ }^{30}$ The numbers of colonial officials increased substantially over the early twentieth century. At the start of World War One, forty district administrators were stationed in Nyasaland, fifty-two in Uganda, and 177 in the East Africa Protectorate. ${ }^{31}$ By 1937, there were fifty-one in Nyasaland, eighty-three in Uganda, 109 in Northern Rhodesia, 164 in Kenya, 185 in Tanganyika, and twenty in Zanzibar. ${ }^{32}$ Passage to Rhodesia and Kenya was expensive and both the initial capital requirements and living costs were high. ${ }^{33}$ In both areas there were few

\footnotetext{
${ }^{24}$ Ibid., 5, 110-130.

${ }^{25}$ Ibid., 5.

${ }^{26}$ Warwick Anderson, Colonial Pathologies: American Tropical Medicine, Race, and Hygiene in the Philippines (Durham: Duke University Press, 2006); Warwick Anderson, The Cultivation of Whiteness: Science, Health, and Racial Destiny in Australia (Melbourne: Melbourne University Press, 2002).

${ }^{27}$ Kennedy, Islands of White, 6; Elspeth Huxley, Out in the Midday Sun: My Kenya (New York: Viking, 1987), 54 .

${ }^{28}$ Kennedy, Islands of White, 26-31.

${ }^{29}$ Ibid., 77-78.

${ }^{30}$ In East Africa at the beginning of the twentieth century, the Church Missionary Society (CMS), Church of Scotland Missions, Mill Hill Fathers, and the White Fathers (a Catholic mission organisation) all ran medical missions. Ann Beck, A History of the British Medical Administration of East Africa, 1900-1950 (Harvard University Press, 1970), 18; A. Scott Moreau, Gary Corwin and Gary McGee, Introducing World Missions: A Biblical, Historical, and Practical Survey (Grand Rapids: Baker Academic, 2004), 125; Martin Klein, Slavery and Colonial Rule in French West Africa (Cambridge: Cambridge University Press, 1998), 115.

${ }^{31}$ Kirk-Greene, Symbol of Authority, 4.

${ }^{32}$ Ibid., 5 .

${ }^{33}$ Kennedy, Islands of White, 6, 57, 116.
} 
opportunities for working class migrants, as settlers hired local labour for farm and domestic work. ${ }^{34}$ Furthermore, in Kenya the substantial Indian population occupied the economic spaces which in Rhodesia were filled by white artisans, clerks, and small business owners. ${ }^{35}$ The result were societies in which the majority of white settlers came from Britain's upper and middle classes. ${ }^{36}$ Kenya in particular had a reputation for being settled by the British aristocracy. ${ }^{37}$

The years of the Scramble for Africa were also revolutionary years for European medicine in the tropics. Tropical medicine as a defined medical specialty developed in the 1890s, alongside - and intimately tied to - Britain's annexation of African territory. From the 1880s, medical breakthroughs advanced the European understanding of disease in warm climates. Malaria research attracted a great deal of publicity and culminated in Ronald Ross's proof in 1897 that malaria parasites were transmitted by mosquitoes. ${ }^{38}$ Germ theory and understandings around antisepsis and asepsis advanced treatment efficacy in Europe and the tropics. ${ }^{39}$ Over the late nineteenth and early twentieth centuries the specialty of tropical medicine also developed, around which formed networks of researchers and clinicians with professional authority, institutions, and publications. ${ }^{40}$ The Liverpool School of Tropical Medicine and the Journal of Tropical Medicine were both established in 1898 and the London school was founded just one year later by Patrick Manson. ${ }^{41}$

The correlation between the growth of tropical medicine and Britain's expansion in Africa is not a coincidence. Since the 1960s, historians have recognised that medicine, practiced on Europeans and over colonial subjects, played a vital role in colonialism. ${ }^{42}$ Medicine could act as a tool of empire by preserving European health in the tropics, and facilitating conquest and administration of captured territory. ${ }^{43}$ Furthermore, as David Arnold explains, by the end of the nineteenth century "medicine developed as a central agency for the acquisition of knowledge and the extension of control," and became "one of the ways in which

\footnotetext{
${ }^{34}$ Ibid., 6.

${ }^{35}$ Ibid., $50-51$.

${ }^{36}$ Ibid., 6.

${ }^{37}$ Ibid., 47.

${ }^{38}$ C. R. George, 'Blackwater Fever: The Rise and Fall of an Exotic Disease', Journal of Nephrology 22 (2008), 123.

${ }^{39}$ Paul Landau, 'Explaining Surgical Evangelism in Colonial Southern Africa: Teeth, Pain and Faith', The Journal of African History 37.2 (1996), 264.

${ }^{40}$ Deborah Neill, Networks in Tropical Medicine: Internationalism, Colonialism, and the Rise of a Medical Specialty, 1890-1930 (Redwood City: Stanford University Press, 2012), 2-3.

${ }^{41}$ Mark Harrison, Disease and the Modern World: 1500 to the Present Day (Hoboken: John Wiley \& Sons, 2013), 134.

${ }^{42}$ Roy MacLeod, 'Introduction' in Roy MacLeod and Milton Lewis (eds.), Disease, Medicine and Empire: Perspectives on Western Medicine and the Experiences of European Expansion (London and New York: Routledge, 1988), 4.

${ }^{43}$ Ibid., 2.
} 
imperialism sought to 'know' the people and establish its authority over them." 44 Medical aid to colonised peoples was widely used by European powers to justify imperial ambitions; the image of the tropical doctor represented, to contemporaries, empire at its most benevolent. ${ }^{45}$ Medical interventions perfectly suited the wider narrative of colonialism bringing science and technology to 'primitivism' and 'superstition'.

Historians have noted that this supposed benevolence was undermined by the fact that many 'tropical' diseases had been generated, or at least worsened, through colonialism. European contact, land disenfranchisement, increased mobility, the breakdown of traditional public health systems, white settlement, and environmental modification all took their toll on colonised peoples' health. ${ }^{46}$ Despite the colonial medical presence in British East and Central Africa, Megan Vaughan judges the early twentieth century to be a "peculiarly unhealthy time" for the local population. ${ }^{47}$ Colonialism is now agreed to have brought more sickness and death to its subjects than it cured through medical interventions; in Africa, colonial medicine had a limited reach before the Second World War (indeed, before 1914 missions provided more medical care than the state) and medical successes were generally slow and restricted in scope ${ }^{48}$ Some historians, most notably Alfred Crosby, have also stressed the causative role of ecology/biology in European imperialism, describing germs - rather than colonists themselves - as "chiefly responsible for sweeping aside the indigenes and opening the Neo-Europes to demographic takeover". ${ }^{49}$ Although the legitimacy of separating and independently apportioning responsibility to diseases and colonists is debatable, Crosby does highlight the profound transformations diseases wrought on colonised societies. ${ }^{50}$

Medical historians have not always so closely associated colonial medicine with colonialism itself. Before the 1960s, most medical historians wrote triumphalist histories focusing on heroic biographical studies and individual epidemic diseases. ${ }^{51}$ The causal link between medical technology and European imperialism was established by Philip Curtin's

\footnotetext{
${ }^{44}$ David Arnold, 'Disease, Medicine and Empire' in David Arnold (ed.), Imperial Medicine and Indigenous Societies (Manchester: Manchester University Press, 1988), 17.

${ }^{45}$ Ibid., 3; Margaret Jones, 'The Ceylon Malaria Epidemic of 1934-35: A Case Study in Colonial Medicine', Social History of Medicine 13.1 (2000), 88.

${ }^{46}$ Megan Vaughan, Curing Their Ills: Colonial Power and African Illness (Stanford University Press, 1991), 3839.

${ }^{47}$ Ibid., 38.

${ }^{48}$ Arnold, 'Disease, Medicine and Empire', 4; Beck, 51; Megan Vaughan, 'Healing and Curing: Issues in the Social History and Anthropology of Medicine in Africa', Social History of Medicine 7.2 (1994), 288.

${ }^{49}$ Alfred W. Crosby, Ecological Imperialism: The Biological Expansion of Europe, 900-1900 (Cambridge: Cambridge University Press, 2004), first published 1986, 7, 196.

${ }^{50}$ Ibid., 197-108.

${ }^{51}$ MacLeod, 'Introduction', 4.
} 
influential quantitative studies of medical advances and British military personnel morbidity and mortality in the tropics. ${ }^{52}$ In the early 1970s historians argued for a wider exploration of medicine and imperial control, proposing that the raft of interwar and post-World War Two international health organisations were examples of the 'new imperialism' and were colonial medicine's successors. ${ }^{53}$ In 1988 two prominent edited collections - Arnold's Imperial Medicine and Indigenous Societies and Roy MacLeod and Milton Lewis's Disease, Medicine and Empire - established a wide base of case studies illustrating colonial medicine's commonalities (such as its connection with imperial control) as well as the importance of local specificity. ${ }^{54}$ Recent historical interests have broadened further, encompassing the production of tropical medicine within Britain (particularly useful here is Ryan Johnson's work on products for Europeans in the tropics) and tropical medicine as an international specialty. ${ }^{55}$ Contemporary historians such as Vaughan and Helen Tilley have also shifted away from a simple narrative of medical oppression to explore the negotiation of African agency and how medical discourses constructed African subjects. ${ }^{56}$

Tropical medicine also facilitated European imperialism in less direct ways. The speciality gave scientific validity to the idea of an inherently different and dangerous tropical world, the 'other' to Europe's safe and temperate climate. ${ }^{57}$ As the acceptance of germ theory de-emphasised climatic disease causation, tropical medicine's focus on parasites and vectors returned environment as central to disease production. ${ }^{58}$ To use Michael Worboys' phrase, diseases in the tropics became, under the influence of tropical medicine, tropical diseases: inextricably linked with colonised 'tropical' places, captured within a tropical medical

\footnotetext{
${ }^{52}$ Philip Curtin, The Image of Africa: British Ideas and Action, 1780-1850 (London: MacMillan, 1965); Philip Curtin, Death by Migration: Europe's Encounter with the Tropical World in the Nineteenth Century (Cambridge: Cambridge University Press, 1989).

${ }^{53}$ MacLeod, 'Introduction', 5.

${ }^{54}$ David Arnold (ed.), Imperial Medicine and Indigenous Societies (Manchester: Manchester University Press, 1988); Roy MacLeod and Milton Lewis (eds.), Disease, Medicine, and Empire: Perspectives on Western Medicine and the Experience of European Expansion (London: Routledge, 1988).

${ }^{55}$ See, for example, Ryan Johnson, 'Tabloid Brand Medicine Chests: Selling Health and Hygiene for the British Tropical Colonies,' Science as Culture 17.3 (2008), 249-268; Ryan Johnson, 'European Cloth and "Tropical" Skin: Clothing Material and British Ideas of Health and Hygiene in Tropical Climates,' Bulletin of the History of Medicine 83.3 (2009), 530-560; Ryan Johnson, 'Commodity Culture: Tropical Health and Hygiene in the British Empire,' Endeavour 32.2 (2008), 70-74; Ryan Johnson, 'Colonial Mission and Imperial Tropical Medicine: Livingstone College, London, 1893-1914,' Social History of Medicine 23.3 (2010), 549-566; Neill.

56 Vaughan, Curing Their Ills; Helen Tilley, Africa as a Living Laboratory: Empire, Development, and the Problem of Scientific Knowledge, 1870-1950 (Chicago: University of Chicago Press, 2011); Vaughan, 'Healing and Curing'.

${ }^{57}$ Arnold, 'Disease, Medicine and Empire', 7.

${ }^{58}$ Ryan Johnson, 'European Cloth and "Tropical” Skin': 547.
} 
paradigm, and under the authority of proliferating specialists and institutions. ${ }^{59}$ At the same time as highlighting the role of environmental factors in tropical disease, scientific advances also shifted part of the blame for disease that had been originally apportioned to tropical climates onto local people. ${ }^{60}$ Anderson argues that early twentieth century tropical medicine pathologised indigenous populations and so justified restrictive sanitary reforms. ${ }^{61}$

Although there is a substantial literature exploring colonial and tropical medicine, the bulk of work exclusively considers professional medicine. Outside a missionary context, few historians discuss amateur medical practice by colonists as part of the colonial medical system. One of the few and best studies of amateur medicine is Narin Hassan's Diagnosing Empire: Women, Medical Knowledge, and Colonial Mobility (2011), which explores the relationship between women's travel, women's travel writing, and medicine and colonialism in nineteenth century India and the Middle East. ${ }^{62}$ As part of her discussion, Hassan considers women travellers' doctoring of local people through a study of the intimate medical encounters between two Victorian women and their patients. ${ }^{63}$ Hassan concludes that amateur treatment was "a portable and sometimes spontaneous act that allowed women to domesticate and refashion medical knowledge in the colonies." ${ }^{64}$ No studies of colonial Africa explore amateur treatment so directly. Johnson examines missionaries trained at Livingstone College, yet as they received lectures from illustrious tropical medical researchers and (albeit limited) hospital training, their situation is hardly comparable to that of the average settler. ${ }^{65}$ In a 1996 article, Paul Landau notes the prevalence of amateur missionary treatment, but his argument is not targeted at the amateur nature of the medical interactions. ${ }^{66}$

The body is central to any discussion of health and sickness - it experiences states of illness and wellness, is transformed by them, and provides the means to communicate the experience. One of the paradoxes of European medicine in the tropics was the coexistence of a firm faith in Western science and medical technology alongside a perception of the European

\footnotetext{
${ }^{59}$ Michael Worboys, 'Germs, Malaria and the Invention of Mansonian Tropical Medicine: From "Diseases in the Tropics" to "Tropical Diseases"” in David Arnold (ed.), Warm Climates and Western Medicine: The Emergence of Tropical Medicine, 1500-1900 (Amsterdam: Rodopi, 1996), 183, 195-197.

60 Rod Edmond, 'Returning Fears: Tropical Disease and the Metropolis' in Felix Driver and Luciana Martins (eds.), Tropical Visions in an Age of Empire (Chicago: Chicago University Press, 2005), 181.

${ }^{61}$ Anderson, Colonial Pathologies, 2.

${ }^{62}$ Narin Hassan, Diagnosing Empire: Women, Medical Knowledge, and Colonial Mobility (Farnham: Ashgate, 2013), 3.

${ }^{63}$ Ibid., 41.

${ }^{64}$ Ibid., 40.

65 Johnson, 'Colonial Mission and Imperial Tropical Medicine', 555-556.

${ }^{66}$ Landau instead focuses on the symbolic and spiritual implications of missionaries' practice of minor surgery. Landau, 261-281.
} 
body as intensely vulnerable to the tropical environment. Both medical authorities and many settlers conceived of the white body as fragile - a closed entity that could be unbalanced and invaded by its surroundings. ${ }^{67}$ Many specialised products developed, which promised to protect the vulnerable bodies of their customers from the tropical exterior. The universalising tendencies of British tropical manufacturers and medical authorities, combined with networks of empire, meant that body protection regimes and equipment across Britain's tropical empire displayed strong commonalities. The body management techniques that Elizabeth Collingham describes during the British Raj, for example, paralleled those employed in British Africa. ${ }^{68}$

Despite trans-imperial similarities, historians have repeatedly emphasised the geographic and temporal specificity of colonial and tropical medicine. Given the importance of local context, histories of East and South-Central Africa (in particular Kenya and Rhodesia) are vital for positioning a discussion of medicine in the region. There is, of course, a wealth of national and regional histories, but this project has relied most heavily on Dane Kennedy's work. Kennedy's Islands of White: Settler Society and Culture in Kenya and Southern Rhodesia, 1890-1939 (1987) is particularly useful as it engages with the questions of body management that emerge from Collingham and Johnson's scholarship. ${ }^{69}$ Kennedy not only describes the protective techniques and equipment that colonists used to shield their bodies against the environment, but also considers the psychological and community functions that such theories and equipment offered white settler societies in Kenya and Rhodesia. ${ }^{70}$ Histories of the civil service in Africa, most notably those by Anthony Kirk-Greene, are also important sources. $^{71}$

This project is based on the contention that amateur treatment in British East and SouthCentral Africa was a fundamental element of the colonial medical system that bolstered British authority and control. It will explore how white settlers gained medical knowledge and then applied it in every-day home medical treatment. It will question whether settlers' medical approaches displayed shared characteristics, in terms of focus, techniques, and etiologies, which would allow amateur treatment and disease prevention to be considered a distinctive body of practice. Lastly, it will examine the shifting patterns of agency and colonial hegemony

\footnotetext{
${ }^{67}$ Elizabeth Collingham, Imperial Bodies: The Physical Experience of the Raj, c.1800-1947 (Cambridge: Polity, 2001), 2.

${ }^{68}$ Collingham.

${ }^{69}$ Kennedy, Islands of White, 109-127.

${ }^{70}$ Ibid.

${ }^{71}$ See, for example, Kirk-Greene, Symbol of Authority; Anna Crozier, Practising Colonial Medicine: The Colonial Medical Service in British East Africa (London and New York: I.B.Tauris, 2007); Dalton, Heather, 'The Gold Coast: The Wives' Experience,' Oxford Development Records Project Report No. 15 (Oxford: Rhodes House Library, 1985).
} 
within medical encounters between European amateur doctors and African patients. The term 'amateur', used here to signal individuals without formal medical training or qualifications, does not necessarily indicate an absence of any medical knowledge or that treatments were unsuccessful. European migrants to Africa, as will be illustrated in chapter one, learned about medicine through many channels and some developed substantial skills. It does, however, signal more accurately than alternative terms (such as 'lay' or 'popular') the location of settler practice outside of professional medicine. ${ }^{72}$

Throughout the late nineteenth and early twentieth centuries, autobiographical writings from Britain's African territories captured public attention and garnered wide readerships. Explorers, settlers, missionaries, and officials produced memoirs and novels that piqued interest in tropical places and added to the British knowledge and awareness of tropical Africa. Although a few highlighted empire's darker side (Joseph Conrad's 1899 Heart of Darkness being the classic example), colonial memoirs and novels generally depicted the British presence in Africa as positive ${ }^{73}$ In the interwar period, 'Kenya novels' (popular romantic fiction set in Kenya's white highlands) in particular romanticised the East African colonial experience for the British reading public. ${ }^{74}$ The period between 1890 and 1939 is boxed by two of the most influential (and controversial) African colonial memoirs: Henry Morton Stanley's In Darkest Africa (1890) and Karen Blixen's iconic memoir Out of Africa (1937). ${ }^{75}$ Indeed, probably the best illustration of the influence of literary representations of empire is Out of Africa's continuing success and the persistence of its romanticised images within popular culture. ${ }^{76}$

Colonial memoirs present a number of challenges for the historian. Even the terms that define health, bodies and disease, such as 'the tropics', are problematic for contemporary readers. It is impossible to avoid them, but they necessitate qualification and explanation. The term 'tropics' was a fundamental concept for Europeans in tropical empires and it spawned

\footnotetext{
72 The use of the term 'lay' in opposition to 'professional' is complicated in colonial Africa by its religious connotations and the substantial amateur and professional missionary involvement in healthcare. The term 'popular' is also somewhat misleading, as the European communities discussed here never made up more than a small proportion of the overall population of the region.

${ }^{73}$ Angela Woollacott, Gender and Empire (London: Palgrave Macmillan, 2006), 67-68.

${ }^{74}$ C. J. D. Duder, 'Love and the Lions: The Image of White Settlement in Kenya in Popular Fiction, 1919-1939', African Affairs 90.360 (1991), 429, 432, 434.

${ }^{75}$ Joseph Bristow, Empire Boys: Adventures in a Man's World (New York: Harper Collins Academic, 1991), 128; Karen Blixen, Out of Africa and Shadows on the Grass (London: Penguin, 1985), first published 1937 and 1961.

${ }^{76}$ Duder, 438.
} 
related concepts (such as tropical medicine and tropical hygiene), which rested on the same assumption of a distinctive tropical zone that was inherently pathological to the white body and mind. Today, 'tropical' diseases are generally considered diseases of poverty rather than place. ${ }^{77}$ This discussion does use the term 'tropical', but to signal the nineteenth and early twentieth-century usage of it, rather than as a geographic/medical reality. In their descriptions of amateur doctoring of local people, white authors rarely provide detail about their patient, generally describing them as 'black' or 'African'. When the information is there, this discussion always uses patients' names or ethnic identities, but the colonial homogenisation typical of the sources restricts the ability to grant all African individuals equal names and voices as Europeans.

This project is based primarily on twenty-four memoirs and memoir collections written by white migrants to Africa, supplemented by twenty-one advice books and travel guides, nine letters or letter collections, five diaries or diary notes, four novels, five reports, and assorted contemporary newspapers. The letter sets, newspapers, and diaries were selected based on availability (they are generally scarce and difficult to access) and the memoirs were chosen to achieve a spread of sources across geographic locations, time, profession, and social class. ${ }^{78}$ For many authors, writing (whether for publication or not) was a crucial method of shaping and understanding the transition and rupture of migration to British Africa. Others wrote as witnesses to a historical moment. As increasing settlement, World War Two, Kenya's Mau Mau Uprising (1952-1960), and independence steadily transformed the region, many settlers felt driven to record their memories of a world they saw rapidly vanishing. Some memoirs even explicitly claim to be historical documents. Kenneth Bradley, a popular and prolific author, commented about his Diary of a District Officer that "one day, since it was at least accurate, it may, I hope, be useful to some historian". ${ }^{79}$ For a few, payments from writing could also

\footnotetext{
${ }^{77}$ MacLeod, 'Introduction', 5.

${ }^{78}$ Few complete letter sets from colonial Kenya have survived, as letters were typically either destroyed or lost during journeys home, or in the mass departures following independence. Letters and diaries that exist are usually inaccessible, undigitalised, and minimally catalogued in overseas archives, although a small number were accessible through the Empire Online database, library ordering, and published collections. Newspapers from the region are also difficult to access, except through a single database of colonial African newspapers, which was not available for use in this project. Interloaning the following newspapers was attempted: Tropical Life; The Leader of British East Africa; Rhodesia Journal; The East African Standard, Mombassa Times \& Uganda Argus; The Livingstone Mail; and The African World. Only The African World was available to interloan in large quantities (several reels of microfilm versus articles from a single issue). The African World was supplemented by the small numbers of periodicals available through Empire Online. Patricia Lorcin, Historicizing Colonial Nostalgia: European Women's Narratives of Algeria and Kenya 1900-Present (London: Palgrave Macmillan, 2011), 15.

${ }^{79}$ Kenneth Bradley, Once a District Officer (London: Macmillan, 1966), 111.
} 
supplement meagre civil service pay or farming profits. Bradley, for example, funded his children's schooling with instalments for Blackwood's Magazine. ${ }^{80}$

The combination of the settler communities' high levels of education, social privilege, and their sense of living in an era and location of particular interest produced a colonial community with a strongly literary tradition. From the late nineteenth century onwards a large number of memoirs recounting Europeans' experiences in British East and South-Central Africa were published. ${ }^{81}$ Colonial service authors usually wrote for a small audience of family/friends and were often not published, or were printed in short runs for private distribution. ${ }^{82}$ Some memoirs did achieve commercial success, published by large publishing houses and widely read by the general public. In its first few months Kenneth Bradley's Diary sold over 100,000 copies. $^{83}$

Women are well represented among colonial authors from British East and SouthCentral Africa. Female settlers, travellers, missionaries, and the wives of civil servants all published memoirs reflecting on their time in British Africa. A number of women achieved fame as authors. Blixen's Out of Africa is arguably the most famous of all colonial memoirs and Elspeth Huxley and Beryl Markham, for example, also produced well-regarded books with a wide readership. ${ }^{84}$ Kirk-Greene has observed that there are comparatively large numbers of African colonial memoirs written by the wives of civil servants, when compared to the number of 'wife of' books related to other professions. ${ }^{85}$ Kirk-Greene suggests that the difference indicates that civil service wives were intimately involved with their husbands' careers, more so than in most professions in Britain. ${ }^{86}$ The same comment could be made for female missionaries, or women who settled farms in British Africa.

The same impetus for writing - the sense of having lived through something worth recording - is strong in women's writing, coupled with the additional factor of having done so as a woman. Although women's writings generally represent the authors as brave, capable and

\footnotetext{
${ }^{80}$ Ibid., 110.

${ }^{81}$ The bibliography of Kirk-Greene's Symbol of Authority lists sixty-two unpublished memoirs, 124 published memoirs, and fifteen collected memoirs, plus many more written reminiscences collected as part of Rhodes House Library projects. As Kirk-Greene focuses on District Officers, the wider canon of white settler and missionary literature includes vastly more titles. Kirk-Greene, Symbol of Authority, 306-308, 311-315.

${ }^{82}$ Alistair Tough, 'Oral Culture, Written Records and Understanding the Twentieth-Century Colonial Archive: The Significance of Understanding from Within’, Archival Science 12.3 (2012), 259.

${ }^{83}$ Ibid.

${ }^{84}$ Blixen, Out of Africa; Elspeth Huxley, The Flame Trees of Thika: Memories of an African Childhood (London: Chatto \& Windus, 1959); Beryl Markham, West with the Night (London: Virago Press, 1988), first published 1942.

${ }^{85}$ Kirk-Greene, Symbol of Authority, 206.

${ }^{86}$ Ibid.
} 
competent, often relishing the opportunities for outdoor pursuits and physical work that British Africa brought, they nonetheless draw heavily upon a sense of transgression: of being a woman in a man's country. Maria Frawley notes the frequency of gender in the titles of Victorian women's travel writing; another common feature was the notion of being 'alone' in Africa (despite the inevitable presence of numerous African servants and porters), an image given greater potency by the author's femininity. ${ }^{87}$ Thus missionary Mathilde Goy's memoir was entitled Alone in Africa and Hellen Caddick's travel volume A White Woman in Central Africa. ${ }^{88}$ Jessie Currie's The Hill of Good-Bye: The Story of a Solitary White Woman's Life in Central Africa tantalised her audience by referencing her gender, whiteness, and racial isolation all in one title. ${ }^{89}$

The contents of white women's African memoirs generally differed from memoirs written by men. Victorian women's travel writing about Africa was generally intended for a female audience, providing domestic detail and discussing the author's emotional reactions to her surroundings. ${ }^{90}$ The climate, isolation, and mental and physical illnesses are common subjects. ${ }^{91}$ Men's memoirs are characteristically reticent on the subject of physical health. While male authors do mention illnesses, they generally do so briefly and vaguely. On mental health they are almost silent, although "nervous disorders" (particularly neurasthenia) were a very common cause of invaliding from the tropics, and the colonial administration in Africa viewed mental and physical wellbeing as equally important for their District Officers. ${ }^{92}$ For example, Donald Cameron's My Tanganyika Service and some Nigeria barely mentions mental health, yet two relatively brief comments reveal that he temporarily resigned after he "collapsed completely", overcome by the strain of constant work. ${ }^{93}$ In contrast, Richards, who also nearly had "a serious nervous breakdown" for similar reasons, discusses her struggles extensively. ${ }^{94}$ Furthermore, Cameron redirects his mental health into the public domain as context for his opinions on rest leave, while Richards confines her writing to her own experiences. ${ }^{95}$

\footnotetext{
${ }^{87}$ Maria Frawley, A Wider Range: Travel Writing by Women in Victorian England (Madison: Fairleigh Dickinson University Press, 1994), 105; Karen Tranberg Hansen, Distant Companions: Servants and Employers in Zambia, 1900-1985 (Ithaca: Cornell University Press, 1989), 37.

${ }^{88}$ Mathilde Keck Goy, Alone in Africa; Or, Seven Years on the Zambesi (London: James Nisbet \& Co., 1901); Helen Caddick, A White Woman in Central Africa (London: T. Fisher Unwin, 1900).

${ }^{89}$ Jessie Monteath Currie, The Hill of Good-Bye: The Story of a Solitary White Woman's Life in Central Africa (London: George Routledge \& Sons, 1920).

${ }^{90}$ Catherine Barnes Stevenson, Victorian Women Travel Writers in Africa (Farmington Hills: Twayne Publishers, 1982), 9,23

${ }^{91}$ Ibid., 19.

${ }^{92}$ Crozier, Practising Colonial Medicine, 95; Kirk-Greene, Symbol of Authority, 166.

${ }^{93}$ Donald Cameron, My Tanganyika Service and Some Nigeria (G. Allen, 1939), 233, 261-262.

${ }^{94}$ Richards, $137-138$.

${ }^{95}$ Cameron, 269.
} 
Men's minimal discussion of health is probably attributable to several factors: an overall focus on public rather than private life, an eschewing of the domestic, and the association between African colonies and idealised hyper-masculinity. Boys' adventure stories in tropical settings, exemplified by the works of George Henty, created an image of the "empire as an array of exciting places where [men] could test their mettle and prove worth". ${ }^{96}$ Leopards, raging torrents and threatening tribesmen all became challenges for enterprising, cool, and manly young men. Although exotic tropical diseases held a certain glamour (compare the relatively frequent mentions of malaria to the almost total silence about dysentery and diarrhoea), tales of a male protagonist sweating and shaking in a tent held little of Henty's heroism. For women, who were assumed to be physically vulnerable in the masculine African climate, describing illnesses in print conformed to societal expectations.

Women's memoirs also include far more information on the amateur treatment of local people. White men and women were expected to provide medical aid to their African staff and the surrounding communities. The 1922 Handbook of Nyasaland commented that "except in large centres Europeans in Nyasaland will be obliged to attend to the ailments of their native labourers and of villagers". ${ }^{97}$ As late as 1939, Emily Bradley's Household Book for Africa suggested that the European be ready to act as doctor for "the Africans in his charge". ${ }^{98}$ Both men and women carried out such treatment, but when white women were present the responsibility typically fell to them. Women's domestic role extended into a perceived duty of care and motherhood towards local African populations. ${ }^{99}$ White women nursed, carried out first aid, and performed basic medical treatment in African communities, liberally recording their experiences in memoirs. While this project does utilise sources from men and women, women's writings form the backbone.

Memoirs make both problematic and useful sources. They are mediated and reshaped records of an author's life, usually created later in life with the passage of time allowing for retelling, readjustment, and (selected) forgetting. With attitudes towards race and colonialism shifting dramatically after World War Two, memoirs written since 1945 have a particularly high likelihood of having been reshaped to align more closely with contemporary thought. Gillian Whitlock, for example, situates Huxley's The Flame Trees of Thika (1959) as part of

\footnotetext{
${ }^{96}$ Woollacott, 60.

${ }^{97}$ Stephen Samuel Murray, A Handbook of Nyasaland (London: Crown Agents for the Colonies, 1922), 231.

${ }^{98}$ Emily Bradley, A Household Book for Africa (Oxford: Oxford University Press, 1939), 158.

${ }^{99}$ Elsbeth Locher-Scholten, 'So Close and Yet so Far: The Ambivalence of Dutch Colonial Rhetoric on Javanese Servants in Indonesia, 1900-1942' in Julia Clancy-Smith and Frances (eds.), Domesticating the Empire: Race, Gender, and Family Life in French and Dutch Colonialism (Charlottesville: University of Virginia Press, 1998), 9.
} 
the construction of a white Kenyan indigeneity and narrative of racial harmony in the wake of the Mau Mau. ${ }^{100}$ The problem of historical re-writing is most acute when discussing Europeans' treatment of local peoples, but no parts of memoirs ever provide a clear window onto the past. Editors and publishers could also adjust the content and message of memoirs, as a few well-known examples make clear. ${ }^{101}$ Scholarship on colonial literature from across disciplines helps interpret colonial texts, including exploring the specific genres of travel writing, women's travel writing, and women's colonial autobiography. ${ }^{102}$

Within memoirs, medical anecdotes play complex roles. The structural conventions and audience entertainment required of travelogues and memoirs necessitated moments of drama and danger. ${ }^{103}$ Alongside stories of near misses with big game, the most reliable way to provide these elements was through graphic descriptions of exotic diseases and injuries. For some, vivid descriptions of sickness and suffering appear almost as offerings, with hardship giving a claim to African territory. Illness and death act as a penance for occupation, and pain invokes a certain belonging. Whitlock explains that scenes of burial as metaphors for claiming the land are common in settler texts. ${ }^{104}$ Denys Finch-Hatton's famous burial scene in Out of Africa, for example, renders him inseparable from the continent, and the lions that sit upon his grave signal Africa's acceptance. ${ }^{105}$ Tales dispensing medical aid to local people position the author as part of a benevolent empire, removed from settler brutality. They represent, therefore, an assertion of the author's innocence (reminiscent of the strategy of 'anti-conquest' that Mary Louise Pratt identifies in white men's African travel writing), while still retaining a position of authority. ${ }^{106}$ Although this project will not deal at length with medical anecdotes as written and textual phenomena - instead considering them mainly as historical evidence - the two cannot be separated, and the issue of medical tales as literary devices will recur throughout the discussion.

\footnotetext{
100 Gillian Whitlock, The Intimate Empire: Reading Women's Autobiography (London: Cassell, 2000), 131.

${ }^{101}$ For example, Ruth Fisher's Twilight Tales of the Black Baganda was so named by her publisher because of the British public's relative familiarity with the Baganda people; Fisher was furious as her book was set among the Bunyaro. Cedric Pulford, Casualty of Empire: Britain's Unpaid Debt to an African Kingdom (Woodford Halse: Ituri Publications, 2007), 88.

${ }^{102}$ In particular, this project has drawn on the work of Gillian Whitlock, Elleke Boehmer, Sarah Mills, Mary Louise Pratt, Catherine Barnes Stevenson, and Maria Frawley to understand the textual conventions of memoirs and travel writing. Whitlock; Stevenson; Frawley; Elleke Boehmer, Colonial and Postcolonial Literature: Migrant Metaphors (Oxford University Press, 1995); Sara Mills, Gender and Colonial Space (Manchester: Manchester University Press, 2005); Mary Louise Pratt, Imperial Eyes: Travel Writing and Transculturation (London and New York: Routledge, 1992).

${ }^{103}$ Fabian, 87.

104 Whitlock, 113.

105 Ibid.

106 Pratt defines 'anti-conquest' as a literary device that allows white bourgeois subjects to state simultaneously European hegemony and their own innocence with respect to the more violent and overtly coercive aspects of colonial control. Pratt, 7.
} 
Although memoirs present challenges, they hold one substantial advantage. The many roles that medical anecdotes play in memoirs results in their frequent inclusion. The same cannot be said for letters and diaries. Letters and diaries can be almost impossible to interpret without frequently unavailable background information, and also often include less information about medical experiences than memoirs. Like memoirs, letters and diaries are constructed documents and are also subject to audience influence. ${ }^{107}$ Kirk-Greene sums up the problem when he writes that, "as for letters home ... they often tend to omit things that 'Mum would rather not read about' or 'Dad would not be interested in'". ${ }^{108}$ In Cara Buxton's letters from Kenya to her nephew Desmond, for example, she does not write to him about a serious illness, in which she "as near died as made no difference", until she had almost recovered, and even then she gave almost no detail about her diagnosis, symptoms, or treatment. ${ }^{109}$ Rather, she joked and made light of the experience. ${ }^{110}$

Examining European migrants from many professions across several colonies raises the question of whether it is valid to generalise about such a range of individuals. Although there was no single, collective colonial medical experience, this work proposes that the medical experiences of missionaries, settlers, and officials in rural areas across British East and SouthCentral Africa were sufficiently similar to discuss them as a group. Kennedy argues that while Kenyan and Rhodesian settler societies were certainly not identical, they did share a common culture, a common set of beliefs around the African climate and peoples, and similar pressures for social conformity, as well as similar environments and demographics. ${ }^{111}$ Kirk-Greene suggests that there was a fundamental similarity in the civil service in all Britain's African territories, with a "shared idiom and common ethos". ${ }^{112}$ White communities did include many social divisions, but at the same time, the finer divisions should not overshadow the fundamental similarities between colonists. ${ }^{113}$ Even the apparently substantial difference

\footnotetext{
${ }^{107}$ Lorcin, 15; Georgina Endfield and David Nash, "'Happy Is the Bride the Rain Falls On": Climate, Health and "the Woman Question" in Nineteenth-Century Missionary Documentation,' Transactions of the Institute of British Geographers 30. 3 (2005), 382.

${ }^{108}$ Kirk-Greene, Symbol of Authority, xix-xx.

${ }^{109}$ Cara Buxton to Desmond Buxton, 7 February 1916, GB 0162 Micr.Afr.585, Rhodes House Library, Oxford; Cara Buxton to Desmond Buxton, 14 April 1916, GB 0162 Micr.Afr.585, Rhodes House Library, Oxford.

${ }^{110}$ Ibid.

${ }^{111}$ In both Kenya and Rhodesia the local population substantially outnumbered white setters. In Kenya the ratio was 1 to 175, while in South Rhodesia it was 1 to 25. Kennedy, Islands of White, 1, 8.

112 Kirk-Greene, Symbol of Authority, xviii.

113 Julian Scott, who grew up in Kenya, later described the settler community as divided into three tribal groups: the English aristocracy, civil servants, and settlers. Huxley's The African Poison Murders vividly illustrates the stratifications among settlers themselves. Duder, 436; Elspeth Huxley, The African Poison Murders (New York: Penguin, 1989), first published as Death of an Aryan, 1939; Joan Considine and John Rawlins (eds.), Childhood Memories of East Africa, 1920-1963 (Slyne-with-Hest: Bongo Books, 2002), 72.
} 
between 'permanent' settlers and officials is less stark than it might appear. Officials could spend many years in various postings through the region, and settlers frequently migrated back to Britain; indeed, many settlers always intended to return to Britain. ${ }^{114}$ Through the remainder of the discussion, the term 'settler' is used to describe Europeans who, for varying purposes and lengths of time, lived in rural British East and South-Central Africa.

The final point to touch on is the chosen time period. The years between 1890 and 1939 saw great changes - the development of formal administration within the region, substantial British migration, and the emergence and consolidation of the tropical medicine speciality but also many continuities. Throughout the half century in question, the advice literature remained remarkably consistent, and settlers continued to live in rural isolation and perform medicine themselves. 1890 is an appropriate place to begin the discussion, as it was not only a crucial decade for the development of the tropical medical specialty, but also the decade in which much of East Africa came under British rule. The beginning of World War Two forms a natural ending. Over the war years many important medical developments occurred, including new synthetic antimalarials, insecticidal DDT, and penicillin. After the war political changes destabilised settler society, with the Mau Mau Uprising followed by decolonisation through the early 1960s.

The chapters are ordered thematically, rather than chronologically, and primarily consider 1890-1939 as a single period. They will move through discussing amateur medicine in European communities, tropical hygiene and body management, and amateur medicine administered to local people. The chapters will, however, make reference to changes within the timeframe where appropriate. It also should be noted that this project primarily examines physical illnesses and injuries. Mental health in early twentieth-century colonial Africa is a fascinating subject, and does display many parallels to physical health. Space constraints, however, prohibit its inclusion here in any depth, although it will be discussed briefly in chapter three.

Richards' story, then, takes on a greater significance when viewed in the context of amateur medical practice. Rather than individual acts of medical intervention, her amateur doctoring becomes part of a distinctive body of practice that, alongside professional medicine, played its part in sustaining the colonial presence in British Africa. The first chapter will

\footnotetext{
${ }^{114}$ In the interwar years, according to customs data, nine Europeans exited Kenya for every ten who entered it. Alyse Simpson, The Land That Never Was (Lincoln: University of Nebraska Press, 1985), first published 1937, 83-84; Dane Kennedy, 'Introduction' in Alyse Simpson, The Land That Never Was (Lincoln: University of Nebraska Press, 1985), v.
} 
explain how settlers like Richards learned about medicine; it will discuss the conditions that encouraged settlers to practice medicine, and evaluate how their practice related to professional and indigenous systems of medicine. The second chapter will explore the distinctive etiologies of disease and techniques of amateur medicine, then highlight some of the previous conclusions through a case study of malaria. Chapter three shifts from strictly medical matters to consider hygiene advice and disease prevention more broadly. Moving beyond an exclusively European focus, the final chapter examines white settler women's doctoring in local communities. 


\section{Chapter One}

Into the 'White Man's Grave': Sources of Medical Knowledge and Patterns of Amateur Practice

In Alyse Simpson's 1937 memoir The Land that Never Was, set in interwar Kenya, the autobiographical (though pseudonymous) protagonists Joan and Jim leave their Kenyan farm for an unsuccessful safari with their neighbour Bill. ${ }^{1}$ Bill dived into a river and brought on fever, for which Joan administered quinine. ${ }^{2}$ The next morning he "came crawling to breakfast with his forearm bandaged and covered in blood". ${ }^{3}$ Awoken by burning pain, Bill noticed two red spots on his forearm that suggested an adder bite. "As he could not be certain and did not want to die just yet," Simpson wrote, "he took his penknife, cut the flesh criss-cross and dropped a tablet of permanganate into the wound". ${ }^{4}$ Bill's first aid closely followed recommendations in the 1922 Handbook of Nyasaland, which advised tying a cord around the limb, incising and bleeding the area, and rubbing permanganate of potash or carbolic acid into the snakebite. ${ }^{5}$

Joan and Bill's safari encapsulates crucial aspects of European medical experiences in British East and South-Central Africa. No source of professional medical aid was nearby; the person concerned, or their family or friends, carried out immediate treatment, despite their lack of medical training; and the treatments, although simple, possessed a medical logic. Simpson used medical anecdotes to give drama to her safari narrative, which was otherwise lacking, given they managed little successful shooting. Bill's supposed snake bite - and his gruesome treatment - offers exotic danger, a frisson of horror and excitement for the reader. Bill and Joan's status as medical amateurs provides further drama, as their ability to treat the injury is uncertain. Will they be able to avoid death by malaria or snake? Do they possess enough

\footnotetext{
${ }^{1}$ Alyse Simpson's characters are regarded by Kennedy and Whitlock as autobiographical, though, as Whitlock notes, the exact relationship between the experiences of the Simpsons and Joan and John is not clear. Simpson utilised pseudonyms for all her main characters and locations, and provided ambiguous and contradictory geographical details to ensure that no locations could be identified. She even remains vague about the precise time at which her story is set, although it is undoubtedly within the interwar period. Kennedy attributes her deliberate anonymity to "sensitive personal reasons," unsurprising given her cutting critiques of settler society and colonial race relations. Kennedy, 'Introduction,' v-vi; Whitlock, 119; Simpson, The Land That Never Was, 229-255.

${ }^{2}$ Simpson, The Land That Never Was, 244, 246.

${ }^{3}$ Ibid., 247.

${ }^{4}$ Ibid.

${ }^{5}$ Murray, A Handbook of Nyasaland, 235.
} 
medical knowledge (and have the courage, in the case of Bill) to sway their fate, or is it left to chance? Authors typically heighten tension, exoticness, and the sense of danger in their memoirs through amateur medical adventures.

This chapter begins by discussing white settlers' preparations for immigration to tropical Africa. It briefly discusses the British public perception of Africa in the late nineteenth and early twentieth centuries, then explores in greater depth the information and equipment available for settlers to learn about medicine before and after arriving in Africa. The second section shifts to consider settlers in East and South-Central Africa, situated in rural, isolated areas far from doctors and hospitals. It discusses the scope of amateur medicine in these areas, proposing that it should be recognised as a crucial part of the broader colonial medical apparatus. The final section examines the coexistence of amateur medicine with both professional European medicine and local medical systems.

"A hundred years ago a prolonged residence in the Tropics was regarded with well-founded horror. The best the white settler in the lands of the sun dared hope for was 'a short life and a merry one,' but too often the merriment was sadly lacking." ${ }^{6}$ While this quotation, which began George Giles' 1904 advice manual Climate and Health in Hot Countries and the Outlines of Tropical Climatology, suggested that British fears of tropical settlement had abated, such ideas still had great currency in the early twentieth century. Lurid descriptions of diseases and publicity over early missionary and exploration mortality shaped the British image of Africa into one of a white man's grave. ${ }^{7}$ Even as medical knowledge and technology reduced the deadliness of African exploration, and the British press triumphantly reported tropical medical discoveries, the public remained enamoured of representations of Europeans pitted against an exotic and deadly Africa. Henry Stanley and David Livingstone's writings, combined with mission reports and popular fiction, presented sensational disease as a fundamental element of the continent. ${ }^{8}$ As Michael Jennings writes, "the effect upon the popular imagination was

\footnotetext{
${ }^{6}$ George Giles, Climate and Health in Hot Countries and the Outlines of Tropical Climatology (London: J. Bale, Sons \& Danielsson, 1904), iii.

${ }^{7}$ Endfield and Nash, 380.

${ }^{8}$ Ibid., 378.
} 
considerable: Africa became synonymous with sickness and suffering" among the British public. ${ }^{9}$

Although the term 'white man's grave' is primarily associated with West Africa, the South-Central region also had a reputation that more than earned the title. ${ }^{10}$ Early missionary expeditions experienced extremely high death rates; fifteen out of the eighteen members of the London Missionary Society's 1858-1864 mission to the Zambezi died. ${ }^{11}$ East Africa was perceived as healthier, and Colonial Office promotional material for settlers emphasised the environmental familiarity of areas like Kenya's Highlands. ${ }^{12}$ Although death rates among white residents fell dramatically from the second half of the nineteenth century onwards (largely owing to medical/sanitary advances), historians disagree as to whether mortality reductions influenced public perceptions. ${ }^{13}$ Anna Crozier explains that from 1900 the perceived risks of East African residence diminished in the British public mind. ${ }^{14}$ Curtin argues that the public understood medical improvements relatively well, although the white man's grave image persisted within the public imagination, probably sustained through popular depictions of sensationalised disease. ${ }^{15}$ László Máthé-Shires states that "the popular image of Africa...did not alter and change as a result of these medical advancements". ${ }^{16}$ Even as mortality declined - and in the face of simultaneous knowledge of medical progress - the image of Africa as deadly or endangering to the white body persisted.

Given Africa's grave reputation, it is not surprising that Europeans bound for Africa sought out medical information as part of their preparation. Most migrants already possessed some basic medical knowledge. In Victorian Britain, people with limited financial means seldom consulted doctors except during serious illnesses, instead relying upon home remedies and diagnoses. ${ }^{17} \mathrm{~A}$ wide literature supported home practice and provided information on conditions and medicines. ${ }^{18}$ Medical sections appeared in household guides, almanacs, magazine advice columns, and the many home medical books produced between 1890 and

\footnotetext{
${ }^{9}$ Michael Jennings, “"This Mysterious and Intangible Enemy”: Health and Disease Amongst the Early UMCA Missionaries, 1860-1918', Social History of Medicine 15.1 (2002), 87.

${ }^{10}$ Endfield and Nash, 380; Jennings, 65.

${ }^{11}$ Endfield and Nash, 380.

${ }^{12}$ Crozier, Practising Colonial Medicine, 53.

${ }^{13}$ Curtin, The Image of Africa, 392; David Arnold, 'Disease and Imperialism' in David Arnold (ed.), Warm Climates and Western Medicine: The Emergence of Tropical Medicine, 1500-1900 (Amsterdam: Rodopi, 1996), 99-107.

${ }^{14}$ Crozier, Practising Colonial Medicine, 53

${ }^{15}$ Curtin, The Image of Africa, 392.

${ }^{16}$ László Máthé-Shires, 'Imperial Nightmares: The British Image of "the Deadly Climate" of West Africa, c.184074,' European Review of History 8.2 (2001), 143.

17 Sally Mitchell, Daily Life in Victorian England (Westport: Greenwood, 1996), 204.

${ }^{18}$ Ibid.
} 
1939. ${ }^{19}$ By the end of the nineteenth century, health and hygiene advice literature had developed into a thriving genre, which aimed to instruct readers in all matters of health. ${ }^{20}$ Styles varied from the highly specialised, which included detailed scientific background, to shorter, simple works with minimal explanatory detail. ${ }^{21}$ Readers could choose from a number of health periodicals, such as Good Health and Health: A Weekly Journal of Sanitary Science. ${ }^{22}$ Gordon Staples penned health columns for the Boys' Own Paper and the Girls' Own Paper. ${ }^{23}$ Although most books and periodicals offering domestic health/hygiene advice catered for a middle-class readership, some works also reached working class audiences. ${ }^{24}$ The Young Women's Christian Association gazettes, aimed at a working class readership, frequently featured health topics including hygiene and nutrition. ${ }^{25}$

Organisations such as the Red Cross, St John's, Boy Scouts, and Girl Guides offered opportunities for more structured medical teaching to a lay audience. Robert Baden-Powell's 1908 Scouting for Boys contained a chapter entitled 'Saving Lives,' which stated that every boy had "a chance of being a life-saving hero if he chooses to prepare himself for it" and offered a range of first aid instructions. ${ }^{26}$ The chapter provided first aid directions for many conditions, including burns, acid burns, broken limbs, bleeding, blood poisoning, choking, and snakebite. ${ }^{27}$ Baden-Powell recommended practical demonstrations of first aid techniques, and stressed that they "should be practiced by every boy in turn." ${ }^{, 28}$ First aid was not only for boys. Baden-Powell's 1909 Girl Guides: A Suggestion for Character Training for Girls listed first aid as a crucial area of training - an everyday competency - for Guides. ${ }^{29}$ Although focused on generalised first aid rather than tropical medicine, a wealth of basic medical information was accessible to the general public.

Future migrants had to turn to a smaller range of sources for health information tailored to the tropics. Tropical outfitters - businesses dedicated to supplying clothing and equipment for tropical climates - acted as intermediaries between consumers and purveyors of

\footnotetext{
19 Ibid.

${ }^{20}$ Hilary Marland, Health and Girlhood in Britain, 1874-1920 (London: Palgrave Macmillan, 2013), 51; Nancy Tomes, 'The Private Side of Public Health: Sanitary Science, Domestic Hygiene, and the Germ Theory, 18701900', Bulletin of the History of Medicine 64.4 (1990), 510.

21 Tomes, 520.

${ }^{22}$ Marland, 51.

${ }^{23}$ Ibid.

${ }^{24}$ Tomes, 521.

${ }^{25}$ Marland, 51.

${ }^{26}$ Robert Baden-Powell, Scouting for Boys, Elleke Boehmer (ed.) (Oxford: Oxford University Press, 2004$), 249$.

${ }^{27}$ Ibid., 265-267.

${ }^{28}$ Ibid., 248.

${ }^{29}$ Rosie Kennedy, The Children's War: Britain, 1914-1918 (London: Palgrave Macmillan, 2014), 108.
} 
professional medical advice. They also gave advice, providing lists of necessary items for tropical travel, such as medicine chests and water filters. ${ }^{30}$ Catalogues of recommended clothing and equipment were nothing if not thorough, and while some items were genuinely useful, other parts of lists were inflated to create demand. Kirk-Greene notes that the 1937 Army Navy Stores catalogue weighed four pounds and stretched to over 1,200 pages. ${ }^{31}$ Tropical outfitters frequently advertised in colonial advice books. Hints and Tips for NewComers to West Africa, for example, included five advertisements for outfitters. ${ }^{32}$

Some migrants received limited formal medical training before leaving Britain. From 1908 the Imperial Institute in London ran a mandatory short course (initially two months, then later expanded to three) for District Officers. ${ }^{33}$ The curriculum ranged across many subjects and was widely viewed as a waste of time by candidates, but it did include lectures on tropical hygiene, medicine, and sanitation. ${ }^{34}$ Kirk-Greene quotes A. F. Bridges, a civil servant who took the course in 1921, recalling that "the Tropical Hygiene lectures were given by a gloomy doctor who, after describing the symptoms of many tropical diseases one could get, often gruesome, usually ended by saying that "the patient usually dies"." 35 In 1926 the course was expanded, shifted to Oxford and Cambridge, and renamed the Tropical African Service Course; in 1928 it was extended to a full academic year and refocused towards the academic rather than vocational. ${ }^{36}$ The Inyati and Hope Foundation missions required missionaries to undergo six months' training in hospitals, gaining skills in diagnosis, treatment, maternity care, and simple surgery. ${ }^{37}$ Livingstone College in London, founded in 1893, took missionaries from all denominations to "enable those going abroad to lonely posts to recognise the more common diseases, and apply ordinary remedies" for themselves and the communities in which they were stationed. ${ }^{38}$ During the College's peak between 1900 and 1913, it trained between twenty-five and forty missionaries per nine month course. ${ }^{39}$

\footnotetext{
${ }^{30}$ Dalton, 10.

${ }^{31}$ Kirk-Greene, Symbol of Authority, 56.

${ }^{32}$ Bushman, Hints and Tips for New-Comers to West Africa (London: John Bale, Sons \& Danielsson, 1924).

${ }^{33}$ Kirk-Greene, Symbol of Authority, 42-43; William Golant, Image of Empire: The Early History of the Imperial Institute, 1887-1925 (Exeter: University of Exeter, 1984), 14-15; Anthony Kirk-Greene, On Crown Service: A History of HM Colonial and Overseas Civil Services, 1837-1997 (London: I.B.Tauris, 1999), 27.

${ }^{34}$ Kirk-Greene, Symbol of Authority, 43.

35 Ibid.

${ }^{36}$ Ibid., 43-44.

37 Michael Gelfand, Tropical Victory: An Account of the Influence of Medicine on the History of Southern Rhodesia, 1890-1923 (Cape Town: Juta, 1953), 7.

${ }^{38}$ Johnson, 'Colonial Mission and Imperial Tropical Medicine', 549-550.

${ }^{39}$ Ibid., 550.
} 
Some settlers found formal training once they reached Africa. Fisher, a CMS (Church Missionary Society) missionary in Uganda, visited the Mengo hospital and shadowed a doctor "to observe and take notes for future use". ${ }^{40}$ For migrants not employed as civil servants or missionaries, formal training was far rarer, but some opportunities existed. In 1913 a St John Ambulance Brigade was established in Salisbury, and held lectures "embodying instructions in first aid, accidents and tropical diseases such as malaria". ${ }^{41}$ Michael Gelfand explains that "the next year examinations were held and many ladies were successful. The movement was started and carried on for many years solely by women." 42 Non-governmental organisations like the Red Cross and St Johns seldom appear in memoirs, but for the few settlers with access to them they were doubtless influential.

Public debates and events related to medical matters, both in Britain and Africa, also provided opportunities for settlers to gain medical knowledge. Manson (widely viewed as the 'father of tropical medicine') visited Southern Rhodesia, addressing a large public meeting in January 1914 at the Grand Hotel in Bulawayo. "Creating a tremendous impression on the public," Manson heightened popular interest in malaria prevention measures, including encouraging the use of mosquito nets and the construction of mosquito-proof homes. ${ }^{44} \mathrm{He}$ also stressed not just the personal importance of malaria prevention, but the economic necessity of malaria control for Rhodesia. ${ }^{45}$ Similarly, in the late 1910s J. G. Thompson from the London School of Hygiene and Tropical Medicine toured the country, addressing public meetings. ${ }^{46}$ The first Livingstone Exhibition, held in Central London in January 1900, showcased commodities associated with tropical empire. ${ }^{47}$ Pharmaceutical manufacturers had a strong presence, including Burroughs Wellcome \& Co. (BWC). ${ }^{48}$ In Africa, the colonial press reported medical discoveries and featured health/hygiene advertisements. The African World, for example, included articles on sleeping sickness, mosquito control, the South African Institute for Medical Research, and miners' phthisis, and ran advertisements for castor oil and

\footnotetext{
${ }^{40}$ Ruth Fisher, On the Borders of Pigmy Land (London: Marshall Brothers, 1904), 26.

${ }^{41}$ Gelfand, 130-131.

42 Ibid., 131.

43 Ibid., 180.

${ }^{44}$ Ibid., 174, 180.

${ }^{45}$ Ibid., 180.

46 Ibid., 183.

47 Johnson, 'Commodity Culture', 70.

${ }^{48}$ Ibid., 71.
} 
soap, Humphreys \& Crook outfitters, Bovril nutritional food, and British East Africa's Kijabe Hill health resort. ${ }^{49}$

Pharmaceutical and outfitting firms produced a raft of advertising through the early twentieth century. Many of them reinforced popular images of the savage and dangerous tropics and civilised yet vulnerable white settlers. ${ }^{50}$ Strong parallels exist with advertising in Victorian Britain, which heavily associated "racial hygiene and imperial progress" with soap what Anne McClintock describes as "commodity racism". ${ }^{11}$ BWC advertisements appear frequently in advice books, consistently aligning the manufacturer with explorers and other imperial figures. ${ }^{52}$ Although BWC deliberately fostered an image of sensationalised tropical diseases to create demand for their products, those products, and those of other similar firms, did offer psychological comfort for migrants during the anxious pre-voyage period and once in Africa. Pamphlets and instructions that accompanied the products provided medical information targeted at an amateur audience, which they could readily understand, adapt, and apply. Charlotte Mansfield, who travelled through Rhodesia in 1909, was "specially proud" of her Tabloid medicine chest and happily explained that "so carefully were the directions given on the labels that all danger arising from a possible over-dose was eliminated". 53

Once settlers arrived in East and South-Central Africa, they often found that experience (theirs' and other settlers') were the most useful sources of medical knowledge. In Flame Trees, upon meeting a newly arrived neighbour, Tilly Grant immediately provides medical information about the district: what diseases were present, and the necessity of shooting "a native dog behaving in a suspicious way" and boiling water. ${ }^{54}$ Joan, in The Land that Never Was, was warned by the hotel manager that mosquitoes bred in the swamp at the bottom of their farm and was advised to take nightly quinine. ${ }^{55}$ Paddy Upton, raised in 1920s colonial

\footnotetext{
49 'The Sleeping Sickness', The African World, 25 August 1906, 131; 'Mosquitoes and Malaria', The African World, 25 August 1906, 130; 'Miners' Phthisis', The African World, 27 June 1914, 426; 'Medical Research', The African World, 27 June 1914, 427; 'Castor Oils, Soft Soap', The African World, 25 August 1906, 101; 'Humphreys \& Crook', The African World, 25 August 1906, 120; 'Add Bovril', The African World, 2 September 1911, 145; 'Mountain Health Resort', The African World, 11 April 1914, 524.

${ }^{50}$ Johnson, 'Commodity Culture', 72.

${ }^{51}$ Anne McClintock, Imperial Leather: Race, Gender, and Sexuality in the Colonial Contest (London and New York: Routledge, 1995), 209.

52 Thomas Heazle Parke, Guide to Health in Africa: With Notes on the Country and Its Inhabitants (London: Sampson Low, Marston, 1893), 61-62; John Murray, How to Live in Tropical Africa: A Guide to Tropical Hygiene and Sanitation (London: The African World Ltd., 1912), xxviii; Johnson, 'Commodity Culture', 72; Jude Hill, 'Globe-Trotting Medicine Chests: Tracing Geographies of Collecting and Pharmaceuticals,' Social and Cultural Geography 7.3 (2006), 368, 370.

${ }^{53}$ Charlotte Mansfield, Via Rhodesia: A Journey through Southern Africa (London: S. Paul, 1911), 204-205.

${ }^{54}$ Huxley, Flame Trees, 61.

${ }^{55}$ Simpson, The Land That Never Was, 41.
} 
East Africa, explained that his mother contracted blackwater fever while pregnant with him. ${ }^{56}$ "Luckily Dad had nursed a friend with Black-water the previous tour so he more-or-less knew what to do," Upton wrote. ${ }^{57}$ Despite blackwater fever's very high mortality rate, his mother survived. ${ }^{58}$ Emma Leach often provided medical attention to people injured in mine accidents in 1910s Rhodesia, including successfully cleaning and reattaching half her husband's thumb, which had been severed by a piston-rod. ${ }^{59}$ Her skill, one of her children explained, came simply from "reading and experience". 60

Leach's reading highlights a particularly important, though elusive, source of amateur knowledge: the medical advice book (see examples in figure two). It is very difficult to determine precisely how widely they were used, although the fact that many were published and that they sometimes went through several impressions suggests reasonable popularity. They divide roughly into two types: medical handbooks, written by doctors (typically either tropical medical specialists or with tropical experience) and usually published in London; and general guidebooks or household guides that included medical sections, as was also common in British household manuals. General guidebooks were usually not written by doctors; indeed, they were often anonymous and produced by interested parties, such as railways or the Crown Agents for the Colonies. It is not clear how the books were distributed, although the five shilling price on Stephen Samuel Murray's 1922 Handbook of Nyasaland indicates that at least some were sold publicly rather than distributed freely to missionaries or civil servants. ${ }^{61}$

Gauging how people learned from and used medical handbooks is very difficult. Almost no authors mention advice books in their memoirs, though, like Leach, Blixen mentions looking up a hot poultice for leg sores "in my books". ${ }^{62}$ Joan described Chavesse's Advice to a Mother as "my usual splendid standby," but admitted that, being intended for readers in Europe and North America, it "was not much use to me when it came to tropical diseases." 63 Pye Henry Chavesse's manual was recommended and extensively quoted in A. R. Barnes' 1890 Colonial Household Guide; Barnes' use probably reflected the fact that Chavesse's manual was

\footnotetext{
${ }^{56}$ Considine and Rawlins, 47.

57 Ibid.

${ }^{58}$ Ibid.

${ }^{59}$ Madeline Heald (ed.), Down Memory Lane with Some Early Rhodesian Women, 1897-1923 (Bulawayo: Books of Rhodesia, 1979), 209.

${ }^{60}$ Ibid.

${ }^{61}$ Murray, A Handbook of Nyasaland, title page.

${ }^{62}$ Blixen, Out of Africa, 30.

${ }^{63}$ Simpson, The Land That Never Was, 95.
} 
extremely popular and by 1868 had reached its ninth edition. ${ }^{64}$ Yet it is interesting that - despite constant sensationalising of the African disease environment in novels and the popular press some settlers felt comfortable utilising medical books aimed at temperate locations.
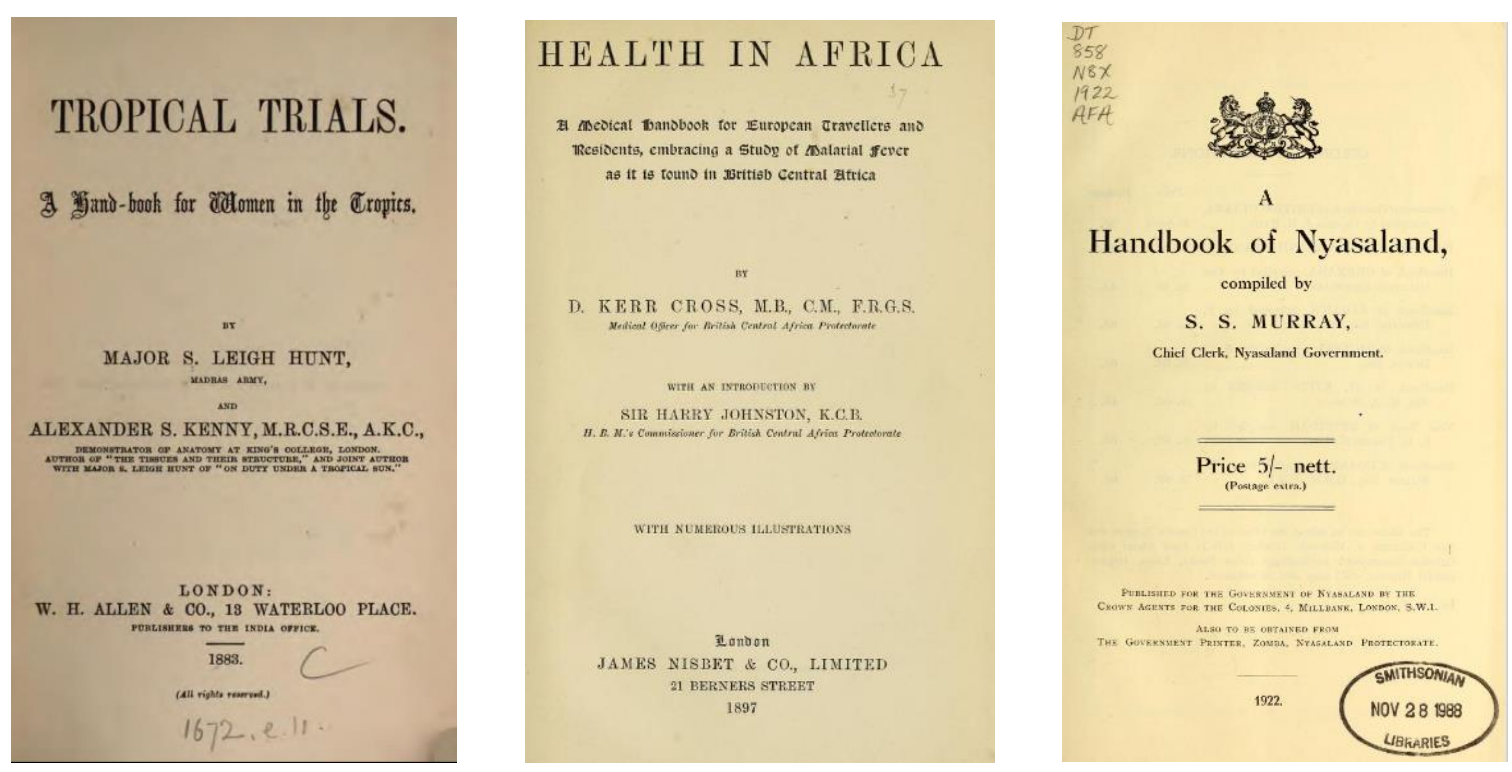

Figure Two. Three tropical advice books that offered medical information to European travellers.

A few authors highlight medical handbooks' potential for misuse. Emily Bradley recounted a story of a District Commander's wife, who "nearly came a fearful cropper, trying to use one on an outstation". ${ }^{65}$ After her ten month old daughter developed a sore, swollen throat and a high temperature, she used "one of those large, expensive omnibus guides to amateur doctoring" to diagnose diphtheria. ${ }^{66}$ She sent a messenger to the nearest hospital, a few hundred miles away. ${ }^{67}$ Before he returned, the mother discovered that the baby was teething and simply needed a gum lanced, by which time the baby was close to death from "fever, starvation and diarrhoea". ${ }^{68}$ "The medical compendium," Bradley wrote, "was consigned...to the borers and the white ants". ${ }^{69}$ The District Commander's wife concluded that

\footnotetext{
${ }^{64}$ A. R. Barnes, Where the Lion Roars: An 1890 African Colonial Cookery Book, David Saffery (ed.) (London: Jeppestown Press, 2006); Staci Freeman, 'Medicine and Morality: The Use of Rhetoric in Victorian Marriage and Child Rearing Manuals', MA Thesis, East Central University, 2012, 63.

${ }^{65}$ Although Emily Bradley's Dearest Priscilla is an advice book for colonial service wives, it also has a strong autobiographical element, as Bradley includes many discussions of her experience as a District Officer's wife in interwar Northern Rhodesia. Emily Bradley, Dearest Priscilla: Letters to the Wife of a Colonial Civil Servant (London: Max Parrish, 1950), 157-158.

${ }^{66}$ Ibid.

${ }^{67}$ Ibid., 158.

${ }^{68}$ Ibid.

${ }^{69}$ Ibid.
} 
amateur guides “were not much help unless you are trained, and if you are then you don't need one. They serve to frighten the ignorant with their gruesome pictures and horrific analyses of symptoms, and if you turn to them when you are in trouble, they can easily be misleading.",70 After inheriting a medical guide, Joan found it encouraged hypochondria and misdiagnosis, being "so vividly described that I suffered in turn from hookworm, insanity and pernicious anaemia". 71

Undoubtedly, such anecdotes confirmed many professionals' distrust of the dangers of self-diagnosis and amateurs possessing 'too much' information. In a few guidebooks, there is a tension between warnings that amateurs keep within the confines of their limited expertise and the purpose of the books, which was to impart medical information to non-professionals. Tropical Trials admonished the reader that "it is no uncommon thing to meet with women, whose medical faith is limited to the resources of the family medicine-chest... and, the magic influence of this chest, fostering a false sense of security, they defer seeking medical advice until much harm has been done." 72 The result, the authors explained, was that symptoms develop "which too often end fatally," and they urged the reader to make no delay in summoning "medical men" when needed. ${ }^{73}$ How to Live in Tropical Africa commented that "a little learning is a dangerous thing" and encouraged the reader to focus on prevention rather than cure. ${ }^{74}$ Both books, however, also provided a wealth of medical detail. Most handbooks took a more positive view of amateur treatment and suggested it was essential for Europeans in Africa to understand basic medical principles and techniques.

Crozier identifies a strong tendency to stress the exotic and sensational over the routine in British medical guides for sub-Saharan Africa. ${ }^{75}$ Yet while some guides do focus on sensationalised tropical diseases, others do so to a far lesser degree. ${ }^{76}$ All guides dwell on malaria, as it was both the most widely publicised tropical disease and ubiquitous among Europeans in British Africa. Nevertheless, guides also typically devote extensive sections to discussing more 'mundane,' 'temperate' illnesses, and some give these greater space and profile than exotic tropical diseases. Tropical Trials discusses very few distinctively tropical

\footnotetext{
${ }^{70}$ Ibid., 157-158.

${ }^{71}$ Simpson, The Land That Never Was, 153.

${ }^{72}$ Shelley Leigh Hunt and Alexander S. Kenny, Tropical Trials: A Handbook for Women in the Tropics (London: W. H. Allen, 1883), 177-178.

${ }^{73}$ Ibid.

${ }^{74}$ Murray, How to Live, 1912, 94.

75 Anna Crozier, 'Sensationalising Africa: British Medical Impressions of Sub-Saharan Africa, 1890-1939', Journal of Imperial and Commonwealth History 35.3 (2007), 397.

${ }^{76}$ William Simpson, The Maintenance of Health in the Tropics (London: Bale \& Danielsson, 1916).
} 
illnesses, aside from malaria. ${ }^{77}$ Neither Thomas Parke's Guide to Health in Africa nor S. Leigh Hunt and Alexander Kenny's On Duty under a Tropical Sun focus overwhelmingly on tropical diseases, and instead devote significant space to considering non- 'tropical' illnesses (including severe conditions that would in Britain usually require a doctor, and minor illnesses generally treated at home). ${ }^{78}$

As well as noting the multiplicity of resources with which settlers armed themselves for life in Africa, it is important to recognise their particular characteristics. Many were produced by the businesses, such as BWC, that proliferated around Britain's tropical empire and were frequently accompanied by imperialist rhetoric and ideas of tropical difference and danger. There was often a lag between professional medical understandings and what settlers read in their guidebooks. Even if medical guidebooks reflected cutting-edge science when released, which was not universally true, reprinting perpetuated older advice. ${ }^{79}$ Many settlers bought a single medical compendium and used it for many years. The 1890 Colonial Household Guide that reproduced Chavesse's advice well illustrates the persistence of older medical advice, as does Alyse Simpson's description of Chavesse as her "usual splendid standby". ${ }^{80} \mathrm{~A}$ time lag between professional and popular scientific awareness is not uncommon. Nonetheless, in the context of tropical medicine - a field that defined itself by its modernity and rapid progress - it highlights the danger of equating all medicine practiced in British Africa with the cutting-edge science of the British tropical medical establishment.

There were, then, a wide range of resources for settlers travelling to British Africa to learn medical information and techniques. Despite existing outside the professional medical establishment, settlers were well placed to develop considerable expertise. The next section will illustrate that once settlers were established on the farms, mines, and stations of rural East and South-Central Africa, they found myriad opportunities to apply and develop their medical skills.

Many white settlers in rural British East and South-Central Africa between 1890 and 1939 lived under conditions of geographic and cultural isolation. In memoirs, authors typically emphasise

\footnotetext{
${ }^{77}$ Hunt and Kenny, Tropical Trials.

${ }^{78}$ Parke; Shelley Leigh Hunt and Alexander S. Kenny, On Duty Under a Tropical Sun (London: W. H. Allen, 1882).

${ }^{79}$ Collingham, 90.

${ }^{80}$ Simpson, The Land That Never Was, 95.
} 
their isolation and solitude, describing with relish the distances between them and white civilisation. It is important to take claims of isolation with a grain of salt: authors were generally surrounded by African servants and porters and often lived near African settlements. Yet there is no doubt that rural settlers viewed themselves as profoundly isolated. They generally lived with few white neighbours, slow mail, and very rough and difficult access, particularly during the rainy season. ${ }^{81}$ Although technological advances (such as telephones, radios, and aeroplanes) all helped connect rural settlers to larger settlements, until 1939 (and beyond) rural settlers still experienced substantial isolation from centres of white settlement. The 1914 'Leader' Annual's population lists for Kenyan districts illustrate the astounding sparseness of the white settler population: in Naivasha, the Southern and Northern Masai reserves, Ravine Uasin Gishu, Baringo, and Turkana there were an estimated 975 Europeans and 115,500 indigenous people; while in Nyeri, Fort Hall, Embu and Meru there were just 156 Europeans in comparison to 917,000 indigenous people. ${ }^{82}$

Unless settlers were fortunate enough to live near a medical mission or another source of professional medicine (which in rural areas was uncommon), their geographic isolation also translated into isolation from European medicine. Increasing rural settlement through the early twentieth century and rising numbers of medical professionals did make consulting a doctor easier over time, but even through the interwar period most rural settlers experienced significant delays and difficulties in seeking professional advice. ${ }^{83}$ The nearest hospital to the Grant family, who lived near Thika (Kenya), was two days away. ${ }^{84}$ To get to hospital from Blixen's house in Naivasha, she had to take an ox-cart and then catch a train to Nairobi. ${ }^{85}$ Over seventy Great War veterans settled at Kericho, Kenya, in 1919, where (as Huxley explained) "the nearest hospital was at Kisumu, nearly sixty miles by rail from Lumbwa - if you could get to Lumbwa." 86 Stationed in Rhodesia, Kenneth and Emily Bradley received a vivid reminder of their isolation when their baby fell violently ill. With no doctor within one hundred miles and their car missing a wheel, they had no means of accessing medical help. ${ }^{87}$ Even the landing-

\footnotetext{
${ }^{81}$ Gelfand, 176-177.

${ }^{82}$ The 'Leader' Annual and Gazetter of British East Africa, 1914 (Nairobi and Mombassa: Caxton Publishing, 1914), 19.

${ }^{83}$ For example, the first private practice in Nairobi was only established in 1911, by the notoriously eccentric Dr Roland Burkitt. Huxley, Out in the Midday Sun, 3.

${ }^{84}$ Huxley, Flame Trees, 39.

${ }^{85}$ Karen Blixen, Letters from Africa, 1914-1931 (Chicago: Chicago University Press, 1981), 86.

${ }^{86}$ Huxley, Out in the Midday Sun, 80.

${ }^{87}$ Bradley, Once a District Officer, 71.
} 
strip that they later cleared for future emergencies was of limited use, as they had no radio and so "someone would still have to bicycle that hundred miles to call an aeroplane". ${ }^{88}$

Medical isolation could have devastating effects. A number of authors mention exhausting journeys to take patients to medical professionals and some report sick friends and family dying before a doctor arrived. Sonny, the young son of a settler family in Rhodesia, died of malaria before the doctor reached them. The family's neighbour had diagnosed Sonny's malaria then ridden to Salisbury to summon a doctor. ${ }^{89} \mathrm{He}$ did not return with the doctor until six forty-five the next evening, as "the doctor had been away on call ... and...there was only one doctor in the district". ${ }^{90}$ Sonny had died at six o'clock. ${ }^{91}$ In Flame Trees, a neighbour died in childbirth, having needed a doctor but having been unable to summon one in time. ${ }^{92}$ Although death in childbirth with medical attendance was not uncommon even in the United Kingdom, for both examples the tragedy was heightened by the possibility of help and its ultimate failure to arrive in time. Huxley described a family acquaintance, Rose, who gave birth without any medical attendance or any European neighbour present. ${ }^{93}$ "She despatched a runner to Naivasha, about twenty miles away, but...no one came."94 After giving birth, and not knowing what to do, she decided not to cut the umbilical cord. ${ }^{95}$ She opened champagne and waited nearly eighteen hours before a doctor arrived. ${ }^{96}$ The doctor "had to operate, but had brought no anaesthetics. Rose, and the baby, survived."97

Medical isolation placed much of settlers' healthcare in their own hands. For less severe illnesses or injuries, and for serious conditions before professional medical help could be reached, settlers performed basic medical tasks. Medical handbooks warn the reader of such duties. David Cross's 1897 Health in Africa stated that "the majority of those resident in Central Africa are stationed a long way - sometimes a week's journey - from a medical adviser. They are thus, by the exigencies of their position, compelled to acquire some knowledge of medicine." ${ }^{98}$ Even a quarter century later, the Southern Rhodesia handbook made a similar remark, that "the settler may be situated at some distance from the nearest doctor, and the

\footnotetext{
${ }^{88}$ Ibid.

${ }^{89}$ Heald, 20.

${ }^{90}$ Ibid.

${ }^{91}$ Ibid.

${ }^{92}$ Huxley, Flame Trees, 284.

${ }^{93}$ Huxley, Out in the Midday Sun, 158-159.

${ }^{94}$ Ibid.

${ }^{95}$ Ibid., 159.

${ }^{96}$ Ibid.

${ }^{97}$ Ibid.

${ }^{98}$ David Kerr Cross, Health in Africa: A Medical Handbook for European Travellers and Residents (London: James Nisbet \& Co., 1897), v.
} 
provision of a few simple remedies...will be a wise precaution," although the authors expected medical aid in a matter of hours, not days. ${ }^{99}$ With a fully stocked medicine chest, Parke explained, "the intelligent traveller will be able to deal with most symptoms of disease and injury; so far as this can be done in the absence of skilled medical and surgical advice." ${ }^{100}$ As late as 1939, Emily Bradley's Household Book for Africa noted that occasions still arose when "any European is likely to be called upon to perform the offices of a trained physician for himself". 101

Some rural settlers also took very active roles in the funerary process. During hot and wet times of year, bodies decomposed rapidly and required fast burial. Buxton, a settler in the Kenyan highlands, wrote in a 1917 letter that "unluckily he [the postmaster] got so bad on the way [to hospital] we brought him into a settlers [sic] house where he died. Then of course there was everything to be seen to and here one has to be very quick too." 102 Together with a neighbour she constructed a coffin, then while she slept her friend lined Buxton's wagon and the coffin with white. ${ }^{103}$ Buxton then drove the wagon to fetch the body and took it to be buried. 104 "Somehow that kind of thing one never has anything to do with in England - does one," she commented. ${ }^{105}$ Goy, stationed as a missionary with her family in the Zambesi area in the 1890s, took measurements for her husband's coffin and grave, after he died of fever. ${ }^{106}$ She also helped construct the coffin. ${ }^{107}$ In Huxley's 1938 detective novel Murder on Safari, set in a pseudonymous interwar Kenya, the Europeans build coffins for two murder victims using gin crates, and bury one of the victims themselves. ${ }^{108}$

The high level of detail in medical handbooks further indicates the medical responsibilities of untrained Europeans. Medical guidebooks typically provide extensive detail including many different treatment contingencies, discussion of medical research, and full background information. The combination of great detail and multiple options suggest that authors presumed a degree of medical ability amongst their readership. Although handbooks are necessarily highly prescriptive, authors often listed multiple treatment options, allowing the

\footnotetext{
99 Southern Rhodesia: Handbook for the Use of Prospective Settlers on the Land (Cape Town: Minister for Agriculture and Lands, 1924), 9.

100 Parke, 62.

${ }^{101}$ Bradley, A Household Book for Africa, 158.

102 Cara Buxton to Desmond Buxton, 2 June 1917, GB 0162 Micr.Afr.585, Rhodes House Library, Oxford.

103 Ibid.

104 Ibid.

105 Ibid.

106 Goy, 52.

107 Ibid.

${ }^{108}$ Elspeth Huxley, Murder on Safari (New York: Viking, 1989), first published 1938, 75, 104, 147.
} 
readers a certain measure of autonomy within the advice-book framework. When Parke described the treatment of pneumonia, he listed different scenarios, including how to respond to high fevers, dry skin, bowel troubles, a "full-blooded" patient, and weak or old patients, requiring the reader to identify those often subjective symptoms and then apply his suggestions. ${ }^{109}$ On Duty lists many remedies for constipation, including diet alteration, abdominal massage, and numerous types of purgatives, again allowing the reader a degree of autonomy to create a treatment specific to the patient. ${ }^{110}$

Many instances of ill-health appear through the pages of colonial memoirs. From a sample of twenty-seven memoirs, letters, and diaries, 158 discussions of specific illnesses were identified. By far the greatest number (43, or 27\%) were cases of malaria or unidentified fever. No other illness made up such a large proportion of the total. Accidental woundings or concussions appeared eleven times, and childbirth, miscarriage, and related complications appeared nine times. The sources contained eight mentions of jiggers (fleas that lodge within the body, most commonly the feet, causing pain, itching, and lesions), six of influenza, five of sunstroke, and four of dental problems. Blackwater fever, dysentery, and accidental poisoning each received three references. The remaining illnesses are either unidentifiable, multiple conditions, or receive only one or two mentions. The last category includes appendicitis, asthma, bilharzia, burns, chickenpox, colds, colic, croup, diphtheria, dipsomania, enteritis, eye infections, frontal sinusitis, heart attack, insomnia, measles, pneumonia, rabies, rheumatic fever, rheumatism, ticks, tonsillitis, typhoid, scarlet fever, sciatica, sick headache, stomach ache, and veldt sores.

Drawing definite quantitative conclusions from these data is difficult. Memoirs are not statistically accurate representations of the disease profile of European settlers; they lean towards privileging the unusual, easily described and personally significant - for example, the death of a child from malaria, as opposed to a routine skin infection. However, it is possible to draw some general conclusions. Malaria was a major health concern in terms of its prevalence and importance in people's lives. Unsurprisingly, given settlers' lifestyles and frequent inexperience, wounds and other accidents were frequent. So too were the ubiquitous jiggers. Pregnancy and childbirth were hazardous in remote areas, where expectant mothers were frequently without the assistance of experienced midwives or doctors. As the time period considered includes the 1918 influenza pandemic, influenza appears regularly in sources

\footnotetext{
${ }^{109}$ Parke, 104.

${ }^{110}$ Hunt and Kenny, On Duty, 53-55.
} 
recording the late 1910s and early 1920s. Probably the most striking aspect of the data is the lack, aside from malaria, of distinctively 'tropical' diseases. Most of the diseases that settlers discussed are familiar health concerns that could have afflicted them in England, although the isolated conditions of rural British Africa did nevertheless render settlers' experiences of those diseases distinctive.

Authors recorded seeking professional medical aid in forty-six of the 158 cases of amateur treatment studied. That leaves 112 cases in which the author did not specify the treatment or in which no medical professionals were present. Even for cases in which medical aid was engaged, before it arrived settlers had to perform whatever nursing, first aid or treatment they could. To make the decision to summon professional aid, a choice costly in money and time, settlers had to attempt to diagnose the illness and its severity. The process of diagnosis is very difficult to locate in the sources, as authors typically simply state the disease from which they suffered. A few instances in which authors admit they misdiagnosed suggest it may have been a reasonably common occurrence for unfamiliar or uncommon illnesses.

For many reasons, including the incomplete data and the difficulties of retrospective diagnoses and prognoses, it is impossible to estimate quantitatively the impact of amateur treatment on European health and life expectancy in tropical Africa. The question of the statistical significance of amateur treatment for morbidity and mortality, therefore, while intriguing, is not one that could be answered without large scale quantitative studies, and even then it is not certain that any kind of robust assessment could be made. It is clear, however, that amateur medicine played an important role in colonial medicine, as well as the colonial enterprise more broadly. Although professional medical expertise lay behind many of the sources of amateur knowledge and their application - doctors wrote medical handbooks, lectured civil service recruits, and designed popular medicine chests - much of the actual application and practice of medicine was undertaken by settlers themselves. For geographically isolated settlers, a working knowledge of home medical care was as essential to survival as other domestic skills such as cooking (indeed, for wealthy settlers it was more important: it was easy to hire skilled local cooks and domestic servants, but settlers almost never turned to local people for medical care). Settlers sustained European life and health in areas necessary for colonial expansion - farms, mines, and remote district stations - and therefore formed a crucial part of the colonial medical apparatus that supported European rule.

Yet European amateur medicine was not the only medical system that existed in rural East and South-Central Africa. The last section will examine the relationship between amateur 
medicine and the two other dominant medical systems in the region: professional colonial medicine and local communities' medical systems.

The bulk of amateur medicine complemented rather than competed with professional medicine. Trained doctors and nurses were almost always patients' preference, but because of substantial geographic and financial barriers, medical professionals only attended serious illnesses. Routine attacks of malaria, for example, would not generally warrant a doctor's visit. ${ }^{111}$ In The Land that Never Was, Joan summoned the doctor, as her daughter "had been stricken with an eye disease which I did not understand". ${ }^{112}$ Rather than visit, the doctor sent the family "a bottle of nitrate of silver and some hazy instructions," not believing the ailment necessitated a journey. ${ }^{113}$ Amateur treatment was generally only practised in the absence of readily available professional medicine.

Settlers did not always believe that their local doctor possessed the same expertise as those in London or larger colonial centres. Authors sometimes travelled long distances to consult a specialist or a more experienced doctor. Richards, for example, took her son to consult a London specialist about his asthma. ${ }^{114}$ Women feared pregnancy in the tropics, especially rural areas, and it was common for women, with the financial means, to return to Britain or to go to a larger city, like Nairobi, to give birth. ${ }^{115}$ Many women did give birth at home, although childbirth appears infrequently in memoirs written before the 1960s. Alyse Simpson's memoir is one of the few that discusses the narrator's struggles while pregnant and after birth, describing intense anxiety about pregnancy, financial stress, difficulties in finding professional medical support, and ongoing postpartum illness. ${ }^{116}$ Even Simpson, however, offers no detail about the birth experience. Childbirth appears more frequently in recent memoirs, probably

\footnotetext{
${ }^{111}$ Considine and Rawlins, 52.

112 Simpson, The Land That Never Was, 111.

113 Ibid.

${ }^{114}$ Richards only sought help in London after the doctor in Rhodesia had recommended treatment methods that worsened her son's condition, then explained that there was nothing more he could do. Richards, 149.

115 Dane Kennedy, 'Diagnosing the Colonial Dilemma: Tropical Neurasthenia and the Alienated Briton' in Durba Ghosh and Dane Kennedy (eds.), Decentring Empire: Britain, India, and the Transcolonial World (Hyderabad: Orient Longman, 2006), 175; Dalton, 44, 47; Heald, 214-215; Considine and Rawlins, 24, 47.

116 Simpson, The Land That Never Was, 44, 51, 76, 79.
} 
reflecting the increased acceptability of such discussions and the time elapsed since the events occurred. ${ }^{117}$

Very occasionally authors assert their own medical authority over that of professionals, usually based on claims of personal knowledge of the patient and their medical history. One Rhodesian settler recalled that her father died in the 1918 influenza pandemic, after the doctor "would not listen to mother, who knew that the treatment he was prescribing for Dad was wrong for his chronic liver complaint." 118 Blixen wrote in a letter that "I have been [in bed] for a week with what the doctor calls malaria but I myself consider to be pneumonia."119 Another Rhodesian settler was hospitalised at Umtali for blackwater fever, and his wife argued with the matron over treatment. ${ }^{120}$ The matron "refused to give him a little brandy, which he needed as he was so exhausted," but eventually allowed him a glass of water. ${ }^{121}$ The wife angrily noted that she was not permitted to speak to her husband or the doctor. ${ }^{122} \mathrm{He}$ died that night. ${ }^{123}$

Some authors made negative comments about colonial doctors' skill. Blixen did not "much believe in" the tonics prescribed by her Nairobi doctor, and his anti-malarial injection "merely caused severe blood poisoning" in her arm. ${ }^{124}$ When considering an operation for sinusitis, she commented that she "dare not on any account let them do it here". ${ }^{25}$ Michael Hopkins' doctor near Machakos, Kenya, mistakenly extracted the wrong tooth. ${ }^{126}$ 'Going home' to England was standard advice among colonial doctors, particularly to patients suffering badly from malaria, but it was commonly disregarded. For many, such a solution was unaffordable or impractical. Menina Slade recalled that she was taken to Dr Roland Burkitt in Nairobi, and he "took one look at me and turned to my father saying, "with her colouring, she'll never survive this climate - get her back home, Gordon!"127 Although her parents insisted that she wear a spine pad, "there was never any question that I should be sent back to England". ${ }^{28}$ Generally though, patients preferred professional medicine and privileged professional advice above their own expertise.

\footnotetext{
${ }^{117}$ Both Heald and Rawlins and Considine's collections include families' memories of birth, which, although none are given in great detail, include more intimate medical information than is common in older memoirs.

${ }^{118}$ Heald, 247.

119 Blixen, Letters from Africa, 303.

${ }^{120}$ Heald, 67-68.

${ }^{121}$ Ibid., 68.

122 Ibid.

123 Ibid.

${ }^{124}$ Blixen, Letters from Africa, 30-31.

125 Ibid., 256.

${ }^{126}$ Considine and Rawlins, 145.

127 Ibid., 18.

${ }^{128}$ Ibid.
} 
European settlers' medical isolation only extended to professional European medicine. White settlers usually lived near African communities, which had their own medical structures, practices, and expertise. John Iliffe's study of local medical systems in East Africa explains that most communities had several layers of medical practice, including domestic remedies, elderly neighbours or relatives, and a wide variety of specialist healers. ${ }^{129}$ There were, Iliffe explains, different types of healers, with some focusing on divination/diagnosis and others on treatment. ${ }^{130}$ Those who treated disease generally learned via an apprenticeship and employed a range of herbs, often with "genuine, if mild, medicinal properties," and among other techniques could treat snake bite, set bones, bleed using a cupping horn, treat fever through encouraging perspiration, and cauterise to stop bleeding. ${ }^{131}$

Settlers generally had no interest in local medical systems and often discussed them with contempt. Missionaries in particular were affronted by indigenous medical treatments, though many other settlers shared their views. Fisher, after seeing an old woman wearing a shell and piece of wood around her neck to cure chest pain, wrote "when 'Heaven lies about us' and every common bush is aflame with God, it is inconceivable how any man can remain cognisant only of the Spirit of Evil." 132 A Rhodesian settler blamed "a concoction made of boiled jackal skin" prescribed by "the witch-doctor" for the death of the family's servant, Chikutsa, "of whom we were all very fond." 133 Chikutsa had contracted pneumonia and "Mother was dosing him and doing her best," but his wife contacted a local healer and, the author claimed, the treatment "killed him off in a very short time". ${ }^{134}$

Most accounts simply ignored local medical systems altogether. Rather than noting any pre-existing medical structures, memoirs typically represent local communities as devoid of any medical practitioners - places of ill-health requiring colonial intervention. Two authors did make some positive remarks. Mansfield wrote that "in addition to the weaving of spells and giving of philtres, native doctors often have genuine skill. They will set fractures, and stitch wounds with fibres from the castor-oil plant, the leaves being used for dressing." 135 Pointing to the witchdoctor's "small special basket," she commented "but why laugh at the witchdoctor's basket, since such useless things as the huge red and green glasses which fill each

\footnotetext{
${ }^{129}$ John Iliffe, East African Doctors: A History of the Modern Profession (Cambridge: Cambridge University Press, 1998), 9.

130 Ibid.

${ }^{131}$ Ibid., 10.

${ }^{132}$ Fisher, On the Borders, 121.

${ }^{133}$ Heald, 218.

${ }^{134}$ Ibid.

${ }^{135}$ Mansfield, 337.
} 
chemist's window in England are recognised as trade-marks of the pharmaceutical profession?" 136 Colonial administrator John Cairns acknowledged that "tribal doctors" were useful for psychological illnesses, and that sometimes such doctors did effect miraculous cures. ${ }^{137}$ Mansfield and Cairns were nevertheless the exception.

Just three examples of Europeans employing African healers or medicines appeared in all the sources studied. After Goy's husband injured his knee "it swelled so much that it required lancing". ${ }^{138}$ After she "undertook to do it myself, but failed through want of courage," she called in "a native doctor" who "did it fairly well". ${ }^{139}$ In Flame Trees, the Grants' neighbour broke his leg but did not wish to travel to a European doctor, and so had his leg set and bound "by one of the Kikuyu, who laid claim to some surgical skill". ${ }^{140}$ A Rhodesian settler family were offered "some native medicine" by their servant Old Jack when their son (Sonny) fell ill with malaria, but refused it on the advice of a neighbour. ${ }^{141}$ After Sonny died the family often felt "regret that we did not allow old Jack to obtain his native remedy". ${ }^{142}$ Old Jack administered the remedy (Nkano bark) when another son fell ill with severe malaria. ${ }^{143}$ The son survived. ${ }^{144}$

Settlers who utilised local medicine were all to a certain extent vulnerable: not wealthy, and highly geographically and socially isolated. Europeans on the margins of white settler society may have employed local remedies more frequently than the settler population as a whole. As such people wrote fewer memoirs than more elite settlers, examples of African treatment of Europeans could be under-represented in the sources. It is also possible that accounts of Africans performing medical services for Europeans are left out of memoirs as they do not fit the conventional colonial image of helpless local populations, waiting for the charity of a benevolent empire and white settler population. Regardless, even if African treatment of Europeans does appear at a lower rate in the sources than it occurred in reality, there is no evidence that it occurred more than very infrequently.

A very small number of authors utilised local magical charms or medicines. Elspeth Grant in Flame Trees consulted a Kikuyu witchdoctor to request medicine to protect her duiker

\footnotetext{
136 Ibid.

137 John Cairns, Bush and Boma (London: J. Murray, 1959), 81.

138 Goy, 23.

139 Ibid., 23-24.

${ }^{140}$ Huxley, Flame Trees, 233.

${ }^{141}$ Heald, 20.

142 Ibid., 21.

143 Ibid., 21.

${ }^{144}$ Ibid.
} 
(a sub-Saharan antelope) Twinkle from being eaten by a python. ${ }^{145}$ In comparison, her mother Tilly responded with anger and scepticism when one of the family's workers, Njombo, almost died after a witchdoctor placed bad magic on him. ${ }^{146}$ The contrast between the adult and child view is telling. Whitlock argues that Flame Trees is an attempt to construct a white African identity and "to stake a claim to a state of white indigeneity" after the Mau Mau Uprising. ${ }^{147}$ Whitlock notes that the child protagonist "is free to find a space between the two worlds, black and white" and that "the child comes to represent a different way of being part of both European and indigenous cultures, uniquely placed to draw upon the knowledge of both." 148 When Elspeth seeks protection for Twinkle she claims cross-cultural belonging; unlike her mother, she can enter the magical world of the Kikuyu, although she confines her involvement to a deliberately harmless, childlike magic.

The only other author who deliberately dabbles in local magic is Blixen. She wrote in one letter that "at present [the Muhammadans] are teaching me some of their sorcery; but it is strictly secret so I cannot tell you about it. A special spell was made for 'my sister's toto [child],' and I hope it may bring the little puss good luck." ${ }^{149}$ Unlike Huxley, Blixen approached 'sorcery' with interest and some condescension, rather than serious need. Two other authors had peripheral contact with local magic: Caddick was presented a charm for "a good heart" and one colonial administrator fled with his family after discovering pieces of bark used by the local witchdoctor placed pointing near his baby's head. 150 "Go there," he wrote, "you who do not believe, go, and in some way upset the witch-doctors as I did ... it will have you in a grip of fear - at any rate until the sun rises." ${ }^{151}$

Jigger extraction is the one exception to the almost total lack of involvement of local people in European healthcare. Colonial memoirs are filled with almost identical accounts of jiggers. Caddick's account is typical: she described jiggers as "horrible," explained that they lay eggs under the toe nail which ulcerate if left untreated, and noted that Africans remove jiggers with little pain, "whereas, if you try to do it yourself, you often make a large hole and a very sore place." ${ }^{152}$ Servants almost universally removed settlers' jiggers; just one individual remembered her parents carrying out the operation. ${ }^{153}$ Mansfield advised travellers to "ask a

\footnotetext{
${ }^{145}$ Huxley, Flame Trees, 191-193.

${ }^{146}$ Ibid., 142-160.

${ }^{147}$ Whitlock, 128, 131.

148 Ibid., 128.

${ }^{149}$ Blixen, Letters from Africa, 64.

${ }^{150}$ Heald, 35; Caddick, 147.

${ }^{151}$ Heald, 35.

152 Caddick, 174-175.

${ }^{153}$ Considine and Rawlins, 52.
} 
native to extract either jigger-flea or tick for you, because they are very clever at taking out the little creatures whole". ${ }^{154}$ Fisher even paid the high price of 500 cowrie shells to have a man named Mbeda remove the jiggers from one of her servants. ${ }^{155}$

The frequent involvement of local people in jigger extraction was probably partially because it was a process that required very specific skills, of which most settlers would have had no experience. The procedure was too minor to require a medical professional, but it necessitated careful, practiced technique. Yet there was likely another element. Medical treatment is an intimate process, rendering the patient vulnerable and to some extent submissive before the individual performing the treatment. Africans doctoring white settlers therefore inverted the colonial power relationship. The key to jigger extraction's popularity may be that it complicated imperial power dynamics less than most treatments. Extraction was performed on the white settler's feet, thereby physically maintaining a position of white dominance. The patient retained full faculties, minimising their vulnerability. It could also be conceptualised as an extension of a servant's grooming and dressing duties.

Some of the literature on colonial medicine in Africa addresses the issue of medical creolisation. John Rankin, for example, queries whether medical creolisation - the melding of different medical cultures - occurred in early nineteenth-century West Africa. He concludes that although some "very patchy evidence" suggests limited creolisation, competition characterised the medical environment. ${ }^{156}$ European medicine between 1890 and 1939 did incorporate plants from tropical regions that were utilised in local medicine, but their use is better characterised as appropriation rather than creolisation. ${ }^{157}$ No evidence suggests a merging of settler and local medicine, and the various medical cultures did not compete to treat Europeans. Professional and amateur European medicine complemented each other, and white settlers rarely utilised local healers and medicines.

This chapter began with a single anecdote: the story of Joan, Jim and Bill's safari and Bill's treatment for malaria and a possible snake bite. Simpson included it in her memoir partly for the shock value of Bill's violent first aid, and partly because of its personal significance. Yet

\footnotetext{
154 Mansfield, 214.

${ }^{155}$ She judged the shells to be equivalent in value to seven pence halfpenny. Fisher, On the Borders, 165-166.

${ }^{156}$ John Rankin, 'Healing the "African Body" in the Age of Abolition? British Medicine in West Africa, c.18001860', Ph.D. Thesis, McMaster University, 2010, 151.

157 Johnson, 'Commodity Culture', 72.
} 
treatment like Bill's has a wider significance when contextualised within colonial Africa's amateur treatment tradition.

Bill's snakebite treatment reflected almost exactly a treatment recommended in the Handbook of Nyasaland, illustrating one of the many sources of medical knowledge available outside formal training institutions. As well as advice books, outfitters, public events and debates, promotional material from pharmaceutical companies, and other settlers all provided settlers immigrating to Africa with medical knowledge. Medically isolated, Joan and Bill turned to self-treatment, as was common practice throughout British Africa. Bill would almost certainly have called in a doctor had one been available - amateur treatment almost never competed with professional medicine - and, like the vast majority of white settlers, he did not seek out a local healer. Through their medical practice, settlers like Joan formed a crucial part of the colonial medical system. The medical techniques settlers used, and how those compared to professional medical advice, will be explored in the next chapter. 


\section{Chapter Two}

"What an Amount of Quinine we took!": Amateur Disease Etiologies and Treatment Methods, with a Malaria Case Study

In the view of contemporaries and in the judgement of many scholars, the late nineteenth and early twentieth centuries were a special period for medical science. ${ }^{1}$ The increasingly widespread acceptance of germ theory over miasmatic theory and the flourishing bacteriology of the period seemingly laid the way for a new, modern medical practice. At the forefront of this new scientific medicine was the emerging specialty of tropical medicine, and throughout the 1890s the specialty accumulated figurehead scientists, supporting institutions, and a raft of scientific breakthroughs.

Yet recent scholarship has complicated the traditional narrative of medical progress. Historians have noted strong continuities throughout this era of radical change. Many scholars argue that the medical profession, particularly on the geographic periphery, clung to ideas of environmental causation of disease long after germ theory was well established. ${ }^{2}$ Ryan Johnson, for example, has illustrated that many medicines for tropical travellers marketed as modern were well-established remedies cunningly repackaged and mass marketed. ${ }^{3}$ A small but growing number of works consider more broadly the persistence in the late imperial world of older ideas, and the conservative trends within early twentieth century modernity. ${ }^{4}$ In white settlers' medical practice in British Africa, older medical ideas coexisted with more modern developments. Settlers' medical techniques and conceptions of disease causation blended tropical medical science with age-old home remedies and medical ideas, creating a unique disease management regime that suited their skills and experiences of sickness.

This chapter will first examine settlers' conceptions of disease causation, and argue that settler writings constructed a mixed model of disease - drawing upon older environmental

\footnotetext{
${ }^{1}$ Matthew Ramsey, Professional and Popular Medicine in France 1770-1830: The Social World of Medical Practice (Cambridge: Cambridge University Press, 2002), xii; Arnold, 'Disease, Medicine and Empire', 17; Worboys, 185.

2 Endfield and Nash, 309; Crozier, 'Sensationalising Africa', 405; Worboys, 186, 191; Anderson, The Cultivation of Whiteness, 81; Kennedy, 'Diagnosing the Colonial Dilemma'; Anderson, Colonial Pathologies, 131-145.

3 Johnson, 'Tabloid Brand Medicine Chests'.

${ }^{4}$ See, for example, Kate Hunter, 'More than an Archive of War: Intimacy and Manliness in the Letters of a Great War Soldier to the Woman He Loved, 1915-1919,' Gender \& History 25.2 (2013), 339-354; Kristine Alexander, 'The Girl Guide Movement and Imperial Internationalism during the 1920s and 1930s,' The Journal of the History of Childhood and Youth 2.1 (2009), 37-63.
} 
etiologies as well as modern understandings of vectors - that reflected their awareness of contemporary science and their lived experiences of African environments. The chapter will then explore the treatment methods employed by amateurs. Although conclusions are limited by a scarcity of evidence, it will propose that settlers employed a range of treatments that blended a few well-known medical products with home remedies. The last section will examine malaria - the most distinctively and symbolically tropical disease that settlers regularly encountered - as a case study of amateur practice, first asking how settlers wrote about malaria, then how they attempted to treat it.

Throughout the eighteenth and early nineteenth centuries, medicine and wider Western culture viewed health and sickness as direct results of the body's interaction with its surroundings. ${ }^{5}$ Through most of the nineteenth century, British doctors theorised that tropical climates generated disease through two mechanisms: the simple action of sun and temperature, and a more complex idea of diseased space, in which the environment itself became "intensely diseased". ${ }^{6}$ The individual body existed in a delicate and permeable state, vulnerable to any shift in the environment. ${ }^{7}$ It was, for example, a "commonplace of the old medicine of warm climates...that the 'quality' of European blood deteriorated in moist heat". 8 Similarly, Victorian medical orthodoxy held that heat overstimulated organs. ${ }^{9}$ For delicate Victorian bodies, Africa presented a powerful threat. As Jennings writes of early missionaries, "the very land, Africa itself, was poisoning the European intruders. Just to be in contact with the ground was to risk infection; to breathe the misty air of the marshes was to consume malaria."10

The germ theory of disease formed a direct challenge to environmental etiologies. As many scholars have stressed, germ theory did not represent a total rupture; environmental causative factors continued in popular and professional discussions of disease. ${ }^{11}$ Germ theory did, however, profoundly shift medical understanding and alter how doctors, and eventually

\footnotetext{
5 Lara Marks and Michael Worboys, 'Introduction' in Lara Marks and Michael Worboys (eds.), Migrants, Minorities and Health: Historical and Contemporary Studies (London and New York: Routledge, 1997), 8.

${ }^{6}$ Johnson, 'European Cloth and "Tropical” Skin', 545.

${ }^{7}$ Collingham, 3 .

${ }^{8}$ Anderson, Colonial Pathologies, 85.

${ }^{9}$ Collingham, 2.

${ }^{10}$ Jennings, 73.

${ }^{11}$ For one example, see Gregg Mitman and Ronald Numbers' exploration of the persistence of medical geography after germ theory. Gregg Mitman and Ronald L. Numbers, 'From Miasma to Asthma: The Changing Fortunes of Medical Geography in America,' History and Philosophy of the Life Sciences 25.3 (2003), 391-412.
} 
the wider public, viewed their bodies in relation to their surroundings. The central role of parasites and vectors in many tropical diseases sustained environmental causation within tropical medicine to a greater degree than in most medical fields. Leading historians of tropical medicine, including Anderson and Worboys, identify the persistence of environment within the speciality. ${ }^{12}$ It is unsurprising that the field clung to environmental disease explanations; as a specialty built upon geographic medical specificity, environment is encoded into its very name. As Johnson notes, it was "an easy transmission from miasmas to mosquitoes" - he explains that older climatic etiologies were "at once exorcised and re-inscribed". ${ }^{13}$ In addition, Rob Edmond argues that germ theory "focused attention more on the native subject as a disease carrier". ${ }^{14}$ Indigenous peoples were viewed as intimately connected to the places they inhabited, further reinforcing notions of tropical difference. ${ }^{15}$ "Germs," Edmond explains, "intensified the view of both tropical places and peoples as toxic."16

Crozier drew similar conclusions from her study of tropical medical guidebooks. ${ }^{17}$ Despite being often, though not exclusively, written by qualified doctors, medical guidebooks are of interest as they form something of a border between professional and amateur medicine. Crozier found that most written health advice between 1890 and 1939 outlined ways to alter the physical environment to minimise disease risk. ${ }^{18}$ The advice still distinguished between dry and moist heat and stressed the importance of house design for health. ${ }^{19}$ Even practical malaria advice sometimes did not change after Ross's discovery of the mosquito vector. ${ }^{20}$ She concluded that there was no rapid shift from environmental to parasitological explanations of tropical disease, and that grass-roots medical practice on the colonial periphery changed slowly, even if practitioners did adopt superficial aspects of new medical developments. ${ }^{21}$

As well as reflecting the persistence of environmental beliefs among health advice authors, medical guidebooks' continuities possibly reflect their audiences. Colonial medical guidebooks are not simple mirrors of their authors, but are carefully constructed for an educated, general audience. Popular medical handbooks for the tropics often explicitly identified their intended reader, typically describing an intelligent, educated man with no

\footnotetext{
${ }^{12}$ Anderson, Colonial Pathologies, 131-145; Anderson, The Cultivation of Whiteness, 81; Worboys, 186, 191.

${ }^{13}$ Johnson, 'European Cloth and "Tropical” Skin', 546-547.

${ }^{14}$ Edmond, 181.

${ }^{15}$ Ibid.

${ }^{16}$ Ibid.

${ }^{17}$ Crozier, 'Sensationalising Africa'.

${ }^{18}$ Ibid., 404.

${ }^{19}$ Ibid.

${ }^{20} \mathrm{Ibid}$

${ }^{21}$ Ibid., 405.
} 
medical training, whose remote location would likely require him to perform medical treatments. Perhaps guidebooks' strong emphasis on environment, as identified by Crozier, was influenced by authors' desires to tailor medical information to their audience (as far as was possible without seriously compromising the information they presented). Environmental explanations of disease causation were profoundly embedded in the public consciousness; even for those familiar with germ theory, the idea that one's surroundings strongly influenced health was axiomatic. As well as to advise, guidebooks also sought to reassure, give confidence, and mediate between experts and lay people; all of these are more easily done when the text works within, instead of directly contradicting, the reader's existing knowledge. Rather than reducing readers into passive consumers of information, we can question whether popular beliefs influenced the production of medical knowledge for lay audiences.

Memoirs, letters, and diaries from colonial Africa display numerous examples of environmental thinking persisting after the proof of germ theory and the mosquito transmission of malaria. William Oke Kempthorne wrote in his ledger about a 1905 visit to Rhodesia, that "at Gwanda there used to be, and is still, a great deal of fever, it is running very close for the name of 'the worst fever hole' in Rhodesia... The fever fog lies right along the valley in the wet season." 22 No term could better encapsulate miasmatic ideas than Kempthorne's 'fever fog', yet other comments make it clear he was aware of Ross's discovery. He judges Matetsi to be "a very unhealthy place" on the basis of its plentiful water and mosquitoes. ${ }^{23}$ Yet shortly afterwards he declares Dar es Salaam to be "not very healthy" owing to "there being so much vegetation," again reflecting miasmatic beliefs in the dangers of vegetation and the importance of proper ventilation. ${ }^{24}$ Mansfield attributed her first malaria attack to camping near a large swamp and forgetting to apply Muscatol, "a delightful preventative against mosquito bites," to her arms, suggesting she understood mosquitoes' role in malaria transmission. ${ }^{25}$ Just forty pages earlier, however, she had warned against camping "too near a swamp, for fever may be caught from the rising mist". ${ }^{26}$

Few authors use the term 'germs' in memoirs. When authors do, they often use it in a distinctly unmodern manner. One of the rare examples of the term is Lettice Palmer's

\footnotetext{
${ }^{22}$ William Oke Kempthorne, William Oke Kempthorne's Ledger Notes, Compiled by B. J. Carruthers, 18701919 (Compiled 2002), MS-Papers-11200-36 in Stone Family: Papers, MS-Group-2023, Alexander Turnbull Library, Wellington, 37.

${ }^{23}$ Ibid., 41.

${ }^{24}$ Ibid., 46.

${ }^{25}$ Mansfield, 255.

${ }^{26}$ Ibid., 214.
} 
description of the Thika district as a "sea of germs" in Flame Trees. ${ }^{27}$ Blixen recorded a similar idea in a letter home, during a severe drought: "the plains are on fire every day and are completely black and charred...with the wind blowing from the somali town and the bazaar,you feel the plague and cholera germs are whirling merrily around." ${ }^{28}$ In neither example is the term 'germs' being used in a scientific, medical sense; indeed, appearing in seas and whirls they seem more akin to miasmas than microscopic organisms. Germs function as symbols and a shorthand for filth, disaster, suffering, and the unsuitability of European bodies in Africa. Similar sentiments can be detected in terms such as 'fever fog' and 'fever hole'. Authors employed these phrases for emotional accuracy rather than medical accuracy, favouring older concepts that, for them, held cultural if not scientific truth.

It would be wrong to read such comments as reflecting medical ignorance, as throughout colonial memoirs authors frequently associated malaria and mosquitoes. While a few may have learned of the connection after leaving Africa and before writing a memoir, there is no reason to believe this was generally the case. Julia Smith's Sunshine and Shade in Central Africa (1908) explains to the reader that mosquitoes "have been the cause of more deaths in this country than anything else, for it is from them that one gets the malarial fever." ${ }^{29}$ She then states which mosquitoes transmit malaria and the necessity for precautions. ${ }^{30}$ Other authors also show familiarity with mosquito transmission. Of course, not all settlers knew that miasmatic explanations for malaria were no longer scientifically supported, particularly those in the first decade of the twentieth century. Interviews conducted with Universities' Mission to Central Africa (UMCA) missionaries in 1900 revealed ignorance of malaria causes and prevention. ${ }^{31}$ In a 1921 letter from Norman Leys to Borden Turner, Leys explained that malaria was carried through the air. ${ }^{32}$ Leys, however, was certainly in the minority. Mosquitoes and malaria appeared so frequently in guidebooks, the press, and in public debates that few settlers could have missed the connection by the early twentieth century.

Memoirs engage little with other medical breakthroughs and vectors. A very small number mention the tsetse fly and suggest a knowledge of its transmission of sleeping sickness. Cameron, for example, describes the tsetse fly as a serpent in East Africa's Eden. ${ }^{33}$ Huxley

\footnotetext{
${ }^{27}$ Huxley, Flame Trees, 61.

${ }^{28}$ Blixen, Letters from Africa, 65.

${ }^{29}$ Julia Smith, Sunshine and Shade in Central Africa (London: Edwin Dalton, 1908), 67.

${ }^{30}$ Ibid.

31 Jennings, 84.

${ }^{32}$ Norman Leys and Joseph Houldsworth Oldham, By Kenya Possessed: The Correspondence of Norman Leys and J.H. Oldham, 1918-1926, John Cell (ed.) (Chicago: University of Chicago Press, 1976), 174.

${ }^{33}$ Cameron, 166.
} 
describes ticks, in her 1985 memoir, as "the main carriers of disease". ${ }^{34}$ Interestingly, there are almost no mentions of house flies nor any connection between them and ill health, even though the advice literature identified their danger. ${ }^{35}$ Their absence could reflect a lack of knowledge, a decision that (in often substandard living conditions) concern over flies was unrealistic, or most likely - a result of the sensationalist demands of the memoir and its British audience, for whom malaria-carrying mosquitoes were thoroughly interesting and house flies were not. Unlike mosquitoes, flies were not distinctive to the tropics, and were likely to produce only slight aversion in the reader.

As in professional tropical medicine, environmental ideas of disease persisted within amateur medicine alongside more modern discussions of parasites and vectors. Unlike professional medicine, however, amateur medicine shows little sign of an 'exorcism and reinscription' ${ }^{36}$ Rather than rupturing and transforming amateur conceptions of tropical disease, the discovery of germs and parasites confirmed existing fears of a hostile tropical world. The distinction between swamps causing malaria and the mosquitoes that dwelled in them doing so may have profoundly influenced doctors, but there is little evidence that it did so for settlers. They may have referred to mosquitoes rather than miasma when rating the healthiness of a locality, but they did not abandon the old idea that places could be categorised onto a linear continuum of health that ranged between curative/healthy to pathogenic/deadly. Incorporating new ideas of vectors and germs into older etiologies of disease, settlers created a mixed model of disease transfer that both adopted the most practical aspects of modern tropical medicine and explained their experiences of the environment as a hostile place that carried sickness with it.

Of all the aspects of amateur medicine in colonial East and South-Central Africa, it is the specifics of Europeans' treatment of other Europeans that is hardest to uncover in the sources. Although memoirs and letters readily discuss Europeans' illnesses and mention that they carried out treatments, few provide any detail of those treatments. Sources often drop tantalising hints: the settler 'dosed', 'poulticed', 'applied restoratives', or used 'herbs', all

\footnotetext{
${ }^{34}$ Huxley, Out in the Midday Sun, 74.

${ }^{35}$ Parke, 152; Bradley, A Household Book for Africa, 64, 161; Bradley, Dearest Priscilla, 218.

${ }^{36}$ Johnson, 'European Cloth and "Tropical" Skin', 546-547.
} 
without specifying the crucial ingredient. ${ }^{37}$ Interestingly, sources have no such reticence when discussing their treatment of Africans and so chapter four, which considers amateur European medical practice in African communities, will continue the argument made here. This section - as far as the evidence allows - will suggest that settlers treated European patients with a different range of techniques and medicines than those recommended in professional medical advice books. It will also propose that the difference does not simply reflect a lack of amateur medical skill, but signals a distinctive medical culture.

The first question to consider briefly is why memoirs are so silent about the process of treating friends and family. Some authors may have excluded some medical details to avoid disgusting their audiences, or side-stepped particularly gruesome anecdotes in the name of good taste. Nevertheless, such explanations are not sufficient. Medical anecdotes provide excitement and drama for memoirs, and the fact that many memoirs contain vivid descriptions of sick or injured Africans suggest that a concern for readers' sensibilities was not usually the reason for the silence. Out of Africa, for example, features essentially no discussions of European health (even though Blixen did suffer from many illnesses and injuries), but includes a gruesome description of wounded Kikuyu children. ${ }^{38}$ It seems probable that authors' reticence primarily stemmed from the desire to preserve the privacy of their European patients. Had authors been medical professionals then there would have been clearly defined expectations of confidentiality, and in general the sickroom would have remained closed to a voyeuristic reading public. The contrast between Huxley's autobiographical work and her crime fiction partially reflects the different requirements of the genres, but also speaks to the privacy that real European subjects required. Flame Trees contains very few mentions of European illness and no detail. ${ }^{39}$ Huxley's Murder on Safari, on the other hand, uses vivid descriptions of dead and dying fictional Europeans to provide moments of high drama. ${ }^{40}$

To some degree, authors' amateur status breaks down professional expectations of confidentiality. They are willing to discuss, with names attached, patients' diagnoses and experiences of illness. Yet some of the silence of the sickroom still remains. Authors avoid sharing intimate details about their patients, including the process of their treatment; it is

\footnotetext{
${ }^{37}$ Ruth Fisher, Twilight Tales of the Black Baganda (London: Frank Cass Publishers, 1970), first published 1911, 169; Richards, 142-148.

${ }^{38}$ Blixen's collected letters mentioned severe malaria, jiggers, a barbital over-dose, several attacks of sunstroke, rheumatism, frequent insomnia, several injuries, veld-sores, blood poisoning, an inflamed appendix, influenza, lumbago, frontal sinusitis, chronic dysentery, and severe anaemia. Blixen, Letters from Africa, 4, 7, 29-30, 31, 48, 66, 84-89, 97, 122, 126, 176, 221, 303, 309, 313-314, 415; Blixen, Out of Africa, 74.

${ }^{39}$ Huxley, Flame Trees, 233, 242, 284.

${ }^{40}$ When Sir Gordon Catchpool is gored by a buffalo, for example, Huxley describes his gashed chest, with his "ribs stove in like a broken egg-shell," and his death in great detail. Huxley, Murder on Safari, 86-87.
} 
telling, when instances of European illness appear, that the most vivid medical descriptions almost always centre on the author themselves, the person whose story they had no sanctions on revealing. Providing details on the treatment process would almost always reveal too much intimate medical information to the reader. The fact that authors afforded their African patients no comparable privacy is telling. It suggests that, regardless of authors' intentions (which they typically represent as benevolent), they did not view African patients in the same way as Europeans: not believing they required the bodily privacy of an adult European, and instead exposing their bodies as unfamiliar or exotic curiosities for the white reader.

What information can be gleaned from the scant recording of amateur treatment of Europeans? The basic techniques were nursing, particularly for malaria; diagnosing common illnesses and providing first aid until professional medical aid could arrive; and stitching, cleaning and dressing wounds. Some of these techniques mirrored amateur practice in temperate regions, but others (such as diagnosing 'tropical' maladies) were entirely new. The medicines used are harder to identify. Advice books list staggering numbers of recommended drugs, and it seems inconceivable that many settlers would have purchased them all. The Tropical Trials handbook recommends thirty-four medicines and instruments, and John Murray's 1912 How to Live in Tropical Africa lists forty-eight, although he suggests that the traveller and their medical adviser select from the list. ${ }^{41}$ Cross's Health in Africa is the most extravagant, providing a list of thirty-two medicines "necessary for the treatment of malarial fever in its various forms," commenting sternly that "no one should go to Africa without these." 42 He then follows that list with an additional thirty-six general medicines, plus further equipment for surgical purposes. ${ }^{43}$ The recommended medicines were similar to those that appeared in BWC medicine chests, such as the famous No.250 that was modelled on Stanley's Congo chest and was manufactured from the 1890 s to the $1920 \mathrm{~s} .{ }^{44}$ In fact, the first edition of Murray's How to Live simply recommended one of the BWC Stanley chests, rather than listing the individual medicines. ${ }^{45}$

\footnotetext{
${ }^{41}$ Hunt and Kenny, Tropical Trials, 373; Murray, How to Live, 1912, 296.

${ }^{42}$ Cross, 200-203.

${ }^{43}$ Ibid.

${ }^{44}$ Common medicines that appeared in guidebooks and BWC medicine chests included cascara, Epsom salts, various forms of quinine, ipecacuanha, opiate mixtures, mustard leaves, and equipment such as plaster, thermometers, and lint. Hunt and Kenny, Tropical Trials, 373; Hints on the Preservation of Health in Tropical Africa (London: The Crown Agents for the Colonies, 1943), 45; Johnson, 'Tabloid Brand Medicine Chests,' 255256; Murray, How to Live, 1912, 296.

${ }^{45}$ John Murray, How to Live in Tropical Africa: A Guide to Tropical Hygiene (London: George Philip \& Son, 1895), 125, 232-233.
} 
There is no evidence that settlers utilised anywhere near as many medicines as guidebooks commonly recommended. Alyse Simpson, Mansfield, Fisher, and Smith all possessed medicine chests, although possession does not equate to usage. ${ }^{46}$ Authors very rarely named scientific, laboratory-made medicines, of the types produced by large pharmaceutical firms and listed in advice texts. The exceptions were quinine and disinfectants. Authors more frequently mentioned home remedies and older popular medical substances such as Epsom salts. Thus, a visitor in The Land that Never Was treated colic with his own remedy of brandy and castor oil; a missionary prescribed hot milk and ginger for influenza; Mr Joubert insisted his family gargle with Jeyes fluid and take Epsom salts and quinine during an influenza epidemic; and one family took eucalyptus oil and sugar for coughs. ${ }^{47}$ Many of these mixtures were presumably variants on British household remedies, either reproduced directly for a familiar illness, or adapted for a disease without a British counterpart. Authors may not have mentioned all their commonly used medicines in memoirs, perhaps to avoid technical terminology, or to avoid admitting their improvisation, or because the medicine was too common to seem worthy of comment. It seems clear, however, that settlers generally used a limited, simple range of medicines, comprised of 'folk' remedies combined with a few common pharmaceutical products, such as quinine.

Two pieces of evidence support this interpretation. Firstly, Joan Jolley, whose family settled in Kenya in 1907, recalled that "five basic medicines were kept on farms - aspirin, quinine, children's cough mixture, embrocation [an application for strains or sprains], and liquid paraffin for 'tummy treatment'." ${ }^{48}$ Even more useful is The Kenya Settlers' Cookery Book and Household Guide, produced by the Church of Scotland Women's Guild, which included recommendations for medical treatments. ${ }^{49}$ Coming seemingly from settler women's own knowledge, likely via member submissions, the book more closely matches actual practice than most advice literature. ${ }^{50}$ The Guide is also an interesting example of a women's (and religious) organisation collecting and disseminating women's knowledge, largely (though not exclusively) for a female audience. Most of the Guide's medical advice rests on simple, homestyle remedies. The reader learnt, for example, to make an embrocation of turpentine, vinegar,

\footnotetext{
${ }^{46}$ Simpson, The Land That Never Was, 5; Fisher, On the Borders, 131-133; Huxley, Flame Trees, 40; Mansfield, 204-205.

${ }^{47}$ Simpson, The Land That Never Was, 108; Heald, 149, 182; Considine and Rawlins, 94.

${ }^{48}$ Considine and Rawlins, 94.

${ }^{49}$ Church of Scotland Women's Guild, The Kenya Settlers' Cookery Book and Household Guide Fourth edn. (Nairobi: The East African Standard, Ltd., c.1930s), 314, 339-341.

${ }^{50}$ No doctor or advice book is credited with the medical section of the guide, unlike Barnes' 1890 handbook, which explicitly states the source of her medical advice section. Barnes, 248; Kenya Settlers' Cookery Book, 393341.
} 
salad oil, raw eggs, ammonia, and camphor. ${ }^{51}$ The guide suggested settlers stock aspirin, boracic powder, castor oil, cascara, cough mixture, carron oil, calomine lotion (for irritation), Epsom salts, iodine, olive oil, permanganate of potash, quinine, syrup of figs, scrubb's ammonia (for bites), sloan's liniment, and zinc ointment, plus a first aid box containing basic equipment. ${ }^{52}$ Amateur medicine was based on a small range of familiar substances, rather than a plethora of BWC products for the tropics.

Alongside quinine and disinfectants, the substance most often mentioned during accounts of amateur treatment is alcohol. As in Britain during the period, authors record a wide range of medical uses. Leach employed its anaesthetic properties when "she gave [her husband] half a tumbler of neat brandy to drink" before reattaching his severed thumb. ${ }^{53}$ Another woman fed "white-of-egg and brandy" to her gravely ill baby as a sustaining drink. ${ }^{54}$ Alcohol also had the power to treat, not just preserve or anaesthetise. A visitor at Joan's house claimed he had "a touch of malaria and whisky was the only thing to check it". ${ }^{55}$ Upton remembered being given ammoniated quinine and hot toddies (whisky, lemon, and hot water) for malaria as a child. ${ }^{56}$ When a settler was lost in Flame Trees, the search party discussed heading out "with some brandy in case he's hurt, and a stretcher, in case he's exhausted". ${ }^{57}$ Alcohol could ward off disease: one woman's neighbour in Rhodesia "slept with a bottle of whisky under his pillow and whenever he woke up in the night he would have a good drink" during the influenza pandemic. ${ }^{58}$ Settlers also used alcohol for shock and to oppose the ill effects of the tropics; Joan's lodger needed a lunchtime stout "to counteract the 'thinness' of her blood". 59

Tropical guidebooks almost always strongly encouraged moderation of recreational alcohol consumption, though few advised temperance. Such an approach aligned with the views of the Victorian and Edwardian British medical establishment, which generally supported moderate drinking, particularly among the social elite. ${ }^{60}$ John Murray's How to Live

\footnotetext{
${ }^{51}$ Kenya Settlers' Cookery Book, 340.

${ }^{52}$ Recommended first aid equipment included adhesive tape, bandages, cotton wool, jaconet, lint, scissors, and safety pins. Ibid., 339.

${ }^{53}$ Heald, 209.

${ }^{54}$ Ibid., 157.

55 Simpson, The Land That Never Was, 96.

${ }^{56}$ Considine and Rawlins, 52.

${ }^{57}$ Huxley, Flame Trees, 242.

${ }^{58}$ Heald, 149.

${ }^{59}$ The supposed fortifying qualities of were also reflected in its common use by nursing mothers in Victorian and Edwardian Britain to increase lactation. Simpson, The Land That Never Was, 171; David Gutzke, "The Cry of the Children": The Edwardian Medical Campaign Against Maternal Drinking,' British Journal of Addiction 79.1 (1984), 73.

${ }^{60}$ Gerald Wayne Olsen, “"Physician Heal Thyself”: Drink, Temperance and the Medical Question in the Victorian and Edwardian Church of England, 1830-1914', Addiction 89.9 (1994), 1167-68, 1173.
} 
recommended readers take, of the alcoholic beverages, only cognac at lunch and stated that only at six thirty in the evening could alcohol consumption prove advantageous. ${ }^{61}$ On Duty explained that authorities agreed that the less alcohol consumed in the tropics the better, but qualified the recommendation by commenting that "indeed, there seem to be very many people who derive a certain amount of benefit from partaking of a moderate quantity". ${ }^{62}$ Hints on the Preservation of Health and Climate and Health in Hot Countries took similar approaches. ${ }^{63}$ In contrast, reflecting its female readership, Tropical Trials urged abstinence from alcohol. ${ }^{64} \mathrm{~A}$ few memoir authors weighed into the debate and condemned heavy drinking in the tropics; Caddick, for example, wrote that whisky drinking in Central Africa was a "terrible bane" that caused fever and other harms. ${ }^{65}$

Although guidebooks frowned on all but moderate recreational drinking, they often featured some medicinal uses of alcohol. Cross in 1897 advocated brandy or whisky "in cases of emergency" and champagne for blackwater fever, while the 1922 Handbook of Nyasaland still advised brandy and whisky as stimulants for blackwater fever and in certain circumstances for pneumonia or snakebite. ${ }^{66}$ How to Live also advised champagne and other stimulants for blackwater; Emily Bradley's 1939 Household Book for Africa suggested gin or other spirits as antiseptics for putzes (the putzi fly, which parasitically attacks humans in its larval phase, forming lesions); the 1890 Colonial Household Guide advised giving children alcohol for hiccoughs and gin for violent crying; and the Kenya Settlers' Cookery Book suggested alcohol for cases of strychnine poisoning. ${ }^{67}$ Hunt and Kenny advocated strict moderation of recreational alcohol partially for greater medicinal efficacy. ${ }^{68}$ Stephen Samuel Murray clearly distinguished between appropriate medical practice in Britain and in the tropics, suggesting the tropics required stimulants more than temperate areas; the "average European," he predicted, would feel "the need of an alcoholic stimulant" in tropical Africa's enervating environment. ${ }^{69}$

Amateur treatment did not replicate professional advice around medicinal use of alcohol. It is true that both amateur and professional medicine widely used medicinal alcohol. Alcohol was commonly used in British professional medicine, although its use declined

\footnotetext{
${ }^{61}$ Murray, How to Live, 1912, 236-237.

62 Hunt and Kenny, On Duty, 80.

${ }^{63}$ Hints on the Preservation, 2, 32; Giles, 62.

${ }^{64}$ Hunt and Kenny, Tropical Trials, 118-120.

${ }^{65}$ Caddick, 36.

${ }^{66}$ Cross, 203; Murray, A Handbook of Nyasaland 229, 234-235.

${ }^{67}$ Murray, How to Live, 1912, 89; Bradley, A Household Book for Africa, 161; Barnes, 249-250; The Kenya Settlers' Cookery Book, 341.

${ }^{68}$ Hunt and Kenny, On Duty, 80.

${ }^{69}$ Murray, A Handbook of Nyasaland, 224.
} 
through the late nineteenth and early twentieth centuries, and colonial guidebooks recommend medicinal alcohol for certain conditions. ${ }^{70}$ Professional advice and amateur practice differ not in the fact of alcohol use, but in its frequency and importance. Advice authors recommended alcohol in certain circumstances, but it was a minor portion of their medical discussions and recommendations. In amateur accounts, alcohol is used for a wider range of conditions than in guidebooks and far more frequently.

Alcohol's centrality to amateur medicine raises the question of whether other drugs, in particular opiates, played a similar role. Johannes Fabian's Out of Our Minds notes that early explorers of Central Africa carried medicinal opiates (usually laudanum or morphine) and took them often for particular conditions, such as dysentery, as well as non-specifically. ${ }^{71}$ Interwar Kenya was known for recreational drug use. Although most settlers lived relatively sedate lives, Kenya's infamous (though small) 'Happy Valley' social set, as C. Duder writes, "used the Colony as a background to indulge their own highly developed tastes in gin and adultery," including offering the Prince of Wales cocaine during his 1928 visit. ${ }^{72}$ No memoirs, letters, or diaries mention drug use, medicinally or otherwise, but the medicine lists in advice books frequently feature opiates. ${ }^{73}$ The Kenya Settlers' Cookery Book attests to the ready availability of opiates and similar substances, discussing how to treat morphia, opium, and cocaine poisoning. ${ }^{74}$ The presence of opiates in British Africa is unsurprising, given that they were uncontrolled in Britain until the First World War. ${ }^{75}$ It seems likely that opiates played a role in amateur treatment, but that subsequent shifts in social acceptability and legality silenced memoirs.

Amateur treatment of Europeans in the late nineteenth and early twentieth centuries, then, differed from professional advice. Although sources provide few details on the treatment process, the evidence suggests that settlers relied on a few staple medicines and home remedies, with alcohol as particularly important. No discussion of European health in Africa is complete,

\footnotetext{
${ }^{70}$ Olsen, 1168; John Burnett, Liquid Pleasures: A Social History of Drinks in Modern Britain (London and New York: Routledge, 2012), 172.

${ }^{71}$ Fabian, 67.

72 Duder, 430.

${ }^{73}$ See, for example, William Simpson's 1916 The Maintenance of Health in the Tropics. Simpson recommends laudanum for mild and severe dysentery, and places it on his list of recommended medicines. The recommended medicine list also includes other medicines containing opiates, such as Chlorodyne and Dover's Powder Tablets. Simpson, The Maintenance of Health, 140, 172.

74 The Kenya Settlers' Cookery Book, 341.

75 Opiate and cocaine based substances were restricted in Britain by provision 40B of the Defence of the Realm Act in 1916. The measures were consolidated after the war in the 1920 Dangerous Drugs Act. Howard Padwa, Social Poison: The Culture and Politics of Opiate Control in Britain and France, 1821-1926 (Baltimore: John Hopkins University Press, 2012), 99, 104; John Crellin, A Social History of Medicines in the Twentieth Century (New York: Pharmaceutical Products Press, 2004), 138.
} 
however, without proper consideration of malaria. The next section will examine the representation of malaria in memoirs and use authors' descriptions of malaria to illustrate the trends in amateur treatment identified thus far.

The term malaria, from the Italian mal aria (bad air), entered English in approximately $1740 .^{76}$ Although today viewed as a tropical disease, historically malaria has been endemic across the globe, including in Europe into the early twentieth century. ${ }^{77}$ Initially believed to be caused by bad airs or miasmas, malaria arises from five protozoan species of the Plasmodium genus spread via the female anopheles mosquito. P. falciparum, the variety endemic to tropical Africa, is the most virulent strain and carries the highest mortality risk. ${ }^{78}$ The late nineteenth century was a period of rapid malaria research. Quickly defined by figures such as Manson as the most important tropical disease (although it was not the highest cause of European mortality across the tropics), malaria attracted public attention and debate; indeed, Worboys argues that Manson deliberately drew on malaria to legitimise and facilitate the emergence of the tropical medical specialty. ${ }^{79}$ From about 1850 , doctors began to differentiate malaria from the generic term for miasmatic disease and miasmas. ${ }^{80}$ Ettore Marchiafava identified malaria parasites in 1884, and malaria was distinguished from other fevers between 1890 and $1900 .{ }^{81} P$. falciparum was identified by Camillo Golgi in $1889 .{ }^{82}$

The most famous breakthrough in malaria research came with Ross's 1897 proof of mosquito transmission. Some of the most significant changes for malaria treatment among Europeans in the tropics had, however, occurred much earlier. Quinine was first introduced into Europe (alongside a number of anti-malarials) as cinchona bark. ${ }^{83}$ Jesuits brought the bark from South America in the seventeenth century and it was regularly prescribed through the eighteenth century. ${ }^{84}$ It had slipped from favour in the early nineteenth century, replaced by

\footnotetext{
${ }^{76}$ George, 121.

77 Ibid.

${ }^{78}$ Daniel Headrick, The Tools of Empire: Technology and European Imperialism in the Nineteenth Century (Oxford: Oxford University Press, 1981), 64.

${ }^{79}$ Typhoid fever and several other diseases were responsible for higher European mortality across the tropics than malaria. Worboys, 194-195.

${ }^{80}$ Ibid., 186.

${ }^{81}$ George, 123.

${ }^{82}$ Ibid.

${ }^{83}$ Headrick, 65.

${ }^{84}$ Ibid.
} 
calomel and mercury, when the quinine alkaloid was extracted in $1820 .^{85}$ By 1830 , commercially produced quinine had reached the public, and it was used curatively in West Africa by the $1840 \mathrm{~s} .{ }^{86}$ Once prophylactic quinine came into favour from the $1850 \mathrm{~s}$, death rates among Europeans fell. ${ }^{87}$ While imperialism in Africa still came at a cost in terms of British lives, that cost had been greatly reduced.

As discussed earlier in this chapter, most settlers writing after 1900 were aware of the link between malaria and mosquitoes. Some even displayed a wider familiarity with malaria research and called upon further knowledge to identify when/where infection occurred. Mansfield pinpointed a particular swamp as her source of infection using her knowledge of the connection between swamps, mosquitoes, and malaria, as well as her awareness that "malarial fever takes about nine days to develop". ${ }^{88}$ Authors do frequently ascribe ill-health to landscapes, drawing heavily on miasmatic medical ideas. For authors writing after the first decade of the twentieth century, however, their comments should not generally be read as scientific ignorance. Miasmatic imagery was symbolic, representing settlers' impressions of the landscape rather than medical fact. Thus when Markham wrote of the Ukamba area that "the country is bush, sansevieria, fever, and drought," she did not believe the miasmatic idea that fever rose from the ground itself. ${ }^{89}$ Instead, she drew on such concepts to conjure the image of a hostile, diseased landscape that captured her experience of the Ukamba country.

Discussions and descriptions of malaria fill colonial African memoirs. In part, their prevalence reflects settlers' experiences: malaria was a deadly illness in many parts of East and South-Central Africa, was a defining aspect of settlers' lives, and was the most distinctively tropical and dramatic disease that settlers regularly encountered. Yet it was certainly not the only cause of settler morbidity and mortality in the region. Malaria was a dangerous disease in colonial Africa, but it disproportionately dominates memoirs while other very common and potentially lethal conditions, such as dysentery, are essentially unremarked upon. It seems that malaria held a symbolic value as well for settlers, beyond the simple medical facts of its prevalence and severity. Malaria spoke of tropical difference and danger, and attested to the personal courage and suffering of the author. For missionaries in particular, it contributed to their narrative of sacrifice, written to encourage support from religious audiences in Britain.

\footnotetext{
${ }^{85}$ Ibid., 65-66.

${ }^{86}$ Ibid., 66-67.

${ }^{87}$ Ibid., 69.

${ }^{88}$ Mansfield, 255.

${ }^{89}$ Markham, 201.
} 
Descriptions of malaria also appealed to readers. Malaria was a subject of interest for the British and colonial public and first-hand accounts enlivened a memoir. Vivid and lengthy personal descriptions of malarial attacks are not uncommon, and while they were undoubtedly important life experiences for the author, they were also probably selected for the audience's interest. Currie, for example, included harrowing passages describing her symptoms: burning, restlessness, desperate thirst, aching, shaking, and fixations on various images, in particular "a clear cold spring that trickled from a spout into a stream covered with water-cress" ${ }^{90}$ Kenneth Bradley's Diary of a District Officer discusses malarial hallucinations. ${ }^{91}$ One of the most memorable parts of Jane Moir's A Lady's Letters from Central Africa is her comment that "a horrid fever" left her "looking like Gorgonzola cheese". 92

Authors' descriptions of their state of infection also illustrate malaria's symbolic significance for its suffers. Many represented malaria as a powerful factor in their perceptions of their body and the surrounding world. Currie twice used the phrase "full of malaria," and Markham employed the similar phrase "riddled with malaria," both conceptualising malaria infection as a state that encompassed the whole body and shaped their perceptions of it. ${ }^{93}$ Rather than visiting once, malaria remained with the individual. In The Land that Never Was, Marsden's friends worry about bringing on "his malaria," the disease integrated with and inseparable from Marsden himself. ${ }^{94}$ Authors made strong connections between malaria and their mental state. Currie was sunk into a "malarious depression" and Blixen wrote in one of her first letters from Kenya that "malaria makes you feel so miserable ...the whole world disgusts you like an ill-fitting dress." 95

Settlers held differing opinions of an individual's culpability for contracting malaria. Some advocated strict body management to prevent infection and avoid repeat attacks, and blamed themselves when they failed to take all precautions and fell ill. Thus, Mansfield blamed herself for sleeping beside a swamp unprotected and Joan attributed Bill's "attack of fever" to his diving into a river (wetness and chilling were thought particularly dangerous). ${ }^{96}$ Goy, although sympathising deeply with her husband, also implicitly held him responsible for his malaria attack, after he walked barefoot between a canoe and dry land. ${ }^{97}$ "Of course," she

\footnotetext{
${ }^{90}$ Currie, 96-97, 153, 173-174.

${ }^{91}$ Kenneth Bradley, The Diary of a District Officer (Edinburgh, Thomas Nelson and Sons, 1947), 67-68.

92 Jane Moir, A Lady's Letters from Central Africa (Glasgow: James MacLehose, 1891), 86.

${ }^{93}$ Currie, 35, 41; Markham, 28.

${ }^{94}$ Simpson, The Land That Never Was, 20.

${ }^{95}$ Currie, 168; Blixen, Letters from Africa, 4.

${ }^{96}$ Mansfield, 255; Simpson, The Land That Never Was, 244.

97 Goy, 49.
} 
wrote, "that is enough to cause malaria." 98 Caddick was particularly censorious, sternly commenting that "from what I heard and saw, I feel sure that there would be a great deal less fever if those whose lot it is to live out there would learn to be more careful of their health." 99 Perhaps the fact that Caddick was travelling rather than living in Central Africa hardened her belief that ill-health was not inevitable, but a question of personal effort. Certainly, few settlers took as staunch a view as Caddick in apportioning blame for illness.

Several authors firmly asserted that malaria attacks were primarily an act of fate. Infection became a matter of luck, rather than personal dedication and assiduous bodily management, so individuals could not be held responsible for illness. A letter from George St. Hill from Salisbury in 1895 described the fate of his friend, John Acland: "Poor old Acland is in camp at the hospital with fever...these continual attacks are fearfully depressing and discouraging... he has had awfully bad luck...that damnable fever had literally presented itself as an obstacle to him at every turn". ${ }^{100}$ St. Hill did not blame Acland for his malaria attacks, or preach greater personal responsibility and care, representing a very different understanding of agency and disease from that espoused by authors such as Caddick. Although settlers subscribed to popular notions of body management up to a point, the conception of malaria as beyond one's control remained strong.

Settlers attempted to prevent and treat malaria through a wide range of measures, drawing on professional advice but also selecting and reinterpreting it. Mosquito nets were widely used to prevent malaria before 1897 , as they were thought to keep out miasmas. ${ }^{101}$ Moir, for example, slept under a mosquito net in Central Africa in $1890 .{ }^{102}$ It is impossible to assess how many did not use mosquito nets, as few authors wrote about equipment they did not use. The survey of UMCA missionaries found that most used mosquito nets, but that many took few other precautions to avoid mosquito bites. ${ }^{103}$ Joan waited a long time to buy mosquito netting (during which time her family contracted malaria), which she implied was because of financial constraints - perhaps netting use had an economic dimension not reflected in the sources. ${ }^{104} \mathrm{~A}$ few settlers planted eucalyptus trees, mentioned mosquito screening in houses,

\footnotetext{
${ }^{98}$ Ibid.

${ }^{99}$ Caddick, 35.

${ }^{100}$ George St. Hill, 22 April 1895 in L. O H. Tripp, Histories and Reminiscences 'Some Notes by L. O. H. Tripp about his Friend George H. St. Hill', 79925 in Acland Family Papers, 44, MacMillan Brown Special Collections, Christchurch.

101 Jennings, 76.

102 Moir, 21.

103 Jennings, 84.

${ }^{104}$ Simpson, The Land That Never Was, 115.
} 
or used insecticidal substances. ${ }^{105}$ 'Sanitary segregation', the name given to racial separation (particularly of dwellings) for disease prevention, occurred little in East and South-Central Africa, a point explored in the next chapter. A (perceived) over-scrupulous use of protective clothing and equipment could perhaps present the wearer as slightly foolish, or as an outsider, unintegrated into the community. In Evelyn Waugh's novel Black Mischief (1932), written after his visit to Kenya and set in the fictional East African state of Azania, Waugh uses zealous mosquito avoidance techniques to add humour to his character Monsieur Ballon, who appears as a figure of fun throughout the book. ${ }^{106}$

Quinine was the most widely used treatment and preventative for malaria. Some did view quinine with suspicion, owing to its unpleasant side effects, bitter taste, and links with blackwater fever. ${ }^{107}$ Caddick, for example, followed "the advice once given me by an old traveller" and did not take quinine prophylactically, only taking a dose when she "felt 'cheap". ${ }^{108}$ In 1907, Dr Howard noted that some UMCA missionaries did not take the required prophylactic quinine, particularly those stationed in Zanzibar. ${ }^{109}$ Persuading children to take "beastly bitter" quinine could be a struggle. ${ }^{110}$ Anne Steele, who grew up in British Tanganyika, recalled that "my brother Hugh had a running battle with my father about swallowing his dose." 111 Those who did take regular quinine did so in wildly varying amounts. Currie increased her dose from a few grains at night, on first arrival, to forty grains in a single day. ${ }^{112}$ "What an amount of quinine we took!" she commented. ${ }^{113}$ Although doctors strongly recommended quinine, and settlers tended to follow that advice, settlers determined how that advice was implemented.

Settlers learned about malaria through the channels of amateur medical learning described in the first chapter. Given malaria's frequent appearances in the British and colonial press, it is likely that newspaper reporting contributed substantially to amateur knowledge. Advice books typically emphasised malaria, providing detail far beyond that given for other

\footnotetext{
105 Ibid., 146; Considine and Rawlins, 32, 93; Bradley, Dearest Priscilla, 24.

${ }^{106}$ Evelyn Waugh, Black Mischief (Harmondsworth: Penguin, 1961) first published 1932, 57.

${ }^{107}$ From the late 1890s, public debates raged in the British press about the safety of quinine and its possible role in causing blackwater fever. Charles George argues that the historical record suggests that these fears were correct: blackwater fever appeared around the time when cinchona back was first used to treat falciparum malaria, and died away after the Second World War, around the time when synthetic antimalarials replaced quinine. George, 124; Considine and Rawlins, 32; Heald, 21; Hunt and Kenny, On Duty, 64.

108 Caddick, 34.

109 Jennings, 84.

${ }^{110}$ Considine and Rawlins, 93.

111 Ibid., 32.

112 Currie, 6, 175.

113 Ibid., 175.
} 
conditions. John Murray's How to Live, for example, provided a staggering six chapters of detail on malaria, and then another four on quinine and other anti-malarial preparations. ${ }^{114} \mathrm{He}$ explained the differences between Manson and Ross's treatment recommendations and the German practices, allowing settlers to select their preferred treatment model. ${ }^{115}$ While no other author matched Murray's educative zeal, others also offered substantial detail. The advice literature clearly intended for readers to engage seriously with malaria and understand it enough to develop protective methods tailored to their situation, rather than adopt a single recommended approach. The wealth of information also likely speaks to the strong public interest in malaria, as well as migrants' expectations of tropical guidebooks.

Memoirs illustrate that settlers used medical knowledge to nurse routine malaria attacks. Upton, born in 1925, wrote that the routine for "if you were ill" was "temperature taken, jab a needle in your finger to get blood for the slide, then a dose of Ammoniated Quinine, then sent to bed with a hot toddy...The blood slide went in to the local doctor for proof of malaria - but he seldom came to you." ${ }^{116}$ Even in the 1930s, malaria remained largely within the realm of home treatment. Not only did malaria nursing place a substantial responsibility on the shoulders of settlers, but they were also expected to judge when a malarial attack grew sufficiently severe to summon professional medical aid. These weighty responsibilities again highlight the importance of amateur medical judgement for successful British control of African territory. Tropical medicine's ability to combat malaria certainly underpinned colonialism, but so too did settlers' abilities to adapt and apply medical advances.

Amateur tropical medicine, then, operated alongside professional tropical medicine and possessed a number of characteristics that distinguished it from professional medical advice. Settlers adopted a distinctive outlook on disease causation, melding miasmic and germ/vector transmission to reflect their knowledge of scientific advances while still speaking to their experiences of the intimate linkages between landscape and health and the deadliness of the African environment. Although evidence is relatively sparse, it seems that settlers relied upon a few basic medicines (such as quinine and aspirin), disinfectants, home remedies, and alcohol. A closer examination of malaria illustrates the symbolic importance that it held for settlers; the

\footnotetext{
${ }^{114}$ Murray, How to Live, 1912.

115 Ibid., 139-140.

${ }^{116}$ Considine and Rawlins, 52.
} 
ways in which miasmas and mosquitoes could coexist in authors' explanations; and the fact settlers adapted and implemented the methods and advice created by medical professionals, forming an essential part of the colonial medical system.

Settlers, therefore, emerge not just as extensions or subjects of professional medical advice, but as individuals possessing medical agency with a distinctive form of medical practice. Amateur medical techniques also testify to the persistence of older ideas within an age of medical progress, and within early twentieth century modernity. Tropical medical practice came hand-in-hand with a related field: that of tropical hygiene. Advice authors urged strict bodily management in tropical climates, producing elaborate regulations and equipment to protect white bodies from the tropical exterior. The next chapter will explore how amateur agency and adaptation interacted with these restrictive recommendations. 


\section{Chapter Three}

Sun Hats and Sundowners: Managing Bodies and Minds in the Tropical Climate

"Many and varied are the difficulties that beset a woman, when she first exchanges her European home and surrounding for the vicissitudes of life in the tropics." ${ }^{1}$ So begins Hunt and Kenny's pessimistically titled Tropical Trials: A Handbook for Women in the Tropics (1883), a guide for British women bound for the tropical colonies, in particular India. Hunt and Kenny cover many aspects of tropical life tailored towards women, including dress, household management, mental wellbeing, and home medical treatment. Their advice, in the typical style of tropical advice texts, was highly prescriptive, providing staggeringly detailed recommendations for the minutest aspects of daily life. Such advice falls within the field of 'tropical hygiene,' which aimed to sustain health and prevent disease contraction through a detailed regime of body management and a range of sanitary and technological measures. Like tropical medicine, tropical hygiene of the late nineteenth and early twentieth centuries defined the tropics as inherently pathological to the white body. One of the crucial strands of tropical hygiene involved strategies for managing the transition and then daily life of a European migrating to the tropics. Almost every aspect of tropical life fell within the remit of tropical hygiene experts, and recommendations were reproduced through the advice literature by authors like Hunt and Kenny.

A rich literature has developed that explores the advice given to Europeans in tropical climates. Historians such as Collingham, Johnson, and Kennedy all highlight the prevalence of tropical hygienic advice and equipment, and its underlying purpose of managing white bodies in the tropics by isolating them from the environment. ${ }^{2}$ Within white settler communities, tropical hygiene advice also took on additional meaning. Francis de Caro and Rosan Jordan argue that in British India, sola topis (sun helmets, often pith, with a high crown and wide sloping brim) developed into powerful symbols of Anglo-Indian identity. ${ }^{3}$ Kennedy and Collingham describe the psychological comfort that topis and other hygienic equipment and regimes brought settlers, calming settlers" "real and serious sense of dislocation and

\footnotetext{
${ }^{1}$ Hunt and Kenny, Tropical Trials, 1.

${ }^{2}$ Collingham, 3-4, 62-65; Kennedy, Islands of White, 110-130; Johnson, 'European Cloth “Tropical” Skin', 531532.

${ }^{3}$ Francis De Caro and Rosan Jordan, 'The Wrong Topi: Personal Narratives, Ritual, and the Sun Helmet as a Symbol', Western Folklore 43.4 (1984), 238-239.
} 
vulnerability" through "psychological palliation" and reassuring routine. ${ }^{4}$ Despite the medical advances of the 1890s and onwards, and the continuing colonial narrative of European medical power and superiority, white bodies in the tropics were viewed as profoundly vulnerable. Simultaneous with the belief in the heroic power of Western medical technology came the need to regulate and manage the European body through intricate equipment and strict regulation.

How settlers negotiated ideas of hygiene, separation, and vulnerability in British East and South-Central Africa in the heroic era of tropical medicine is the subject of this chapter. Following the approach of embodied history, this chapter explores the relationship between prescriptive tropical hygiene advice and settlers' construction and regulation of their bodies in the colonial setting. In 'Why All the Fuss about the Body?' Caroline Bynum argues that there are two senses of embodiment used in scholarship: one that denotes place and limits (the body contextualised), and another that suggests desire and potentiality (the body as malleable). ${ }^{5}$ Kathleen Canning identifies a similar duality within body history, which she describes as a "slippage" that "commonly occurs between individual bodies as sites of experience/agency/resistance and social bodies formed discursively." 6 The ideas of bodies as discursive and as experiential/malleable do not have to be viewed as mutually exclusive. Didier Fassin, for instance, utilises the concept of embodiment to interpret the AIDS epidemic in South Africa using structural factors and "the construction of the collective" alongside individual narratives of AIDS. ${ }^{7}$ Embodiment suggests the place of tension, dynamism, and complexity that lies between advice and practice, in which individuals, living in their bodies in a new environment, were acted on by advice but also constructed and negotiated questions of hygiene in unique ways.

Tropical hygiene commented upon almost every aspect of daily life. This chapter explores three crucial aspects of advice/equipment: clothing, 'sanitary segregation', and moral management. It analyses the fragments of settlers' descriptions of their behaviour in relation to the three themes, and compares them to the various strands of hygiene advice that appeared in the popular advice literature. Overall, the chapter will argue that settlers in East and SouthCentral British Africa drew on discourses of bodily hygiene and management then adapted and

\footnotetext{
${ }^{4}$ Kennedy, Islands of White, 110, 126; Collingham, 90.

${ }^{5}$ Caroline Bynum, 'Why All the Fuss about the Body? A Medievalist's Perspective', Critical Inquiry 22.1 (1995), 5.

${ }^{6}$ Kathleen Canning, 'The Body as Method? Reflections on the Place of the Body in Gender History', Gender \& History 11.3 (November 1999), 503.

${ }^{7}$ Didier Fassin, 'Embodied History: Uniqueness and Exemplarity of South African AIDS', African Journal of AIDS Research 1.1 (2002), 63.
} 
reinterpreted them to create dynamic, unique, and individualised body management regimes distinct from professional advice of the period.

From the seventeenth century onwards, clothing was one of a European traveller's first defences against the tropical climate. ${ }^{8}$ A visit to a tropical outfitters to purchase clothing was an important preparation for journeys into the tropical Empire, and advice books are filled with clothing recommendations and advertisements by manufacturers. Clothing continued to be based on climatic etiologies long after the medical establishment had thoroughly accepted germ theory and parasite vectors. ${ }^{9}$ Indeed, Johnson argues that climate theories of disease were actively reinforced and maintained through travellers' patronage of tropical outfitters and their purchases of clothing to shield them from tropical climates. ${ }^{10}$ Protective equipment often persisted after its medical logic had faded, exacerbated by settlers' use of older advice texts. ${ }^{11}$ Even into the early twentieth century, protective clothing based on Victorian medical science remained standard in British Africa (at times essentially unchanged since the 1850s), and not until the 1930s did the more rigid clothing conventions relax. ${ }^{12}$

Although most advice texts viewed correct clothing fabric as crucial, there was no consensus over which fabric best suited tropical climates. The well-known recommendation to "keep the spirits up, bowels open and wear flannel next to the skin" obscures the wide range of opinions expressed through guidebooks as authors weighed up the relative benefits of wool, cotton, linen, silk, and blended fabrics. ${ }^{13}$ Health in Africa favoured cotton and wool worn next to the skin, unless it gave the wearer prickly heat; John Murray preferred flannel for preventing chills and cotton if worn lose and with little skin contact; Harry Ward and John Milligan favoured flannel; Giles saw the benefits in flannel and Jaeger woollen fabric but believed the traveller should opt for a silk-wool blend; Parke sided with loose-fitting wool; and William Simpson with wool. ${ }^{14}$ As Johnson points out, the degree of debate reflected the fact that authors

\footnotetext{
${ }^{8}$ Johnson, 'European Cloth and “Tropical” Skin', 531.

${ }^{9}$ Ibid., 544-545.

${ }^{10}$ Ibid.

${ }^{11}$ Collingham, 90.

${ }^{12}$ Collingham, 90; Curtin, The Image of Africa, 354.

${ }^{13}$ Crozier, Practising Colonial Medicine, 130.

${ }^{14}$ Cross, 4; Murray, How to Live, 1912, 277; Harry Ward and John Milligan, Handbook of British East Africa (London and Nairobi: Sifton Praed and Caxton, 1913), 157; Giles, 23; Parke, 151; Simpson, The Maintenance of Health, 13.
} 
were often attempting a single solution for 'the tropics' or 'Africa', ignoring the substantial local variation. ${ }^{15}$

A few authors advocated 'modern' sun-protective fabrics. In the early twentieth century, scientists developed a small number of specialist fabrics which promised to protect the wearer from the tropical sun's 'actinic' rays - rays believed to impair physiological functioning and generate nervous conditions. ${ }^{16}$ Louis Sambon's woollen 'solaro' fabric placed a neutral colour on top and red underneath to repel actinic rays. ${ }^{17}$ Ironically, solaro was not only ineffective, but was probably detrimental to health as it was hot and uncomfortable. ${ }^{18}$ Nonetheless, solaro and similar fabrics were advertised and even recommended in a few advice books. John Murray warned of the dangers of actinic rays and described solaro as successful and highly regarded, and also recommended 'soltego' for shirting, which was created with the same colour combination. ${ }^{19}$ Although William Simpson does not name specific products, he also recommended red, orange, or yellow fabrics. ${ }^{20}$

One of a settlers' best defences against the sun was a hat. Advice books urged settlers to wear highly protective hats whenever outdoors or under insufficient roofs. Two styles found general acceptance: the sola topi and the double terai (a wide brimmed, double layered hat of heavy felt). ${ }^{21}$ Some authors suggested combining hats with a puggaree/neck creem (a cloth shielding the neck) or veils. ${ }^{22}$ Tropical Trials advised green lining for the topi and John Murray advocated red. ${ }^{23}$ Even in cooler weather, Tropical Trials noted, the head still must be guarded against the sun's rays and a topi must be worn. ${ }^{24}$ When Huxley ventured ashore hatless at Port Sudan, the famous Nairobi doctor Burkitt explained with horror that she risked dementia praecox, cardiac failure, and renal occlusion. 25 "Actinic rays softened the brain, rotted the guts and sapped the moral fibre," according to Burkitt. ${ }^{26}$ "No precautions can be too great," Parke

\footnotetext{
15 Johnson, 'European Cloth and "Tropical” Skin', 542.

16 Ibid., 535.

17 E. T. Renbourn, 'Life and Death of the Solar Topi: A Chapter in the History of Sunstroke' (Seventh Commonwealth Defence Conference on Clothing and General Store, London, 1961), 32-33; Murray, How to Live, 1912, 295-296; Simpson, The Maintenance of Health, 7.

18 Johnson, 'European Cloth and "Tropical” Skin', 533.

${ }^{19}$ Murray, How to Live, 1912, 295-96.

${ }^{20}$ Simpson, The Maintenance of Health, 7.

${ }^{21}$ Ward and Milligan, 157; Helen Callaway, 'Dressing for Dinner in the Bush: Rituals of Self-Definition and British Imperial Authority' in Ruth Barnes and Joanne Eicher (eds.), Dress and Gender: Making and Meaning in Cultural Contexts (Providence and Oxford: Berg, 1992), 244; De Caro and Jordan, 234; Cross, 4; Murray, A Handbook of Nyasaland, 275.

${ }^{22}$ Hunt and Kenny, Tropical Trials, 16-17; Murray, How to Live, 1912, 292.

${ }^{23}$ Hunt and Kenny, Tropical Trials, 17; Murray, How to Live, 1912, 294.

${ }^{24}$ Hunt and Kenny, Tropical Trials, 114.

${ }^{25}$ Huxley, Out in the Midday Sun, 4.

${ }^{26}$ Ibid.
} 
wrote, "for protecting the head." 27 Tropical Trials warned of women straying far from home then discovering that "the head protection...is utterly inadequate, and a serious illness, that often ends fatally, is the penalty paid." 28 Guidebooks only softened their recommendations around the Second World War, suggesting lighter hats rather than topis or double terais, particularly in the Kenyan Highlands. ${ }^{29}$

For additional protection, settlers could supplement clothing and hats with other accessories. Nineteenth-century medical orthodoxy viewed the spine as a point of bodily weakness. ${ }^{30}$ The spine pad developed in response - a three inch wide pad, usually of cork shavings, attachable to clothing. ${ }^{31}$ John Murray recommended a twenty-six inch long pad to button into a coat or shirt; Ward and Milligan suggested them for country work and shooting; Giles advised a cotton-wool spine pad for sun sensitive individuals; and Parke a spine pad for morning and evening sun. ${ }^{32}$ John Murray, Hunt, Kenny, and Parke all recommended cholera belts or flannel cummerbunds to protect the abdomen. ${ }^{33}$ According to the theory of cuteohepatic sympathy, the stomach region was highly vulnerable to cooling and associated harms. ${ }^{34}$ The flannel cummerbund was recommended in India for bowel complaints, including cholera. ${ }^{35}$ Even after the identification of the cholera bacillus, cummerbunds remained standard throughout the tropics. ${ }^{36}$ John Murray suggested that settlers protect their pelvic organs with light flannel, silk or cotton drawers, and remember "the necessity of protecting the genitals and rectum in hot countries." 37

As well as protecting against the sun, authors urged settlers to guard equally against chills. The Kenya Settlers' Cookery Book advised the reader to "avoid a chill as you would a poison". ${ }^{38}$ William Simpson listed avoiding chills as one of his three "axioms which should never be forgotten in the tropics". ${ }^{39}$ The skin, Simpson explained, "is more active and sensitive in a hot climate than in a cold" and so should be kept at a constant temperature. ${ }^{40}$ Published in 1916, yet drawing on pre-germ theory medical ideas, The Maintenance of Health commented

\footnotetext{
${ }^{27}$ Parke, 151.

${ }^{28}$ Hunt and Kenny, Tropical Trials, 15.

${ }^{29}$ For examples, see Bradley, Dearest Priscilla, 239 and Hints on the Preservation of Health, 3.

${ }^{30}$ Collingham, 88.

${ }^{31}$ Ibid.

${ }^{32}$ Murray, How to Live, 1912, 292; Ward and Milligan, 157; Giles, 30-31; Parke, 151.

${ }^{33}$ Murray, How to Live, 1912, 283, 291; Hunt and Kenny, On Duty, 204; Parke, 151.

${ }^{34}$ Collingham, 88.

35 Ibid.

${ }^{36}$ Ibid.

${ }^{37}$ Murray, How to Live, 1912, 287.

38 The Kenya Settlers' Cookery Book, 314.

${ }^{39}$ Simpson, The Maintenance of Health, 4.

${ }^{40}$ Ibid., 10-11.
} 
that the "chill holds a very important place as the exciting cause of disease in warm climates". ${ }^{41}$ Advice authors suggested avoiding chills by keeping shawls and wraps on hand, changing wet clothing instantly, avoiding linen clothing, always dressing children in flannel - no matter how warm the day - in case the weather turned, and eliminating draughts. ${ }^{42}$ If chilled, fever threatened unless individuals took rapid action. ${ }^{43}$ Hot baths, bed, warm drinks, dry clothing, aperient (anti-constipation) medicine, and quinine were all recommended "to prevent the effects of a chill developing when unavoidably exposed to one." 44

Historians argue that protective clothing for the tropics simultaneously isolated settlers from the tropical environment and marked them as distinctively colonial. Rather than solely protecting settlers from specific elements of the tropical environment, protective clothing walled settlers off from the exterior as a whole, forming a barrier between the body and the environment. In Imperial Bodies, Collingham argues that by 1900 the European colonial body was conceptualised as a closed shell that required protecting and preserving. ${ }^{45}$ Kennedy notes that "climatic theories quarantined white settlers from the very environment in which they had established their homes"; the protective equipment inspired by such theories did the same. ${ }^{46}$ Johnson explains that protective clothing also marked settlers as colonial and so separated them from their homelands. ${ }^{47}$ With tropical protective gear often "explicitly based on" local practice, Johnson argues, colonists paradoxically adopted aspects of indigenous cultures to preserve their whiteness and prevent degeneration, which itself was partially marked by adopting local customs. ${ }^{48}$ It is, however, unlikely that many settlers viewed their clothing as an adoption of indigenous customs. Indeed, as 'local practice' varied so wildly, protective clothing supposedly based on indigenous customs may have borne little relation to those settlers encountered. Furthermore, although protective clothing marked settlers as colonial, they could discard it at will. On the journey to India, travellers ritually removed or donned topis at Port Said. ${ }^{49}$

As well as walling off the body, tropical clothing emphasised the contradictory need for ventilation. When John Murray described the essential elements of tropical clothing, he

\footnotetext{
${ }^{41}$ Ibid., 10.

${ }^{42}$ Murray, How to Live, 1912, 186, 291; Hunt and Kenny, Tropical Trials, 13; Ward and Milligan, 159; Parke, 151; Barnes, 252; Cross, 7.

${ }^{43}$ Parke, 151.

${ }^{44}$ Simpson, The Maintenance of Health, 12; The Kenya Settlers' Cookery Book, 314.

${ }^{45}$ Collingham, 3.

${ }^{46}$ Kennedy, Islands of White, 127.

47 Johnson, 'Commodity Culture', 73.

48 Ibid.

${ }^{49}$ De Caro and Jordan, 239.
} 
listed both ventilation and sun protection. ${ }^{50}$ A 1920s Burberry gabardine advertisement captures the dual desire to ventilate and separate the body from the environment, boasting that the fabric "prevents permeation by rain or mists, yet retains natural ventilation". ${ }^{1}$ Wellventilated house designs and locations were equally essential. In Health in Africa, Cross included an entire section on ventilation, beginning with the statement that "pure atmosphere is of the utmost importance." 52 Unventilated air was impure, filled with carbonic acid and organic matter from human breath, microscopic life, dust, and gases from candles. 53 "Vitiated" air could be removed by properly airing a room, although without care ventilation risked draughts, which could bring grievous harms - a delicate balance probably easier in theory than practice. ${ }^{54}$

Thus far, this chapter has considered recommended behaviours as they appeared in popular advice literature. Memoirs, letters, and diaries, however, suggest that recommended behaviour differed from settlers' actual sun protection measures, which will be examined through the remainder of this section. Although advice books encouraged scrupulous avoidance of the sun, especially at mid-day, most rural settlers spent many hours under the tropical sun. Farm work, sports, safaris, and gardening all brought settlers into close contact with the tropical outdoors. Tropical Trials admitted the gap between recommended sun avoidance and white women's actual practice in the tropical empire, commenting that "there are but few occasions when it is really necessary for women to expose themselves to the influence of the tropical sun; but...their doing so, is a matter of almost every-day occurrence." ${ }^{55}$ Blixen picked coffee outdoors in the morning, and Buxton planted coffee. ${ }^{56}$ Buxton wrote in a 1916 letter that she was "very busy" as "I seem to be always riding about...to the various farms I manage to pay the labourers." ${ }^{\prime} 7$ In Flame Trees, Tilly "disregarded the vertical rays of the sun" and worked and rode outdoors during the day. ${ }^{58}$ Yet being outdoors under the sun still possessed a transgressive quality. Huxley entitled her memoir Out in the Midday Sun, probably referencing Noël Coward's 1931 song 'Mad Dogs and Englishmen', but also suggesting the unusualness

\footnotetext{
${ }^{50}$ Murray, How to Live, 1912, 283.

${ }^{51}$ Bushman, 6.

${ }^{52}$ Cross, 6.

53 Ibid.

${ }^{54}$ Ibid., 6-7.

${ }^{55}$ Hunt and Kenny, Tropical Trials, 14.

${ }^{56}$ Blixen, Letters from Africa, 176; Buxton, 14 April 1916.

${ }^{57}$ Buxton, 14 April 1916.

${ }^{58}$ Huxley, Flame Trees, 141.
} 
of the act and using her rejection of bodily protection as a statement of white belonging in Africa $^{59}$

Of all protective equipment, settlers took hats the most seriously and closely followed recommended advice for the majority of the period. Kennedy explains that new settlers assiduously heeded advice. ${ }^{60}$ Huxley commented that "nearly all the Europeans in East Africa... held the same views and took the same precautions" with respect to strict hat and spine pad use. ${ }^{61}$ Blixen wore a topi to her wedding, and Joan saw women wearing topis indoors at a Nairobi club. ${ }^{62}$ Huxley described a new neighbour, who followed the advice "never to remove his hat indoors unless the house had a ceiling, because galvanised sheets did not repel all the sun's rays. ${ }^{63}$ In Black Mischief, two members of the British community even wore sun hats during a romantic encounter in the hills. ${ }^{64}$ Hats appear often in people's recollections of childhood in East Africa. When Jimmy Bruce, for example, recorded his memories of Parklands primary school (Nairobi) in verse, he included the couplet "topees, safari jackets small/ singing hymns in open hall". ${ }^{65}$ Topis and safari jackets become shorthand for British African society, symbolising white Kenya in the early twentieth century.

By the 1930s, with the science of actinic rays steadily waning, hats grew smaller and their usage less constant. When Nora Strange visited Nairobi in the early 1930s, she was amazed at the changes she saw. "Even the sun's actinic rays appear to have lost their power," she wrote, "for in the glare of the morning sun, berets perch at an acute angle on glossy shingled heads, and the lightest of felts have usurped the place of the topee and double terai." ${ }^{\circ 6}$ In Huxley's detective novel Murder at Government House (1937), she described a club in Marula (a thinly veiled pseudonym for 1930s Nairobi). ${ }^{67}$ "One or two of the men carried broadbrimmed black Stetson hats," Huxley described, "but the women...were mostly bareheaded". ${ }^{68}$ As Duder considers Huxley's detective fiction as an unusually accurate fictional treatment of Kenya, Huxley's comment contrasts with Alyse Simpson's observations a decade earlier. ${ }^{69}$

\footnotetext{
${ }^{59}$ White belonging in Africa is a theme in Huxley's writing. For a discussion of white indigeneity in Flame Trees, see Whitlock. Whitlock, 128-31; Huxley, Out in the Midday Sun; Barry Day, The Essential Noël Coward Compendium: The Very Best of His Work, Life and Times (London: Methuen Drama, 2009), 177.

${ }^{60}$ Kennedy, Islands of White, 113.

${ }^{61}$ Huxley, Out in the Midday Sun, 4.

${ }^{62}$ Kennedy, Islands of White, 113; Simpson, The Land That Never Was, 19.

${ }^{63}$ Huxley, Flame Trees, 200.

${ }^{64}$ Waugh, Black Mischief, 42.

${ }^{65}$ Considine and Rawlins, 224-225.

${ }^{66}$ Nora Strange, Kenya Today (London: Stanley Paul, 1934), 38.

${ }^{67}$ Duder, 435; Elspeth Huxley, Murder at Government House (Oxford: Clio Press, 1990), first published 1937.

${ }^{68}$ Huxley, Murder at Government House, 123.

${ }^{69}$ For a scholarly evaluation of the Vachell series and its relation to 1930s Kenya, see Duder, 435-436.
} 
Guidebooks' detailed clothing recommendations were somewhat undermined by the common advice that travellers reuse their British clothes. Books targeted at women and settler handbooks for particular regions often recommended re-using the majority of one's wardrobe, although medical guides aimed at men did so very rarely. Tropical Trials explained that "in tropical countries, except in the matter of material, women wear pretty much what they wear at home". ${ }^{70}$ Mansfield stated that in Rhodesia "no expensive outfit in the way of clothing is necessary, ordinary English clothes being perfectly suitable, with the additions of a few plain print frocks, some thin, easily washed blouses or skirts, and large shady hats of the cheapest nature." $" 71$ The Handbook of Nyasaland suggested that aside from a few essential items (like a sun helmet), the traveller wait to see the local conditions and then purchase as necessary. " $\mathrm{A}$ great number of Europeans engaged in sedentary occupations," Stephen Samuel Murray explained, "wear ordinary clothing, such as they could wear at home, throughout the year."73

Although authors rarely describe everyday dress, memoirs, letters, and novels do suggest that settlers wore a range of clothes, only some of which were distinctively tropical. Joan was surprised to find that white women in Nairobi did not wear khaki. ${ }^{74}$ The trousseau of one Rhodesian settler, itemised in Down Memory Lane, contained little that was specifically engineered for the tropics. ${ }^{75}$ Fisher regretted her Jaegar nightgown, finding it unattractive and wishing for a white one. ${ }^{76}$ In Huxley's description of Marula settlers, the men mainly wore suits and the women "wore printed dresses copied by the local Indian tailor from a model bought on the last trip to England," while a few wore corduroy trousers and slacks. ${ }^{77}$ Outfits in the countryside could be more unconventional than in town: Blixen's wet weather outfit was "long khaki trousers and a kind of blouse reaching to the knee, and bare legs and clogs" ${ }^{78}$ For some settlers, rejecting expensive purpose-designed tropical outfits was a financial necessity. Richards wore hand-me-down clothes, mainly tweeds sent by English relatives, supplemented by cheap silk blouses and outsized men's hats. ${ }^{79}$

Clothing was a dynamic and contested issue in late nineteenth and early twentiethcentury tropical Africa. Tropical advice literature strongly emphasised the regulation and

\footnotetext{
${ }^{70}$ Hunt and Kenny, Tropical Trials, 10.

${ }^{71}$ Mansfield, 93.

${ }^{72}$ Murray, A Handbook of Nyasaland, 275.

${ }^{73}$ Ibid., 275-276.

${ }^{74}$ Simpson, The Land That Never Was, 2.

${ }^{75}$ Heald, 127.

${ }^{76}$ Fisher, On the Borders, 83.

${ }^{77}$ Huxley, Murder at Government House, 123.

${ }^{78}$ Blixen, Letters from Africa, 156.

${ }^{79}$ Richards, 125.
} 
protection of the body through specialised clothing and related equipment. Yet although authors agreed on central points, they differed in the detail, leaving room for settlers' autonomy. Settlers balanced their own interpretations of hygienic requirements against practicalities, budget, and other functions of clothing, creating individualised clothing regimes with far greater personal meaning and variation than reflected in the prescriptive advice literature.

Another area of settler life regulated by tropical hygiene advice was white settlers' interactions with local people. A wide network of rules governed interactions between white settler society and Africans. ${ }^{80}$ This section focuses on 'sanitary segregation' - one type of racial separation that was recommended by some tropical hygiene experts. The connections between colonial medicine and colonial control are rarely more overt than in 'sanitary segregation'. At the same time, the failure of its implementation illustrates the limits, as suggested by Vaughan and others, of colonial medicine's hegemony in East and South-Central Africa. ${ }^{81}$

'Sanitary segregation' was a new malaria control mechanism that appeared around $1900{ }^{82}$ S. R. Christopher and J. W. W. Stephens, sent by the Royal Society to West and Central Africa in 1899, argued that separating Europeans and Africans would more effectively control malaria than medicinal treatment or mosquito destruction. ${ }^{83}$ The argument was inspired by recent research, which had shown that, contrary to general opinion, African adults and children were not immune to malaria. ${ }^{84}$ When experiencing symptoms, they could transmit parasites to mosquitoes if bitten, which could then infect Europeans. ${ }^{85}$ Children were viewed as particularly dangerous carriers of infection. ${ }^{86}$ Advocates of 'sanitary segregation' also argued that it could be useful for containing other diseases, such as plague and smallpox. ${ }^{87}$ In addition to "sanitary segregation', many historians have argued that germ theory itself pathologised local people by shifting blame for disease from the tropical climate to the indigenous body, a process Anderson

\footnotetext{
${ }^{80}$ Kennedy, Islands of White, 148-152.

${ }^{81}$ Vaughan, 'Healing and Curing', 288.

82 Philip Curtin, 'Medical Knowledge and Urban Planning in Tropical Africa', The American Historical Review 90.3 (1985), 598.

${ }^{83}$ Ibid.; Reports to the Malaria Committee of the Royal Society (London: Harrison, 1903), 12, 42.

${ }^{84}$ Curtin, 'Medical Knowledge and Urban Planning', 599-600.

${ }^{85}$ Ibid., 600.

${ }^{86}$ Curtin, Death by Migration, 138.

${ }^{87}$ Curtin, 'Medical Knowledge and Urban Planning', 608.
} 
describes as "the growing racialisation of germ carriage and distribution". ${ }^{88}$ Connections can be seen to the growing fears sparked by Charles Pearson's 1893 National Life and Character: A Forecast, which predicted the decline of the white man and the loss of global power. ${ }^{89}$ Pearson warned of the economic and political threat of non-white peoples, particularly Africans, Chinese, and Indians, while white people - he claimed - were restricted to certain regions of the globe by their need for temperate climates. ${ }^{90}$

Although 'sanitary segregation' was never advice books' main recommendation for malaria prevention, it does appear in early twentieth-century guidebooks. John Murray explains that "Europeans should, if at all possible, exclusively occupy a different quarter of town, or village, a suburb for preference, and never have their houses situated amongst the native huts, as is too commonly seen in African towns." 91 Murray admitted, however, that "this form of segregation may be impractical save for the well-to-do classes," and so suggested that persons suffering from malaria be segregated from others in the home. ${ }^{92}$ Ward and Milligan's Handbook of British East Africa urged the reader not to camp near swamps or African huts. ${ }^{93}$ Segregationist ideas are less extreme in the African advice literature than in that of some colonies. Elsbeth Locher-Scholten's study of Dutch advice manuals for colonial Indonesia reveals far more strident attempts to separate Europeans from the local population. ${ }^{94}$ Yet African advice books sometimes have a similar intent.

Despite the fashion for segregation within town planning, not all East African cities achieved segregation and that which did develop was not generally driven by health concerns. Government projects failed to segregate Zanzibar and Lamu. ${ }^{95}$ Although the towns along the Lake Victoria railway developed with segregation, Curtin argues their design derived from Indian precedent rather than medical logic. ${ }^{96}$ Individuals did not necessarily follow sanitary advice. Hazel Macgregor recalled her mother food shopping in the Mombasa markets, despite the constant concern over hygiene in markets, with fears of contaminated food, prostitution, and venereal disease. ${ }^{97}$ As this project studies rural settlers, little comment can be offered on

\footnotetext{
${ }^{88}$ Anderson, Colonial Pathologies, 3, 8; Edmond, 181.

${ }^{89}$ Marilyn Lake and Henry Reynolds, Drawing the Global Colour Line: White Men's Countries and the Question of Racial Equality (Melbourne: Melbourne University Press, 2008), 75-76.

${ }^{90}$ Ibid., 78-79.

${ }^{91}$ Murray, How to Live, 1912, 200.

92 Ibid.

${ }^{93}$ Ward and Milligan, 157.

${ }^{94}$ Locher-Scholten, 131-153.

${ }^{95}$ Curtin, 'Medical Knowledge and Urban Planning', 610.

${ }^{96}$ Ibid.

${ }^{97}$ Curtin, Death by Migration, 108; Considine and Rawlins, 59.
} 
urban segregation, although cities raise interesting questions of space and health. The location of white, Indian, and African populations within urban areas, and the positioning of places of health/disease such as hospitals, markets, and cemeteries all posed potential challenges to a 'proper' segregation of white/healthy and African/diseased space. In rural areas settlers frequently lived in close proximity to African settlements, as necessitated by the requirement for readily available labour. In The Land that Never Was, Joan mentions "a native whose hut was only fifty yards from our house". ${ }^{98}$

The tension suggested here between sanitary housing and labour requirements points to a larger, and in some respects defining, contradiction of white settler communities in Africa. The white settler colonies of Kenya and Rhodesia always had very small European populations, and economic success and settlement viability rested upon the exploitation of local labour. Colonial success required medical worries to be subordinate to economic considerations, as taken to its extreme medical segregation would have eliminated the exploitation of low-cost labour that made the colonies viable. ${ }^{99}$ Jennings, for example, noted that UMCA missionaries found that practicalities "ruled out segregation as a realistic model for disease management". 100 Giles admitted the dilemma in Climate and Health in Hot Countries, when he wrote: "in selecting a site for camp, it is well to keep as far as possible from native villages, but as a rule one is obliged to pitch tolerably near them, on account of the difficulty of bringing supplies to a greater distance."101

Settlers very rarely represented local people as disease sources, with environmental features forming the vast majority of disease explanations. A few noted their surprise at the cleanliness of Africans they encountered, suggesting they were describing exceptions to a wellestablished narrative. An astounded Cameron admitted that "on one occasion I was so very rude as to dip my finger in a bucket of water and pass it down the uncovered back of a young woman who was standing in front of me in order to ascertain whether she could really be as clean as on the surface she appeared to be. She was." ${ }^{102}$ Although authors avoided describing African people as diseased, they readily critiqued African huts and traditional medical practices, implicitly (and occasionally explicitly) contrasting their hygienic knowledge against supposed African ignorance. Authors do not identify crowded places such as towns, ships, and

\footnotetext{
${ }^{98}$ Simpson, The Land That Never Was, 92.

${ }^{99}$ Kennedy, Islands of White, 147.

100 Jennings, 82.

101 Giles, 87.

102 Cameron, 248.
} 
railways as diseased places, which probably reflects the frequent association made in memoirs between environment, rather than people, and disease.

Settlers' attempts to segregate space racially were complicated by the lack of spatial divisions between domestic places and workplaces, particularly in the early years of colonialism. The divisions blurred most strongly for missionaries. Although African children theoretically posed the greatest disease risk, missionaries also generally aimed to keep them on the mission site. ${ }^{103}$ It was common for missionaries to adopt local children into the home; both Currie and Smith describe adopting girls into their families, who then lived in their houses. ${ }^{104}$ Smith taught school in her yard, and her baby sat amid the pupils, although Smith never forgot the difference between them, writing that her baby "was quite a little king amongst them, and was not at all afraid of their black faces." 105 In teaching and other transactions that took place at the European home, the verandah, together with the yard or terrace, emerges as a crucial site - a transitional space between the 'white' domestic interior and the tropical 'black' outdoors. ${ }^{106}$

Charitable concerns and rare social occasions also eroded recommended spatial demarcations. Blixen wrote in a letter that "it has become a regular habit for the Wakamba totos to come up here on Sunday morning to listen to the gramophone... in some ways I think they regard my house as theirs." 107 Blixen's actions were uncommon, but amateur medical treatment of African people by Europeans regularly brought local people into the European home. The final chapter will explore such encounters in greater detail, but it is important to flag their implication for racial separation. Medical treatment was a deeply intimate process, requiring physical contact, interaction with the patient, and at least some knowledge of their body. ${ }^{108}$ It usually took place in European spaces: generally in the verandah or yard, but occasionally inside the house. Amateur doctoring disrupted segregation recommendations at the most fundamental level, engaging intimately with the precise concern - African illness from which Europeans were to be shielded.

The greatest challenge to white Africa's regulation of racial distance, Kennedy argues, was the presence of African servants within European households. ${ }^{109}$ Settlers generally

\footnotetext{
103 Jennings, 82.

104 Smith, 22; Currie, 44.

105 Smith, 25.

106 Swati Chattopadhyay, 'Blurring Boundaries: The Limits of "White Town" in Colonial Calcutta', The Journal of the Society of Architectural Historians 59.2 (2000), 165-166; Liz Reed, "Mrs Bon's Verandah Full of Aboriginals": Race, Class, Gender and Friendship', History Australia 2.2 (2011), 394; Barbara Brooks, 'In Search of Verandahs', Island 112 (2008), 35-37.

107 Blixen, Letters from Africa, 402.

${ }^{108}$ Hassan, 43, 69.

${ }^{109}$ Kennedy, Islands of White, 152.
} 
employed large numbers of household staff. In Rhodesia, the average European home was staffed by four Africans, while one guidebook recommended a Kenyan household required at the bare minimum - a cook, an ayah (nursemaid), a kitchen boy, two gardeners, and one or two houseboys. ${ }^{110}$ Although servants were housed in separate locations and certain areas (mainly the kitchen stores and liquor cabinet) were forbidden, they were nevertheless present in the vast majority of the house, even the most intimate spheres such as bedrooms. ${ }^{111}$ Some authors describe working alongside servants undertaking kitchen or household chores. ${ }^{112}$ Settlers, according to Kennedy, minimised the challenge of the constant African presence by maintaining distance and prestige, often by degrading and physically punishing servants. ${ }^{113}$ Even with these measures, African servants undermined recommendations for spatial separation. Once again, settlers' desire for labour trumped a strict adherence to hygienic regulations.

Of servants' duties, ayahs' care for white children proved the greatest affront to hygienic segregation. Wet nursing, involving the actual transmission of body fluids between African women and white children, presented substantial challenges to hygiene recommendations. Even dry nursing, however, entailed intimate physical contact and could lead to strong emotional bonds that threatened the mother's authority. Advice books targeted towards women contained warnings of indulgent or neglectful ayahs. Emily Bradley's Dearest Priscilla, for example, advised mothers not to employ ayahs in East Africa or, at the very least, closely monitor them, and warned of bad characters, hygiene concerns, and venereal disease. ${ }^{114}$ Warm relationships between adult Europeans and servants were far rarer and only occurred, Kennedy explains, when white masters felt socially secure. ${ }^{115}$ Such relationships do appear occasionally in memoirs, although they may be exaggerated: examples include Blixen and her servants Farah and Kamante; a Rhodesian family with their servant Chikutsa; and Smith with a woman named Manga, who comforted Smith after the death of her baby. ${ }^{116}$

Accounts of white children playing with African children also subvert hygiene recommendations. Authors' descriptions of peaceful racial harmony among children should be viewed critically, particularly from memoirs written well after the fact. Children playing together across racial boundaries allows authors to suggest, to use Whitlock's phrase, that race

\footnotetext{
${ }^{110}$ Ibid., 153.

${ }^{111}$ Hansen, 66-67.

${ }^{112}$ Currie, 53; Blixen, Out of Africa, 38.

${ }^{113}$ Kennedy, Islands of White, 153-157.

${ }^{114}$ Bradley, Dearest Priscilla, 232.

115 Kennedy, Islands of White, 154.

${ }^{116}$ Blixen, Out of Africa; 33-40, 55, 128-133, 254-256 Heald, 218; Smith, 26.
} 
relations in the region were "structured in terms of consent rather than conflict," and it is likely these encounters are over-emphasised in memoirs. ${ }^{117}$ Nevertheless, it does seem clear that companionship between European and African children did occur, usually as a response to isolation from other white children. The child of one settler family in Rhodesia recalled playing "in the African villages on the other side of the river." 118 In Kenya in the late 1930s/early 1940s, Adam Edmondson played with African children during the holidays, when few European playmates were available. ${ }^{119}$ Annie Hore, a missionary near Lake Tanganyika, wrote that her son Jack "plays with the Waguha boys, whom he invites into the verandah to play with his toys." 120 Although the encounters retained colonial power dynamics (the word "invites" is significant), they did reject the idea that African children posed a deadly disease risk.

'Sanitary segregation' did not exist in British East and South-Central Africa to the extent recommended by early twentieth-century malaria experts. The medical recommendations to separate European from African were always tempered by economic needs, missionary and charitable endeavours, and the sparse white population's requirements for labour. Although medical professionals and advice authors emphasised the overlap between healthy and racial space, it was individual settlers who decided on the degree and shape of segregation.

The third crucial strand of body management advice presented to settlers through the advice literature urged strict regulation of behaviour on moral questions. It was not merely the physical aspects of the British body that were threatened by the tropical environment; Africa endangered the mental stability and moderate habits of the white subject, eroding the individual mentally as rapidly as malaria and other diseases eroded them physically. Europeans in Africa, according to conventional wisdom of the time, were prone to alcoholic excess, sexual impropriety, a decline in personal hygiene, and depressed spirits. The advice literature therefore weighed in on each of these concerns.

Almost every guidebook included advice relating to recreational alcohol consumption. Although few insisted that readers abstain from alcohol, they essentially all agreed that the

\footnotetext{
117 Whitlock, 131.

118 Heald, 103.

119 Considine and Rawlins, 63.

120 Annie Hore, To Lake Tanganyika in a Bath Chair (London: Sampson Low, Marston, Searle \& Rivington, 1886), 214.
} 
tropics required strict moderation. The reputation held by Kenyan settlers was, however, the complete opposite. Kenya's Happy Valley elite, living in the Wanjohi Valley, were famed throughout the Empire for their excessive alcohol consumption. ${ }^{121}$ Although Huxley insisted that the "core was very small, never more than perhaps a dozen individuals," the reputation of Kenya's wealthy settlers did hold an element of truth. ${ }^{122}$ The memoirs of Kenya's elite reveals an endless procession of champagne, whisky, brandy, gin-and-its (gin and Italian vermouth), and pink gins (gin with Angostura bitters). ${ }^{123}$ When settler Berkeley Cole stayed at Blixen's farm, he "had a bottle of champagne out in the forest every morning at eleven." 124 In West with the Night, Markham receives a telegram from Baron von Blixen, requesting that she collect six bottles of gin and six of whisky for a safari. ${ }^{125}$ When Waugh visited Kenya in 1930-31, he met some Happy Valley settlers at Nairobi's Muthaiga Club. He wrote that "everyone drank about ten pink gins before lunch...barman didn't want ready money... Raymond [de Trafford] had party in evening... Continual flow of champagne."126

Happy Valley settlers' lavish lifestyles were not representative of settlers in British Africa, nor even Kenya. Alcohol consumption was not universal; Joan, for example, could not afford regular alcohol. ${ }^{127}$ Yet most settlers probably drank more than advice authors would have deemed suitable. British Africa, even setting aside Happy Valley excess, had a culture of regular alcohol consumption, exemplified by the ritual of 'sundowners' (drinks at sundown). Alcohol consumption is very hard to quantify, but Bushman's 1924 Hints and Tips for NewComers to West Africa indicates the large quantities of alcohol habitually consumed. The author describes whisky, gin, lime juice, and Angostura bitters as "practical necessities" and recommends a bottle each of gin and whisky every four days for a moderate drinker. ${ }^{128}$ Caddick noted the high rates of whisky drinking, and Strange observed with disapproval an eight year old girl drinking a pink gin at eleven in the morning. ${ }^{129}$ At a settlers' Christmas picnic, Buxton watched a mother give a child, who had fallen into a waterfall, a glass of whisky "to cheer him up." 130

\footnotetext{
${ }^{121}$ Huxley, Out in the Midday Sun, 38.

122 Ibid.

123 Burnett, 168; Will Sellick, The Imperial African Cookery Book: Recipes from English-Speaking Africa (London: Jeppestown Press, 2010), 403.

124 Blixen, Out of Africa, 151.

125 Markham, 199.

126 Evelyn Waugh, The Diaries of Evelyn Waugh, Michael Davie (ed.) (Harmondsworth: Penguin, 1979), 346.

127 Simpson, The Land That Never Was, 73, 108, 115, 176.

128 Bushman, 10-11.

129 Caddick, Helen, 36; Strange, 296.

${ }^{130}$ Buxton, 7 February 1916.
} 
Alyse Simpson's The Land that Never Was paints a grim portrait of the settler community and some of her bleakest scenes arise from lonely settlers drinking to excess. On the boat out, Joan noted that "some appeared brutalised, drawing their romance from the whisky bottle," and at her hotel a merchant's delirium tremens "almost shook the flimsy bungalow". ${ }^{131}$ She also witnessed a man drinking to celebrate having sold his farm, shooting liqueur bottles off the bar with a pistol; watched drunk dinner party guests having a food fight with chops, potatoes, meringues and soda siphons; and her lodger drank daily stout and ginand-its, plus Benedictine. ${ }^{132}$ She described a settler "who had been drinking solidly for two days... his blood-shot eyes looking dejectedly at an emaciated goat which he held on a string. Dressed in a white sheet, he was supposed to represent Gandhi. 'This place is dead,' he said at frequent intervals, addressing the goat." ${ }^{\text {"133 }}$ Simpson's account is doubtless coloured by her negative experiences in Kenya, but it does highlight alcohol's prevalence and social functions. Gladys Irene von Broembsen presented a similar image when she described her father discovering a miner's skeleton "lying on the camp-bed [of his tent] with a whisky bottle by its side". ${ }^{134}$

Alongside the alcoholic excess of Kenya's elite, the colony was equally famous for its sexual excess. Happy Valley settlers were famous for promiscuity and adultery within the white community. Nicholas Best - a Kenyan settler and biographer - described the Muthaiga Club as having "probably seen more fornication than any other club of its kind in the world". ${ }^{135}$ As Duder notes, "enough was known at the time through newspaper reports of divorce and breach of promise cases to make the joke 'Are you married or do you live in Kenya?' a common one at the time." ${ }^{136}$ Coded mentions of extra-marital affairs or attractions appear in a few Kenyan autobiographies, but descriptions of more casual encounters are understandably rare, only reported by outsiders like Waugh. ${ }^{137}$ Once again, however, the Happy Valley settlers were a minority. Sources from less illustrious settlers contain no mentions of affairs with other white settlers and, while a few acknowledge that colonial life strained their marriages, memoirs provide no evidential basis for generalising Happy Valley experiences more widely. Although venereal diseases were relatively common in settler communities, they are almost never

\footnotetext{
${ }^{131}$ Simpson, The Land That Never Was, 14, 34.

132 Ibid., 39, 52, 171.

133 Ibid., 189.

${ }^{134}$ Heald, 295.

${ }^{135}$ Nicholas Best, Happy Valley (London: Thistle Publishing, 2013), 103-104.

${ }^{136}$ Duder, 430.

${ }^{137}$ For an example, see Waugh, Diaries, 347.
} 
mentioned in letters or memoirs. Blixen's letters and Out of Africa, for example, are silent about her struggles with syphilis caught from her husband. ${ }^{138}$

While the advice literature generally ignored sexual matters, it sometimes broke silence to condemn sexual relations between white men and African women. Titling the section "facilis descensus" (from facilis descensus Averno, 'the descent into hell is easy'), John Murray warns the reader that "if a man begins to barter his glorious heritage of a thousand years' civilisation for a life of ease and sensual enjoyment in Tropical Africa, no material successes will compensate for his eventual moral degradation." 139 Alongside a slide into alcoholism, as part of the descent "the 'country wife' will become the wife indeed...having strength to drag him down to her own semi-brutal level." 140 In a painful twisting of the colonial power dynamic, advice authors typically blame the African woman for such encounters. Mansfield describes "horrible...liaisons between white men and black women," which she characterises as driven by African women sitting "day after day...outside the lonely man's hut" until eventually "the lonely man forgets he is white". ${ }^{141}$ Through such a sexual relationship, a European man ruptured the bodily boundary that denoted his whiteness and civilised heritage.

Despite strong prohibitions in the advice literature, relationships between white men and African women were common in the late nineteenth and early twentieth centuries (although they declined rapidly in urban areas and with white female immigration). Kennedy concluded that interracial sexual relationships were common in Kenya and Rhodesia, typically conducted through economic coercion. ${ }^{142}$ Nairobi administrators purchased Masai women to act as mistresses; Zumbo women from Mozambique were bought by white Mashonaland settlers for around five pounds in the late 1890s. ${ }^{143}$ An African mistress earned settlers little social embarrassment - it was emotional attachments, which were far rarer, that settler society viewed as a serious threat. ${ }^{144}$ Sexual relationships between white women and African men were all but unknown, although fears of "black peril" ran high and many African men were arrested for dubious 'intention' or 'attempt' charges. ${ }^{145}$ Memoirs are almost completely silent on interracial sexual relations. One of the rare mentions is Currie's comment that most of their white male

\footnotetext{
${ }^{138}$ For a discussion of Blixen's syphilis, see editor's note in Blixen, Letters from Africa, 30.

${ }^{139}$ Murray, How to Live, 1912, 190.

140 Ibid.

${ }^{141}$ Mansfield, 88-89.

${ }^{142}$ Kennedy, Islands of White, 175-176.

${ }^{143}$ Ibid., 176.

${ }^{144}$ Ibid., 175-176.

${ }^{145}$ Ibid., 141-146.
} 
visitors "made up for their solitude and the lack of white woman's society in a way highly disapproved of by the missionaries." 146

Another aspect of moral management recommended by the advice literature was the maintenance of a clean and hygienic home, body, and wardrobe. McClintock notes that by the mid nineteenth century the British soap market had accelerated rapidly. ${ }^{147}$ As germ theory entered the public consciousness (partially through household cleaning product advertising), specialised products extended soap's purpose from cleaning to disinfecting. ${ }^{148}$ In interwar Britain, new suburban developments opened up the possibility of more spacious, cleaner homes than previously available. ${ }^{149}$ Technological and social developments brought electricity, bathrooms, and hot running water to an ever-widening consumer base, with homes kept clean, hygienic, and sanitised through modern science rather than human labour. ${ }^{150}$ The hygienic home represented more than just disease protection, standing for modernity, respectability and, in a colonial context, becoming (to use Janice Boddy's characterisation of soap) "a performative act". ${ }^{151}$ While Stephen Samuel Murray recommended "scrupulous cleanliness" for health reasons, for Emily Bradley personal cleanliness was essential for emotional wellbeing. ${ }^{152}$ "First thing you know, you are wearing [clothes] once too often," she wrote, "and that is the beginning of the Sad Story of a Slut. If there is any doubt, there is no doubt. Into the [laundry] basket!"153

The reality of colonial African life complicated the British and North American interwar notion of hygiene. Consumer goods were expensive and labour very cheap, and so maximising manual labour and minimising expenditure on cleaning products and appliances was the norm. Richards and her friend Effie, for example, made soap in the interests of economy. ${ }^{154}$ Neither were successful: Richards found that her "boys hated it, they said it was like a stone" and Effie accidentally used rotten eggs, creating a revolting smell. ${ }^{155}$ Strict standards of cleanliness and housing were not always possible for settlers with little money and

\footnotetext{
146 Currie, 108.

${ }^{147}$ McClintock, 207-208.

${ }^{148}$ Gertrude Fraser, African American Midwifery in the South: Dialogues of Birth, Race, and Memory (Cambridge: Harvard University Press, 2009), 94; Ingegard Johansson and P. Somasundaran, Handbook for Cleaning/Decontamination of Surfaces (Cambridge: Elsevier, 2007), 128.

${ }^{149}$ Peter Scott, The Making of the Modern British Home: The Suburban Semi and Family Life Between the Wars (Oxford: Oxford University Press, 2013), 1.

150 Ibid.

151 Janice Patricia Boddy, Civilizing Women: British Crusades in Colonial Sudan (Princeton University Press, 2007), 37.

${ }^{152}$ Murray, A Handbook of Nyasaland, 230; Bradley, Dearest Priscilla, 37.

${ }^{153}$ Bradley, Dearest Priscilla, 37.

${ }^{154}$ Richards, 104-105.

155 Ibid.
} 
few servants. "There were maggots crawling between my sheets, my face was swollen with mosquito-bites and a toad had hidden in my slipper," Alyse Simpson wrote. ${ }^{156}$ One woman remembered arranging furniture to avoid leaks in her roof, and arming the family with umbrellas and raincoats when needed. ${ }^{157}$ While men and women faced the same conditions, they appear more in women's memoirs, suggesting women felt greater pressure to follow hygienic dictates. An 1891 letter from Mashonaland settler Hugh Romilly, for example, depicted his loss of a sponge, and so inability to wash, as a humorous adventure rather than a source of distress or mark against him as a white, 'civilised' person. ${ }^{158}$

Settlers were constantly urged in the advice literature to counteract servants' perceived lack of hygiene with constant monitoring. The mistress, according to Tropical Trials, should examine all food, monitor water sources and boiling, issue fresh cloths daily, prevent people from congregating in the kitchen, and ensure that the "cook shall be, at least outwardly, cleanly in dress and habits". ${ }^{159}$ Giles also insisted upon "cleanliness in the kitchen, and in all the operations of cookery." 160 Emily Bradley recommended daily inspections of cookware. ${ }^{161}$ Settlers were aware of this advice, but often described how impractical they found it. "On the second day of our journey," Caddick commented, "I boldly ventured into the improvised kitchen, but I soon came away somewhat horrified at the state of things I found there... as I wished to be able to eat my dinner, I never went on a tour of inspection again". ${ }^{162}$ Richards and Smith drew a similar conclusions. ${ }^{163}$ Huxley even suggested their approach was the norm, writing that kitchens "were generally regarded rather like a witch's lair, to be strictly left alone... no good came of hankering after hygiene, and no cook would stay long if his employer nagged him about it." 164

The advice literature also frequently discussed bathing. Although cold baths were popular in Britain, most African guides frowned upon cold baths. All recommended frequent warm or hot bathing, vigorous towelling, and avoiding lake and river bathing. ${ }^{165}$ Once again, however, prescriptive advice differed from the reality of settler life. Although memoirs rarely

\footnotetext{
156 Simpson, The Land That Never Was, 71.

${ }^{157}$ Heald, 237.

${ }^{158}$ Hugh Romilly and Samuel Romilly, Letters from the Western Pacific and Mashonaland, 1878-1891 (London: D. Nutt, 1893), 371.

${ }^{159}$ Hunt and Kenny, Tropical Trials, 117-118, 129-130, 136-138.

160 Giles, 63.

161 Bradley, A Household Book for Africa, 21.

162 Caddick, 125.

163 Richards, 20; Smith, 77-78.

${ }^{164}$ Huxley, Flame Trees, 82-83.

${ }^{165}$ Ward and Milligan, 159; Murray, How to Live, 1912, 54; Parke, 58; Hints on the Preservation, 4.
} 
mention bathing, the few examples suggest that settlers bathed less often than recommended and sometimes bathed outdoors. Phyllis Addis remembered the difficulty of bathing in early Salisbury, and that her family only bathed on Saturdays. ${ }^{166}$ Another family in Rhodesia recalled swimming in a neighbouring farm's dam, which was later forbidden "as it was found to be infested with bilharzia". ${ }^{167}$ Caddick bathed in a creek while travelling, although she left after realising that "the mosquitoes were more pleased to have me there than I was to stay". ${ }^{168}$ Poverty, frequent traveling, and individual preference all interrupted expectations of personal hygiene.

African and tropical advice literature recommended that settlers manage their mental health individually, through wholesome distractions. Alongside cleanliness and moderation, hobbies and diversions were the main mechanism for supporting oneself mentally, particularly for wealthier settler women who did little domestic/farming work. Dearest Priscilla advised the prospective wife to stay occupied through hobbies, volunteering or a job. ${ }^{169}$ Good books of a high quality were a necessity, and gardening useful. ${ }^{170}$ John Murray also recommended "plenty of wholesome, elevating light literature" as being "one of the best mental tonics and antidotes available against ennui, vapours, home-sickness, and the depressing influence of monotonous commonplace and barbaric contiguity". ${ }^{171}$ Like Emily Bradley, Murray strongly encouraged exercise and hobbies ("hobby is a good horse to ride in all tropical countries"). ${ }^{172}$ He also advocated the "uplifting and sustaining power" of religion. ${ }^{173}$ Tropical Trials takes a similar perspective, recommending light airy rooms, daily walks, gardening, cheerfulness, plentiful sleep, and keeping busy with a range of activities such as reading, drawing, painting, and sewing. ${ }^{174}$

Such advice maps fairly closely onto what settlers describe as important for their wellbeing, although some faced socio-economic barriers. The relatively close relationship is probably attributable to the fact that most advice authors who discussed mental health had substantial personal experience in the tropics, and also because they were delivering recommendations rather than prohibitions. Ada Slatter, in Kenya, sketched and described

\footnotetext{
166 Heald, 2.

167 Ibid., 121.

168 Caddick, 239.

169 Bradley, Dearest Priscilla, 85, 91.

170 Ibid., 70-83, 96.

${ }^{171}$ Murray, How to Live, 1912, 190.

172 Ibid., 188-189.

173 Ibid., 192-193.

${ }^{174}$ Hunt and Kenny, Tropical Trials, 146-147, 179-181.
} 
books as "such a godsend", and Blixen and Currie both painted. ${ }^{175}$ Many settlers enjoyed music, played via gramophone or (for the lucky) piano. ${ }^{176}$ If they had the money, time and inclination, safaris could be a source of great enjoyment: Blixen described being on safari as like having drunk half a bottle of champagne. ${ }^{177}$ She also found that clothes had an important psychological function ("nothing... distresses me more than having nothing to wear"), although many women did not have that luxury. ${ }^{178}$ Gardening was very common. Few settlers mention religion, although it is not clear whether they were reflecting personal apathy or avoiding religious discussions for other reasons. Missionaries, on the other hand, often explicitly stated that religion brought emotional strength. ${ }^{179}$

The colonial social scene's role in sustaining emotional health emerges more strongly from settler memoirs than from the advice literature. Gertrude Page enthused that in her neighbourhood in Rhodesia "of course none of us are very near, but near enough to have some tennis parties and dances and picnics occasionally, and to form a little community of our own". ${ }^{180}$ One family who lived two hours in a cart from Plumtree (Rhodesia) made their own social life: visits with neighbours, tennis, bridge, and picnicking. ${ }^{181}$ Plumtree, the district's social centre, held concerts, a sports weekend, golf, cricket, and a yearly Gilbert and Sullivan opera. ${ }^{182}$ Few memoirs considered here mention clubs, probably as they were less accessible to rural settlers, but in sizeable white settlements they acted as social centres. Most settlers remembered the colonial social scene with pleasure, although a few found it less palatable. Alyse Simpson presents a bleak image of class-obsessed, narrow, and petty Kenyan settlers; Richards had little in common with her neighbours; and Blixen wrote "I hate this kind of little community...through a kind of self-poisoning they always end up as pure venom". ${ }^{183}$ For most settlers, however, hobbies and their social lives were fundamental to mental wellbeing.

\footnotetext{
${ }^{175}$ Sike Strickrodt (ed.), Women Writing Home, 1700-1920: Female Correspondence Across the British Empire Vol. 1 (London: Pickering \& Chatto, 2006), 236-237; Blixen, Letters from Africa, 174; Currie, 179.

${ }^{176}$ For an example, see Heald, 50.

${ }^{177}$ Blixen, Letters from Africa, 59.

178 Ibid., 97.

${ }^{179}$ Fisher, Twilight Tales, 169; Smith, 26; Goy, 6, 50-53.

${ }^{180}$ Gertrude Page, Jill on a Ranch (London: Cassell and Company, Limited, 1921), 212.

${ }^{181}$ Heald, 49.

182 Ibid., 50.

${ }^{183}$ Simpson, The Land That Never Was, 38-39, 189; Richards, 31; Blixen, Letters from Africa, 66.
} 
The medical establishment and wider society believed white settler bodies and minds were intensely vulnerable to tropical surroundings, requiring attention and maintenance in order to live successfully in the tropics. The tropical hygiene recommendations that appeared through the advice literature urged settlers to maintain bodily and mental health through careful dress, 'sanitary segregation', and moral management. Yet the story of body management in British Africa cannot be approximated through the prescriptive advice literature. In all three aspects, the sources reveal the mixture of influence yet individualisation that Bynum contends are the two facets of embodiment. Guidebooks and medical handbooks did influence settlers to adopt aspects of recommended body management techniques, but settlers' bodies were also malleable and individualised, places of tension, negotiation, and adaptation.

Amateur tropical hygiene and body management therefore follows the pattern already identified for amateur medical treatment, of suggestion and individualisation rather than prescription and replication. The next chapter shifts to considering Europeans' doctoring within African communities. Amateur doctoring of this type was a widespread practice and, for many settlers, probably their most intimate contact with the people whose country they had occupied. It was also a politically charged process and an important strand in the region's colonial medical regime. 


\section{Chapter Four}

“I was doctor": Identity, Agency, and the White Woman's Burden

In July 1924, Blixen wrote in a letter to her mother that "I was interrupted here because I had to go out and act as a doctor to a toto whom I diagnose as suffering from the plague, and also an old woman who had been... attacked by a snake". ${ }^{1}$ With rural government medical services and mission hospitals thin on the ground through the early twentieth century, white settler women provided healthcare to local people with a striking frequency. Blixen wrote that she "was doctor...most mornings from nine to ten," commanding "a large circle of patients, and generally had two and a dozen sick people up by my house then". ${ }^{2}$ In Rhodesia, Alice Moon "was doctor to all the African families within reach of the farm" and Ella Silby-Warne and her husband nursed around 200 patients during the 1918 influenza epidemic. ${ }^{3}$ Although not all women practiced as systematically, it is a rare memoir that does not include at least one vivid description of treating an African patient. Like descriptions of medical emergencies within European communities, treatment in African communities forms part of an author's dramatic repertoire, and what tension was lost by the sick figure being outside the narrator's familial/social circle was amply added through vivid and gruesome descriptions.

Advice texts represented such practice as the norm and the expectation; a crucial part of the white man's (or more usually, the white woman's) burden. The preface of Health in Africa explained that "in the eyes of the African every European is a doctor, and at any moment may be called upon to minister to a needy native". ${ }^{4}$ The 1922 Handbook of Nyasaland commented that "except in large centres Europeans in Nyasaland will be obliged to attend to the ailments of their native labourers and of villagers who naturally look to them for treatment". 5 As late as 1939, Emily Bradley noted that "there are occasions when any European is likely to be called upon to perform the offices of a trained physician for himself and the Africans in his charge," although those instances were "mercifully becoming less frequent". 6 Only after the Second World War did the British colonial authorities invest substantially in the

\footnotetext{
${ }^{1}$ Blixen, Letters from Africa, 222.

${ }^{2}$ Blixen, Out of Africa, 28.

${ }^{3}$ Heald, 253, 274.

${ }^{4}$ Cross, v.

${ }^{5}$ Murray, A Handbook of Nyasaland, 231.

${ }^{6}$ Bradley, A Household Book for Africa, 158.
} 
meagre official health services for Africans. ${ }^{7}$ Advice books from the 1890s until the early 1940s therefore consistently painted a scenario of African need, born out of 'natural primitivism' rather than the impacts of colonial takeover, to which European settlers were obliged to respond. Throughout the period, Europeans' responsibility for local Africans' health was firmly entrenched in colonial society as a common practice and perceived humanitarian or Christian duty.

Amateur treatment of local people was strongly gendered. Although men did dispense medical aid, where possible the responsibility almost invariably fell to women. Throughout the British Empire, women's charity was fundamentally linked to domesticity: while white men governed, white women became maternal colonisers. ${ }^{8}$ As Deirdre David notes, "the cultural allocation to women in the home country of duties outside the house - charity work, moral and religious instruction, volunteer nursing, for example - found expression in a kind of imperial social work that took them into mission schools in Africa and secluded women's quarters in India." "Questions of health and medicine were never far removed from European women's social work. In India, the Dufferin Fund (established 1885) provided medical aid for Indian women, constructed hospitals, and supported women's medical training. ${ }^{10}$ As increasing (though still small) numbers of British women trained as doctors through the late nineteenth century, opportunities for their employment became necessary. ${ }^{11}$ Indian traditions of sexsegregation and modesty prevented male doctors from attending high caste women, recommending India as an ideal site for British female doctors. ${ }^{12}$

In East and South-Central Africa, women participated in professional medicine to a far lesser degree than in India. The 'Lady' or 'Woman Medical Officer' was a specific job, and very few positions were available. ${ }^{13}$ The large numbers of men in the medical service partially reflected the low numbers of female graduates, but also evidenced the increased opportunities for female doctors in twentieth-century Britain and the widespread belief that Africa was unsuitable for women. ${ }^{14}$ Missionary women made a more substantial contribution: many female missionaries practised medicine with minimal training, and some adopted the trappings

\footnotetext{
${ }^{7}$ Frederick Cooper, Africa in the World (Cambridge: Harvard University Press, 2014), 26.

${ }^{8}$ Indira Ghose, Women Travellers in Colonial India (Delhi: Oxford University Press, 1999), 109, 111.

${ }^{9}$ Deirdre David, 'Imperial Chintz: Domesticity and Empire', Victorian Literature and Culture 27.2 (1999), 569.

${ }^{10}$ Geraldine Forbes, 'Medical Careers and Health Care for Indian Women: Patterns of Control', Women's History Review 3.4 (1994), 516.

${ }^{11}$ Ibid., 518.

12 Ibid.

${ }^{13}$ Crozier, Practising Colonial Medicine, 24-25.

14 George Weisz, Divide and Conquer: A Comparative History of Medical Specialization (Oxford: Oxford University Press, 2005), 194; Crozier, Practising Colonial Medicine, 24.
} 
and authority of professionals. The Dominican Sisters in 1890s Rhodesia established some of the earliest clinics, despite possessing neither qualifications nor formal training. ${ }^{15}$ Although medicine became increasingly professionalised during the period, nurturing and healing the sick remained a feminine, maternal duty. ${ }^{16}$ In the colonial context, women's nurturing and motherhood encompassed not just their families, but also the non-white population of their neighbourhood. ${ }^{17}$ While white settler women (aside from missionaries) rarely participated in African healthcare in a formalised manner, they continually did so via individual medical treatments of their servants, labourers and neighbours. Even though many settlers would not have associated their amateur medical practice with the broader colonial project, it was nonetheless part of the colonial movement to civilise, modernise, and develop.

Despite the ubiquity of amateur doctoring, few historians explore amateur treatment of local people either in British Africa or in other tropical colonies. ${ }^{18}$ This chapter addresses the gap in scholarship by examining white settlers' amateur treatment in African communities. The first section extends upon chapter two by examining the process of amateur treatment, asking what types of conditions Europeans treated and how they did so. It will demonstrate that amateur treatment in African communities formed a body of practice distinct from the focus of state colonial medicine and the techniques recommended in popular medical advice. The second section explores medical identity in women's colonial memoirs, and will suggest that white women had an ambivalent relationship with their medical practice. The final section shifts focus from doctor to patient, and questions whether it is possible to discern African agency in the amateur treatment process. It will argue that patients possessed a substantial degree of agency within an inherently oppressive colonial framework.

\footnotetext{
15 Ruramisai Charumbira, 'Administering Medicine Without a License: Missionary Women in Rhodesia's Nursing History, 1890-1901', Historian 68.2 (2006), 241.

${ }^{16}$ Hassan, 3.

${ }^{17}$ Locher-Scholten, 143.

18 Hassan's excellent Diagnosing Empire is of limited use, as it focuses on individual encounters of Victorian women in the Middle East and India. Frawley includes a brief discussion of Victorian women's amateur treatment abroad as part of a larger study on travel writing, and explains that their treatments supported the idea of a benevolent empire. Johnson and Landau both explore missionary quasi-amateur practice, but neither focus on the amateur nature of individual encounters. Ann Beck's history of the British East African medical administration acknowledges the popularity of amateur missionary treatment amongst local recipients. John Rankin identifies missionaries as essential to the early nineteenth-century West African colonial healthcare system, although their importance derived from their ability to refer patients to medical professionals, rather than dispense treatment themselves. Hassan; Johnson, 'Colonial Mission and Imperial Tropical Medicine'; Landau; Frawley; Rankin.
} 
Amateur medical practice in African communities focused upon illnesses and injuries that were not specific to the tropics. To analyse amateur treatment quantitatively, all mentions of amateur treatment of Africans by white settlers were collected from fifteen memoirs, letters, and reports, yielding forty-five instances in total. Each condition was classified, and the results are displayed in figure three. The results illustrate a striking lack of tropical distinctiveness. Almost thirty percent of all conditions treated were wounds. Put together with the burns and poisonings, they reach nearly forty-five percent of the total. Treating immediate injuries clearly formed a substantial proportion of amateur practice. Most of the remaining conditions were common in the temperate world and not particularly associated with the tropics, including sores, ulcers, abscesses, pneumonia, dental disorders, and miscarriage. The only diseases that resemble sensational tropical diseases are plague and cholera, each receiving just one mention in the sources.

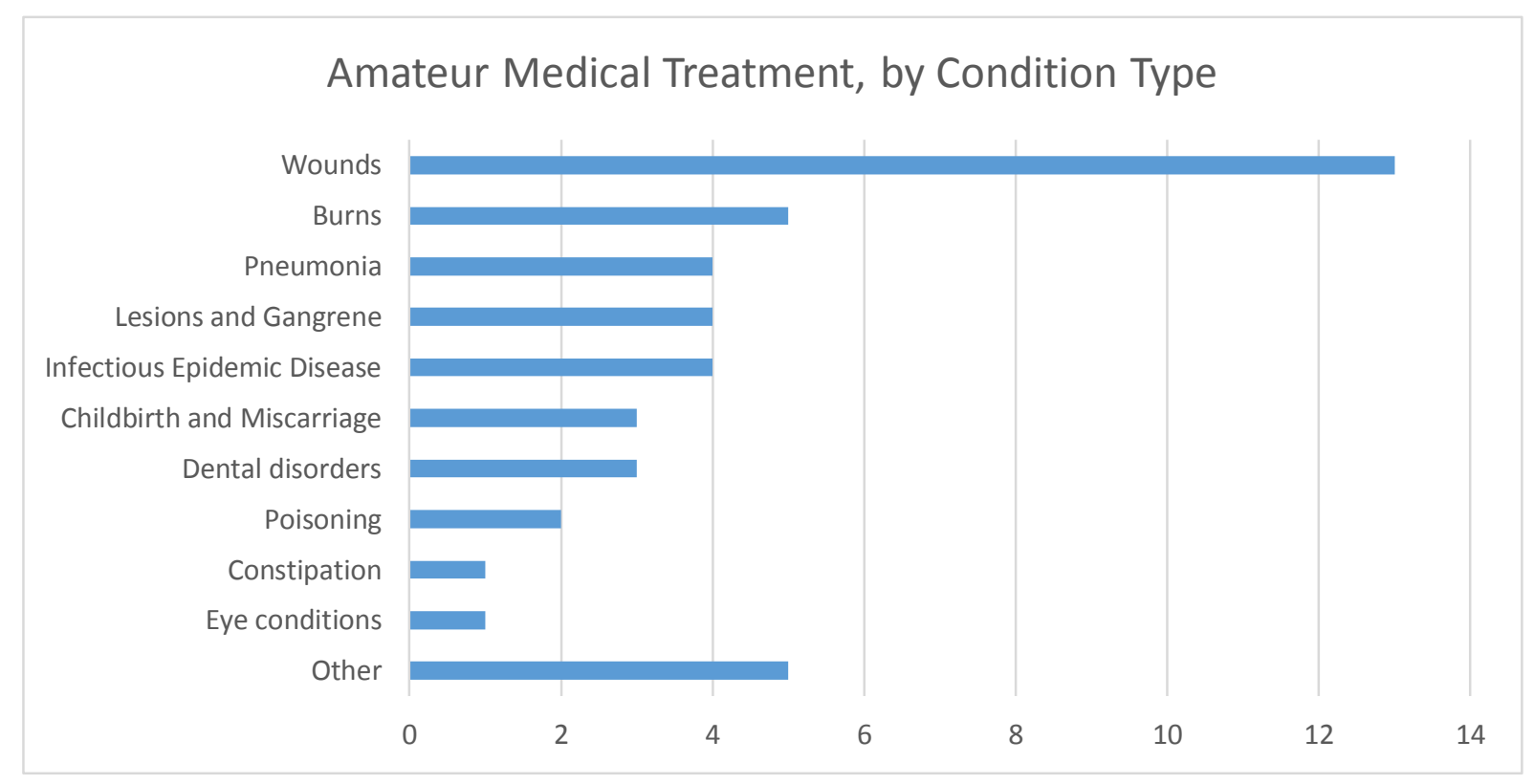

Figure Three. Graph of instances of amateur doctoring of local people that appear in European memoirs.

Although the diseases discussed were very rarely distinctively tropical, the tropical location could influence their frequency. Some of the most common (and most distressing) injuries treated were burns, particularly of children. Sara Carter, a missionary in 1920s Rhodesia, remembered treating "burnt babies who had rolled too near the fire on the floor of the hut during the night." ${ }^{19}$ In Kenya, Blixen explained that she "often had bad burns to treat,

\footnotetext{
${ }^{19}$ Heald, 47.
} 
for the Kikuyu at night sleep round the fires in their huts. ${ }^{20}$ Reflecting their frequency, Huxley selected a burnt child as the single instance of amateur treatment to appear in Murder at Government House. ${ }^{21}$ The frequency of gun wounds, although probably overrepresented, speaks to the ready availability of guns in the region. Writing about South Africa, but also relevant to the East and South-Central regions, William Storey explains that "guns and colonialism went hand in hand": important early trade commodities, necessary for establishing and holding territory, and for hunting game. ${ }^{22}$

Data generated from colonial memoirs do have certain limitations. Authors' selection inevitably privileges successful treatment, favourable portrayals of the narrator, and the dramatic, easy to describe, and acceptable to print. Even with these limitations the data still have value, and can be made more robust through comparisons with other sources. Guidebooks' vocabularies broadly support the conclusions of the memoir data. The Kenya Settlers' Cookery Book lists common Swahili words including ache, ague, accident, bandage, cut, cough, diarrhoea, dysentery, fever, headache, plague, poison, quinine, rheumatism, and scratch. ${ }^{23}$ Swahili words and phrases in the 1914 Leader annual include 'what is the matter?', 'are you sick?', medicine, poison, bandage, 'wash it', 'keep it clean', rub, and swallow. ${ }^{24}$ The Handbook of British East Africa featured similar words and phrases. ${ }^{25}$ All three guides suggest a rudimentary doctoring, limited by language, which was based on first aid and the treatment of common and externally manifesting illnesses.

Probably more useful are authors' evaluation of their medical practice, although such comments are rare. Fisher judged skin diseases, ulcers, and hacking coughs to be "very prevalent," and suggested that amateur doctors regularly encountered wounds. ${ }^{26}$ Blixen indicated that tearing coughs, running eyes, injuries from fights, fevers, and burns were all common. ${ }^{27}$ Missionary Herbert Carter most often treated sore eyes, stomach problems, coughs, colds, cuts, and sores, burns, and dental problems. ${ }^{28}$ Carter, Fisher, and Blixen's observations are very much in keeping with the trends in figure three. Skin diseases, coughs, and eye conditions are probably underrepresented in the data, as these illnesses offered less scope for

\footnotetext{
${ }^{20}$ Blixen, Out of Africa, 29.

${ }^{21}$ Huxley, Murder at Government House, 208.

${ }^{22}$ William Kelleher Storey, Guns, Race, and Power in Colonial South Africa (Cambridge: Cambridge University Press, 2012), 1.

${ }^{23}$ The Kenya Settlers' Cookery Book, 348.

24 'Leader' Annual, 268.

${ }^{25}$ Ward and Milligan, 232, 236.

${ }^{26}$ Fisher, On the Borders, 199-200.

${ }^{27}$ Blixen, Out of Africa, 29.

${ }^{28}$ Heald, 47-48.
} 
dramatic anecdotes. Woundings are likely over-represented. Of the wounding instances around thirty percent are gun injuries, and fights and animal attacks together make up over forty-five percent of the total. We can speculate that the breakdown probably does not reflect actual proportions, but rather the injuries that authors remembered well and believed made good stories.

From the combination of sources discussed, it is possible to draw broad conclusions about amateur doctoring. Basic first aid was fundamental and formed a large proportion of treatments: cleaning, stitching and dressing wounds, dressing burns, and other immediate remedial actions in response to injuries and accidents. The second strand of amateur practice was disease treatment. Diseases were rarely of the type generally considered 'tropical', but were common health complaints found around the globe, including coughs, colds, pneumonia, and other similar conditions. In this focus, amateur doctoring differed from the concerns of state tropical medicine. Edmond argues that imperial tropical medicine characteristically ignored familiar 'temperate' diseases (such as measles) - even when hugely prevalent and destructive in indigenous communities - in favour of sensationalised, exotic 'tropical' diseases that threatened European migrants. ${ }^{29}$ Even considering just state health provisions for local people in British Africa, Vaughan explains that until the 1930s (or for some areas the 1950s or 1960s) "any contact which the majority of Africans had with colonial medicine was likely to have been in the form of a 'great campaign"” against epidemic disease. ${ }^{30}$ Amateur treatment did not reproduce this focus, being instead concerned with individual medical treatments for injuries and diseases that were generally neither distinctively 'tropical' nor epidemic.

Out of the forty-five cases of amateur treatment considered, in twelve the author mentioned bandaging, and in ten disinfectant use. The combination of disinfectants and bandages formed the cornerstone for wound, burn, and lesion treatment, and also appeared in accounts of dental treatment, poisonings, eye conditions, and sore feet. The specific disinfectant varied, including potassium permanganate, iodoform, iodine, boracic powder and solution, and silver nitrate. The liberal use of bandaging and disinfecting, particularly for wounds, closely aligns with the advice literature. ${ }^{31}$ Amateur doctors rarely provided the rationale for bandaging or disinfectant use but their ubiquity indicates a general familiarity with germ theory, antisepsis, and asepsis. Fisher's use of cholera quarantines and Alyse Simpson

\footnotetext{
${ }^{29}$ Edmond, 181.

${ }^{30}$ Vaughan, Curing their Ills, 37, 55.

${ }^{31}$ Hunt and Kenny, Tropical Trials, 276-277; Hunt and Kenny, On Duty, 71-77; Simpson, The Maintenance of Health, 169-170; Murray, A Handbook of Nyasaland, 235; Barnes, 235.
} 
and Blixen's organisation of smallpox vaccinations supports the hypothesis that European settlers were familiar with basic disease management techniques. ${ }^{32}$

It is not surprising that many settlers had an awareness of antisepsis and asepsis. The concepts of antisepsis (the destruction of germs with germicidal chemical agents) and asepsis (the prevention of germs entering a wound site, usually done mechanically, such as through sterilising equipment) had their theoretical foundations in the $1850 \mathrm{~s}$ and $1860 \mathrm{~s}$, with Louis Pasteur's work on germ theory. ${ }^{33}$ In 1867 , Joseph Lister applied Pasteur's principles to wound infection by using carbolic acid to destroy germs, although it was another twenty years before surgeons generally accepted his methods. ${ }^{34}$ From the 1890s, asepsis became increasingly preferred over antisepsis. ${ }^{35}$ Despite shifts within the medical profession, in the early twentieth century a raft of commercial antiseptic products appeared, including antiseptic dressings and standardised chemicals. ${ }^{36}$ Popular antiseptic products proliferated through the 1920s; Listerine (an antiseptic mouthwash named after Lister), for example, became highly successful in the 1920s. ${ }^{37}$ The large numbers of popular antiseptic products and advertisements ensured a widespread familiarity with these concepts among interwar settlers.

Authors mentioned a small number of other substances used in amateur doctoring. Epsom salts, cough mixture, port, brandy, quinine, honey, Vaseline, castor oil, various poultices, egg yolk, linseed oil, and lime water appear in the accounts. The list suggests that amateur treatment rested upon a small number of substances and home remedies. This assessment is supported by The Land that Never Was: Joan visits the doctor when leaving Nymba, commenting that "I had brought my medicine chest...Practically all the bottles were still intact. Healing the natives, as I did all those years, I had needed only three things: quinine, Epsom salts and disinfectant". ${ }^{38}$ A few authors admitted to using deliberately ineffective substances for treatment (although they would not necessarily have been less effective than some women's home remedies). Fisher supplemented her medical stores with a mixture of table salt, mixed spice, and curry powder. ${ }^{39}$ Alexandrina Kitto, at Jessie Mine in Rhodesia, "dosed

\footnotetext{
${ }^{32}$ Blixen, Letters from Africa, 87; Simpson, The Land That Never Was, 92-93; Fisher, On the Borders, 160.

${ }^{33}$ Lois Magner, A History of Medicine (Boca Raton: CRC Press, 1992), 299-300; Thomas Gariepy, 'Antisepsis' in John Heilbron (ed.), The Oxford Companion to the History of Modern Science (Oxford: Oxford University Press, 2003), 41.

${ }^{34}$ Gariepy, 41.

${ }_{35}$ Jie Jack Li, Laughing Gas, Viagra, and Lipitor: The Human Stories behind the Drugs We Use (Oxford: Oxford University Press, 2006), 46; Gariepy, 42.

${ }^{36}$ Gariepy, 42.

${ }^{37} \mathrm{Li}, 46$.

${ }^{38}$ Simpson, The Land That Never Was, 264.

${ }^{39}$ Fisher, On the Borders, 201.
} 
all and sundry" with home-made furniture polish of raw linseed oil, paraffin, and turpentine. ${ }^{40}$ Both presented their actions as clever, but their careful emphasis on local people's gullibility and approval of the 'medicine' suggests guilt, or at least unease, about placebo treatments and the equation of furniture and people implied by Kitto's treatment.

Joan's observation that she needed only three substances for "healing the natives" raises the question of whether settlers performed different treatments upon European and African patients. Joan used a slightly wider variety of medicines for her own family (when she and her daughter Marie contracted eye infections, Joan applied silver nitrate), but as the silver nitrate was sent by Joan's doctor, minimal conclusions can be drawn. ${ }^{41}$ It seems very unlikely that many settlers used placebo treatments on Europeans. Memoirs also suggest that settlers sought professional medical aid for African patients less frequently than for sick Europeans. While settlers did summon doctors for local people, they did so for more severe conditions than would trigger the same response for a European. The Handbook of Nyasaland supports this conclusion, explaining that "in all cases of serious illness of whatever kind an endeavour should be made to obtain the services of a doctor where a European patient is concerned." 42 In treatment methods, however, there is little evidence that settlers operated markedly differently.

Joan's reference to her medicine chest raises the question of their importance for amateur treatment. Hassan characterises medicine chests as "portable property," objects of empire that privileged their owners and allowed them to function as agents of Western imperialism. ${ }^{43}$ BWC promotional material certainly represented chests as modernising and civilising technologies - the early twentieth-century analogue of late nineteenth-century civilising objects such as bibles. Medicine chests in BWC publications at times gain religious overtones. The 1934 BWC volume The Romance of Exploration features a photograph (figure four) of Mrs Glover, wife of the Tibetsi Glover expedition leader, treating an African chief who had been mauled by a leopard. ${ }^{44}$ Surrounded by admiring and vulnerable African figures (primarily women and children), Glover kneels to perform treatment, an almost biblical figure displaying, as Johnson notes, "the self sacrifice and caring qualities needed by the European 'civiliser' for the expansion of empire". ${ }^{45}$ The Tabloid chest prominent in the foreground was doctored or added by BWC. ${ }^{46}$ Although lacking the overtly religious elements of Harold

\footnotetext{
${ }^{40}$ Heald, 201.

${ }^{41}$ Simpson, The Land That Never Was, 111-115.

${ }^{42}$ Murray, A Handbook of Nyasaland, 231.

${ }^{43}$ Hassan, 2, 4, 33.

${ }^{44}$ Johnson, 'Tabloid Brand Medicine Chests', 259.

${ }^{45}$ Ibid.

${ }^{46}$ Ibid.
} 
Copping's The Healer (1930, figure five), the two images are very similar in form, subject, and overall impression. ${ }^{47}$ Indeed, the Healer's medical chest strongly resembles the No.254 BWC chest. $^{48}$

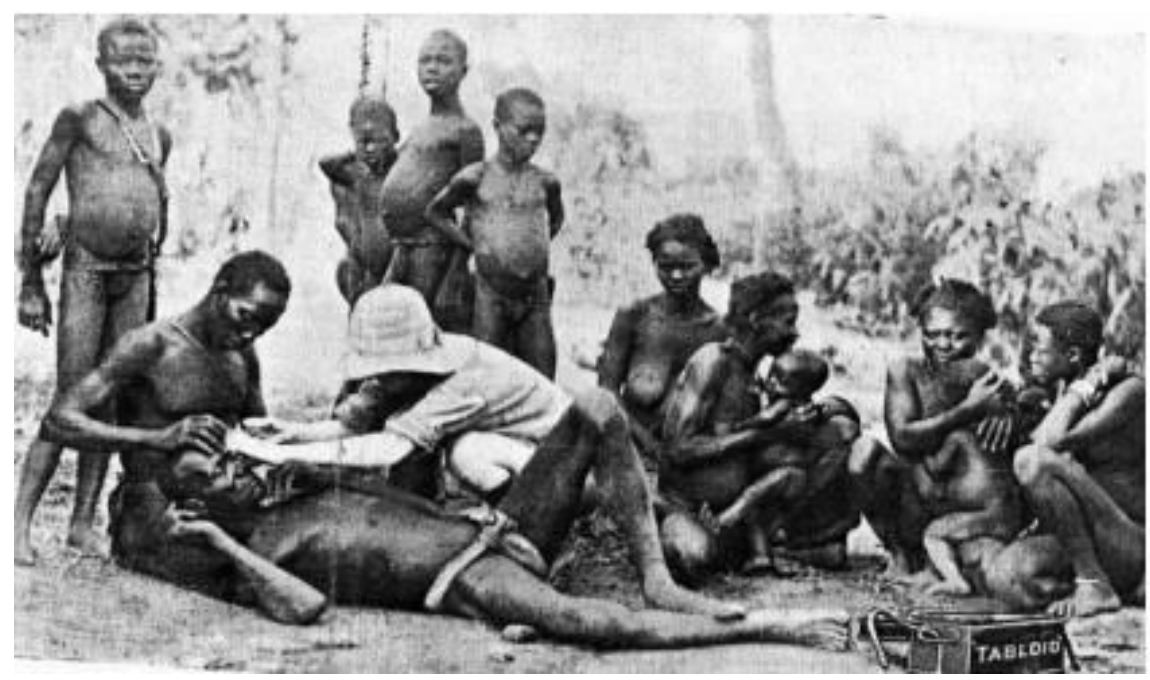

Figure Four. BWC, The Romance of Exploration (London, 1934, p.16) in Johnson, 'Tabloid Brand Medicine Chests', 259.

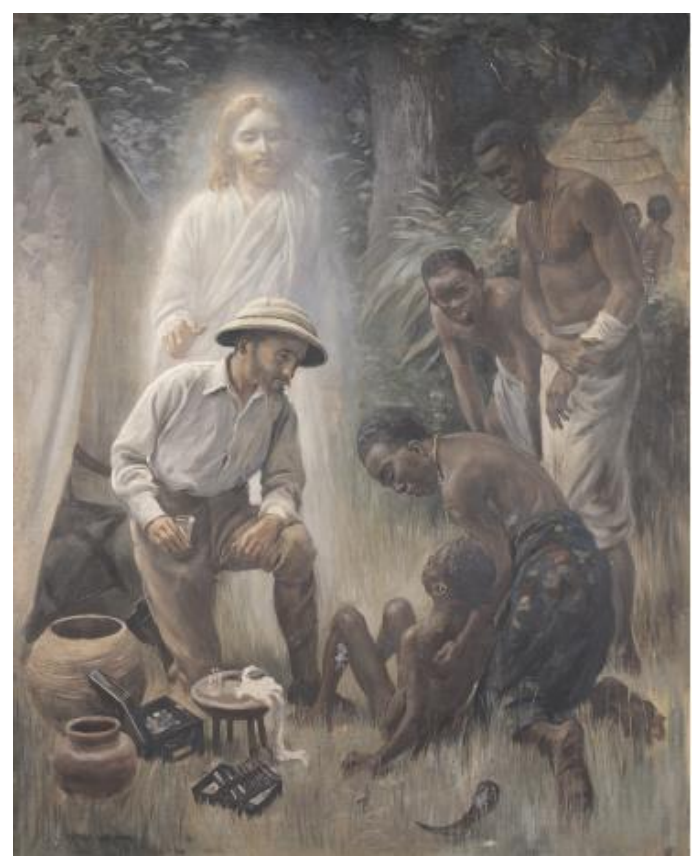

Figure Five. Harold Copping, The Healer (oil, 1916) in Johnson, 'Tabloid Brand Medicine Chests', 260.

Settler women's memoirs, however, scarcely mention commercial medicine chests. Joan's disdain for her chest is typical of the minimal attention chests receive throughout

\footnotetext{
${ }^{47}$ Ibid., 259-260.

${ }^{48}$ Ibid., 259.
} 
memoirs. While authors may have owned commercial medicine chests, and used medicines and information provided in them, their infrequent appearance in memoirs indicates they held little personal significance. Certain objects carried in chests, most notably bandages and disinfectants, do appear much more prominently, and authors clearly saw the practical usefulness as well as the symbolic importance of those objects (such as acting as signs of settler women's hygienic superiority and imperial benevolence, as well as providing reassurance). Although amateur medicine was commercialised, the process was only partial, as evidenced by the widespread use of home remedies. Even when authors mentioned specific medicines, they rarely included the brand, suggesting that the mass marketing success of BWC and other pharmaceutical companies should not be overstated. The only exception, which serves to highlight the usual absence, was Mansfield, who consistently promoted her BWC chest and Tabloid products. ${ }^{49}$

Johnson has illustrated that BWC's tabloid medicine chests far from epitomised modern tropical medical science. Although BWC implied that the chests represented cutting-edge science, Johnson argues that their only modern aspect was mass production and marketing. ${ }^{50}$ BWC's Tabloids (tablets) "were either derived from outside Europe, or had been in use for decades, if not centuries". ${ }^{51}$ Amateur doctoring amplified the lack of medical novelty that Johnson identified in BWC chests. The medicines that authors mentioned utilising for amateur doctoring of African patients included far fewer medicines from tropical regions. ${ }^{52}$ The vast majority are an overlapping mixture of common, age-old European remedies and household products.

Amateur doctoring of Africans, therefore, focused on different diseases than colonial state medical campaigns and utilised treatment options distinct from those recommended by medical professionals and from the commercialised medical products aimed at the amateur market. Having explored the nature of settlers' amateur treatment, the next section will take settler women as its subject, and consider the impacts of amateur treatment upon them and their construction of doctoring identities.

\footnotetext{
${ }^{49}$ Mansfield, 205-206.

${ }^{50}$ Johnson, ‘Tabloid Brand Medicine Chests', 261.

${ }^{51}$ Ibid.

${ }^{52}$ Headrick, 65.
} 
Amateur treatment of local people was an intimate and emotional process for white settler women. For many European women, triumphs and satisfaction mingled with moments of failure, confusion, and distress. Reflecting the mixed emotions associated with amateur doctoring, settler women typically represented their amateur treatment ambivalently, simultaneously claiming and denying their status as doctors.

Settler women's lack of medical knowledge, combined with the severity of the conditions they encountered, meant that failure was inevitable. Although it must have occurred relatively frequently, very few authors acknowledge specific instances of failure. Rather than adopting medical professionals' conventions for discussing patient death (such as dwelling on severity and the limits of possible treatments), authors simply dropped moments of failure from their discussions. Their silence is likely driven by the demands of an audience and their own unwillingness to dwell on painful experiences. Blixen was upset by her "continual failure" to cure her servant Kamante's leg sores. ${ }^{53}$ In Flame Trees, a woman brought Tilly a baby to treat, covered in suppurating burns and flies: "Tilly was doubly horrified, by the baby's ghastly injuries and by her own inability to justify its mother's faith". 54 The sadness, inevitability, and mundanity of death, and the myriad emotions related to the author's inadequacy to provide successful treatments, hover on the edges of women's memoirs - largely unstated, but present and potent.

Women also experienced stress and confusion due to their lack of medical training. In Down Memory Lane, one woman remembered that "sometimes I felt so helpless when I did not know what was wrong and what to do". ${ }^{55}$ Richards paints a vivid scene of amateur medical confusion when required to treat a woman diagnosed with pneumonia, fever, and an enlarged spleen: she "had not the slightest idea where her spleen was" and dropped a mealie meal poultice face down on the floor but applied it anyway, causing her patient to look "malevolently at me because I think it itched". ${ }^{56}$ While on tour during a drought and famine, Emily and Kenneth Bradley attempted to save children dying of constipation, fevers, and other conditions. "We gave enemas where they were needed, to ease the fever which was probably accentuated by malaria, and hoped for the best," Emily Bradley explained. ${ }^{58}$ "It was nervous work. The ignorance was not all on their side, and a death on our hands would have been a

\footnotetext{
${ }^{53}$ Blixen, Out of Africa, 33.

${ }^{54}$ Huxley, Flame Trees, 39.

${ }^{55}$ Heald, 105.

${ }^{56}$ Richards, 125.

${ }^{57}$ Bradley, Dearest Priscilla, 174.

58 Ibid.
} 
major disaster". ${ }^{59}$ The expectation and promise created by settlers' treatment is highlighted by her nervousness. While successful treatments could win favour, failures risked the opposite particularly concerning for Kenneth Bradley, a District Officer.

Tilly's horror at the burnt baby points to the traumatic nature of some injuries that women encountered. Although horrifying injuries were the minority, many memoirs describe at least one. Blixen, for example, performed first aid after three children were accidentally shot. Out of Africa described a child, Wanyangerri: "the blood spouted, like water from a post, from his face - if one could still say that, for he must have stood straight in front of the barrel when it was fired and it had taken his lower jaw clean off". ${ }^{60}$ She struggled to stop the bleeding without choking him. ${ }^{61}$ Flame Trees recounts Lettice Palmer's struggles to administer first aid to a Kikuyu man, who "had a gash right through his skull; part of his scalp was hanging down over his cheek and there was nothing but pulp where one eye" had been. ${ }^{62}$ After attempting treatment, Palmer "dived for the back of the hut and I think was sick," then drank brandy and lay "white and limp" on the sofa. ${ }^{63}$ Even the resourceful Tilly was "flushed and hot and her hands were trembling". 64

As well as unpleasantness, amateur treatment also brought satisfaction and pride. The woman who, in Down Memory Lane, described feelings of helplessness, also proudly described her home-made ointment for burns, her successful treatment of a baby's burnt feet, and stated that "I was fortunate and made few mistakes". ${ }^{65}$ Very few women explicitly claimed satisfaction or pride, but authors' emphasis on the gruesome injuries they successfully treated almost certainly reflects a sense of satisfaction. Most women willingly accepted any requests for treatment, and only Alyse Simpson and Richards record any resentment of amateur doctoring. When Richards' servant was attacked and cut with a chopper, she explained that "for once I refused and told Nkosi ['master', here meaning her husband] that he must go because I could face no more bleeding meat". ${ }^{66}$ Simpson characterised vaccinating the local community for smallpox as "hateful" (presumably because it required scratching arms with a pocket knife), though she admitted that "it had to be done". 67

\footnotetext{
${ }^{59}$ Ibid.

${ }^{60}$ Blixen, Out of Africa, 74.

${ }^{61}$ Ibid.

${ }^{62}$ Huxley, Flame Trees, 73-74.

${ }^{63}$ Ibid., 73.

${ }^{64}$ Ibid., 74.

${ }^{65}$ Heald, 105.

${ }^{66}$ Richards, 83

${ }^{67}$ Simpson, The Land That Never Was, 92.
} 
In Diagnosing Empire, Hassan explains that Victorian women travellers constructed doctoring identities through colonial travel. ${ }^{68}$ White settler women in British Africa responded more ambivalently to amateur practice. Authors avoided overstepping amateur boundaries in their memoirs, and frequently stressed that they only responded to requests for treatment rather than seeking patients. Access to a medical professional directly determined the scale of their medical practice, even though amateurs were capable of successfully competing with medical professionals for African patients. ${ }^{69}$ Some women described themselves as 'doctors,' although they often modified the word with 'quack' or other self-deprecating terms. Blixen, for example, called herself a doctor several times and noted that she "had ambition as a doctor," but also used the phrase "like all great quacks" to refer to herself. ${ }^{70}$

Women seldom explicitly stated their claim to amateur medical authority, and it generally rested upon unspoken assumptions of superiority. A few mentioned filth, dark and dirty huts, and unhygienic conditions, summed up by Fisher's comment that "as for ideas of hygiene, these are absolutely absent from the native's mind". ${ }^{71}$ Some also highlighted the supposed savagery of local medicine and the ignorant, uncaring, and child-like state of the local people. ${ }^{72}$ Such representations rendered women's lack of qualifications unimportant; they derived their authority through their natural position as caring, maternal white women, imbued with civilised notions of hygiene. Frawley has identified that many women travellers justified their involvement or intrusion into indigenous health through similar ideas, drawing upon Victorian ideas of natural maternal instinct. ${ }^{73}$ Although a few women modestly mentioned some limited expertise, they were in the minority, and only Mansfield enhanced her authority through references to commercial medicine chests and branded medicines. ${ }^{74}$

Hassan's Victorian women travellers were empowered by their 'doctoress' identities. "Doctoring," Hassan wrote, "is a portable and sometimes spontaneous act that allowed women to domesticate and refashion medical knowledge in the colonies". ${ }^{75}$ Hassan describes how Victorian female travellers' medical skill and femininity allowed them privileged access to indigenous domestic spaces, and through written accounts women could enter medical dialogues and extend the conventional British women's domestic role. ${ }^{76}$ There are several

\footnotetext{
${ }^{68}$ Hassan, 3, 43-54.

${ }^{69}$ For an example of preference for amateur practitioners, see Beck, 18.

${ }^{70}$ Blixen, Letters from Africa, 38, 30, 267.

${ }^{71}$ Fisher, On the Borders, 205.

72 Ibid., 80, 131, 160; Mansfield, 205; Blixen, Letters from Africa, 379.

${ }^{73}$ Frawley, 118.

${ }^{74}$ Mansfield, 205-206.

${ }^{75}$ Hassan, 40.

${ }^{76}$ Ibid., 3, 20, 25, 64.
} 
reasons why a straightforward narrative of empowerment is less suited to white women's doctoring in colonial Africa. First, and most simply, women almost never sought patients, and the advice literature and essentially universal nature of amateur doctoring suggests it was a well-established expectation, rather than a free choice. Secondly, women did not always receive the benefits Hassan described. As patients usually came to European spaces for treatment, amateur doctoring often did not provide access to indigenous domestic spaces, and when it did women commonly recorded their dislike for these visits. Although women featured amateur doctoring anecdotes in their memoirs, memoirs were often published later in life and cannot easily be viewed as part of a medical dialogue (although they were certainly within a colonial one).

At the same time, women found some satisfaction in amateur treatment (or at least wrote that they did) and, as will be discussed in the next section, did gain influence through medical practice. Overall, women had an ambivalent relationship to amateur doctoring: a prescribed rather than freely chosen activity, it brought sadness, stress, satisfaction, power, and medical authority simultaneously. The final section will move from examining medical encounters as self-contained interactions to situating them within the colonial context. Specifically, it will explore the balance between African agency and colonial authority in amateur doctoring relationships.

Medicine is widely regarded as an important point of contact between colonising Europeans and local populations. As such, we can conceptualise amateur doctoring encounters between white colonisers and local people as (to utilise Pratt's term) contact zones, "social spaces where disparate cultures meet, clash, and grapple with each other, often in highly asymmetric relations of domination and subordination". ${ }^{77}$ Rankin's study of West Africa between 1800 and 1860 employs the concept of a medical marketplace, where different medical traditions competed for customers. ${ }^{78}$ While this approach does encapsulate the medical plurality that also characterised colonial East and South-Central Africa, the free-market imagery of the medical marketplace concept is problematic, as it implies a degree of freedom that vanishes the inherent coercion and constraints of a colonial system. Yet conceiving of amateur medical

\footnotetext{
${ }^{77}$ Pratt, 4.

${ }^{78}$ Rankin, 148, 151.
} 
encounters as a simple transference of colonial hegemonic power also misses the substantial African agency present within individual encounters.

Colonial memoirs illustrate that Europeans generally received large numbers of patients only after establishing a reputation for successful treatments. Many memoirs identify an instance of medical aid, or a particular skill, that gained them a reputation as a healer and attracted African patients. Smith, for example, engaged in little medical work until she treated a man whose neck had been twisted by mine machinery, creating abscesses and reducing him to "a terrible state". ${ }^{79}$ Her regular dressing cured him, and after that she and her husband had many patients. ${ }^{80}$ Local people requiring medical treatment considered settlers' records of medical success and so determined whether to consult them. Parallels can be seen to the experience of Christian missionaries, who usually gained few converts until something proved Christianity as effective as, or more effective than, existing religious beliefs/practices.

Local people tended to consult European amateur doctors for certain conditions and not for others. As Europeans rarely sought patients, the conditions Europeans treated reflects the conditions that local people believed that Europeans could treat effectively and culturally appropriately. The high proportion of wounds and lesions in the treatment records seems a rational identification of settlers' best skills. The disinfectant and bandages that Europeans applied to wounds would have been effective treatments and within amateur doctors' skill range. The memoirs examined contained just three mentions of European involvement with pregnancy, miscarriage, and childbirth. As a culturally important process, it is likely that African communities deliberately rejected European participation in favour of their own care. ${ }^{81}$ Rather than amateur European doctors entirely replacing their own health systems, African communities appear to have incorporated aspects of European treatment into their healthcare system selectively.

Such an interpretation is supported by other patterns in amateur treatment. Several memoirs expressed frustration that patients sometimes waited a long time before seeking treatment. "They generally try all their own native medicines," Smith wrote, "and when they find that they cannot cure the disease they bring it to us, often when it is too late, or when we might have prevented much suffering". ${ }^{2}$ Ann Beck noted that if the CMS doctors at Mengo

\footnotetext{
${ }^{79}$ Smith, 39.

${ }^{80}$ Ibid.

${ }^{81}$ Megan Vaughan highlights the cultural importance of traditional midwifery practices in Nyasaland. Megan Vaughan, 'Health and Hegemony: Representation of Disease and the Creation of the Colonial Subject in Nyasaland' in Dagmar Engles and Shula Marks (eds.), Contesting Colonial Hegemony: State and Society in Africa and India (London and New York: British Academic Press, 1994), 194.

${ }^{82}$ Smith, 40.
} 
did not effect a cure sufficiently fast, patients would often leave and seek treatment from a local witchdoctor. ${ }^{83}$ Tilly, in Flame Trees, was initially consulted after a Kikuyu woman miscarried. ${ }^{84}$ Before Tilly could take her to hospital, the woman's relatives removed her from Tilly's influence and summoned a witchdoctor. ${ }^{85}$ If we ignore the anger and disapproval accompanying authors' descriptions of these events, and read against the grain, then they illustrate that European amateur treatment was part of a range of sources of African community health. They also suggest that individuals, or at least their families, had a certain degree of choice in selecting treatments and changing if greater success seemed likely elsewhere.

Oppositional reading also illuminates patient-doctor conflict over treatment methods, particularly dosage. Vaughan notes that patients frustrated missionaries by misunderstanding medical instructions and purposes - demanding medicine when well, or not taking medicine in accordance with instructions. ${ }^{86}$ Mansfield commented that "if pills are to be given to one man, why, then, any one who looks on must have pains and 'muti' [medicine] too." 87 Fisher urged great care in administering medicine, as patients frequently swallowed several days' dose at once. ${ }^{88}$ She also struggled to communicate the purpose of internal medicine for external complaints. ${ }^{89}$ Although authors typically recounted these anecdotes as evidence of African ignorance and childishness, medical anthropologists have argued that African reinterpretations of European instructions did not necessarily signal misunderstanding, but rather readjustments to better suit African conceptions of treatment, and bodily function and composition. ${ }^{90}$ Luise White suggests, for example, that Africans who took many days' medicine at once may have understood instructions, but believed those instructions were "a misguided and inappropriate way to deal with disease and pain". ${ }^{91}$

Amateur doctoring also subverted colonial expectations around space and contact. Amateur treatment is a physically intimate process involving bodily contact, and also brought sick/injured Africans into white domestic spaces. Europeans generally carried out treatment in

\footnotetext{
${ }^{83}$ Beck, 18.

${ }^{84}$ Huxley, Flame Trees, 136.

85 Ibid.

${ }^{86}$ Vaughan, Curing Their Ills, 60.

${ }^{87}$ Mansfield, 205.

${ }^{88}$ Fisher, On the Borders, 204.

${ }^{89}$ Ibid.

${ }^{90}$ Luise White, Speaking with Vampires: Rumour and History in Colonial Africa (Berkeley: University of California Press, 2000), 99; J. M. Michel, 'Why Do People like Medicines? A Perspective from Africa', The Lancet 325.8422 (1985), 210-211; Caroline Bledsoe and Monica Goubaud, 'The Reinterpretation of Western Pharmaceuticals among the Mende of Sierra Leone', Social Science \& Medicine 21.3 (1985), 275-282.

91 White, 99.
} 
transitional, liminal spaces on the fringes of the home's private space: for Blixen a paved terrace, and for Fisher initially the courtyard or verandah (she later constructed a dispensary). ${ }^{92}$ At times amateur doctoring brought the sick inside the house's private domestic space. A beaten slave found refuge and basic first aid within Goy's home, and in Tilly's house "now and again, the bathroom was transformed into an emergency ward". ${ }^{93}$ In her study of Richards, Hazel Ngoshi characterises the Rhodesian farm and household as "enclaves of colonialism". ${ }^{94}$ African sickness disrupted the enclave and flew in the face of professionally endorsed sanitary segregation. The requirements upon Europeans both to enact imperial benevolence through amateur doctoring and also to maintain imperial power by protecting their own health through 'sanitary segregation' were incompatible, and Europeans appear to have given amateur doctoring precedence over hygienic disease avoidance.

While local people did possess agency within amateur doctoring, it is important not to overstate the claim. It cannot be forgotten that European conquest had dramatically worsened health through the introduction of European diseases, increased mobility, and the disruption of existing public health systems. ${ }^{95}$ In essence, many local people would have consulted European settlers about sickness they would not have experienced had Europeans not been present in the region. Even considering just individual encounters, however, African agency was still limited. Although few Europeans felt able to refuse treatment, they ultimately dictated the form that the treatment took. Amateur doctors could summon professional doctors and pressure an unwilling patient to hospital. Blixen insisted that Kamante be admitted to hospital, although she knew that "he did not want to go" and "he trembled" when she dropped him off; she acknowledged her authority when she commented that "he was prevented by his career and his philosophy from protesting much against anything". ${ }^{96}$ Amateur doctors had the power to decide if symptoms were real, and dispense medicine accordingly.

Furthermore, although Europeans' amateur doctoring was probably primarily motivated by compassion, it nevertheless cemented colonial power. No authors suggested that they doctored with the intention of gaining influence among the local people, but that was often the indirect result. The 1912 Handbook of British East Africa openly identified the

\footnotetext{
${ }^{92}$ Blixen, Out of Africa, 29; Ruth B. Fisher, On the Borders, 57, 80, 199. For discussion of verandahs as threshold spaces, see Brooks, 35-37; Margaret Purser, 'The View from the Verandah: Levuka Bungalows and the Transformation of Settler Identities in Later Colonialism,' International Journal of Historical Archaeology 7.4 (2003), 310; Reed, 39.4.

${ }_{93}^{33}$ Goy, 46; Huxley, Flame Trees, 111.

${ }^{94}$ Hazel Tafadzwa Ngoshi, 'Mapping the Contours of an Imperial and Domestic Settler Subjectivity: Hylda Richards and the Heteroglossia of Her Epoch', Imbizo 1 (2012), 43.

${ }^{95}$ Vaughan, Curing Their Ills, 38-39.

${ }^{96}$ Blixen, Out of Africa, 31.
} 
consequences of amateur treatment, stating that "it is by the administering of medicine and the doctoring of their ailments that one obtains considerable influence over the natives". ${ }^{97}$ Huxley noted that once the Grant family's possession of "healing remedies" became widely known, "women who had refused even to approach us a few weeks ago were already anxious to hand over their children for treatment," speaking to the increasing influence and contact with local people that amateur treatment encouraged. ${ }^{98}$ Successful treatments probably increased the acceptability of particular settlers and thus more generally supported the British colonial presence, even if that was not necessarily the aim of individual settlers.

Lastly, narratives of amateur treatment in popular memoirs bolstered the image of a benevolent empire in the imperial mind. Descriptions of primitive, unhygienic and suffering Africans, elevated through contact with white women, were essential to the narrative of benevolent colonialism, regardless of how well-intentioned individual instances of amateur doctoring may have been. For missionary memoirs, such as those by Fisher, Smith, and Goy, amateur treatment provided religious readers with a vivid illustration of missionaries' Christian work, encouraging financial support and volunteers. Given early missionaries' high mortality and invaliding rates, new recruits and church support were essential. ${ }^{99}$ On occasion, civil service memoirs also played promotional roles. Kenneth Bradley wrote that his Diary of a District Officer was reprinted in 1947 to encourage Colonial Service recruitment as, according to Sir Ralph Furse, it possessed "the merit of being at once factual and romantic". ${ }^{100}$

In the memoirs of settlers who were neither missionaries nor members of the colonial service, descriptions of amateur treatment of local people also fostered a positive perception of Empire among the British public. Conrad's 1899 Heart of Darkness was, as Angela Woollacott notes, "something of a death-knell for the Victorian public's political naiveté" about the human costs of Europe's African empires. ${ }^{101}$ Throughout the Edwardian period, debates over the moral claims of explorers continued in Britain. ${ }^{102}$ Although early twentieth century settler memoirs did not explicitly engage with critiques of empire, they were nevertheless firmly related.

\footnotetext{
${ }^{97}$ Ward and Milligan, 158.

${ }^{98}$ Huxley, Flame Trees, 39.

${ }^{99}$ A 1926 CMS Church Missionary Outlook, for example, called for new recruits and advertised for missionary workers for East Africa. The first volume of Mercy and Truth requested donations for medical work. E. R. Spriggs, 'A Missionary's Job in Tanganyika', Church Missionary Outlook, April 1926, vol.53, available through Adam Matthew, Marlborough, Empire Online, www.empire.amdigital.co.uk, 69-71; 'Recruits Needed for Africa', Church Missionary Outlook, 1926, vol.53, available through Adam Matthew, Marlborough, Empire Online, www.empire.amdigital.co.uk, 74; 'Some of Our Wants', Mercy and Truth, January 1897, Vol.1, available through Adam Matthew, Marlborough, Empire Online, www.empire.amdigital.co.uk, 19-21; Jennings, 65.

${ }^{100}$ Bradley, Once a District Officer, 110.

${ }^{101}$ Woollacott, 67-68.

102 Ibid., 68.
} 
Selflessly providing medical care for local people, the narrator became a Mother Teresa rather than a Mr Kurtz, illustrating Empire's benevolence. Settler memoirs written after World War Two take on an additional significance, claiming white indigeneity and representing settlers as charitable figures during the political instability of the 1950s. ${ }^{103}$ Similarly, memoirs written after decolonisation allow the authors to rewrite Britain's African empire as a benevolent endeavour. The fact that the romanticised view of race relations that appears in Out of Africa (which is formed substantially through Blixen's amateur medical practice) is still widely read and influential is a reminder of the power of seemingly unpolitical women's memoirs to shape the ongoing popular perceptions of British Africa.

Amateur European doctoring of local people appears throughout colonial memoirs. Although largely ignored in the literature, settlers' medical practice was extremely widespread and concentrated on conditions and illnesses that state tropical medicine did not prioritise. European settlers, largely women, carried out basic first aid and treated universal - not distinctively 'tropical' - complaints. They used a limited range of popular medicines and simple home remedies, unlike the long lists of medicines recommended in guidebooks. While some women gained satisfaction from their medical skills, amateur treatment also brought stress and sadness. Women generally developed an ambivalent relationship towards medical activities, avoiding over-stepping amateur boundaries yet also gaining some authority from their work.

The last forty years of scholarship on medicine in the British Empire has firmly established that medicine and colonial power existed hand-in-hand. More recent scholars have sought to temper the narrative of control and oppression with a recognition of indigenous agency in shaping medical systems and experiences. ${ }^{104}$ Amateur treatment displays elements of both colonial oppression and African agency, or, to be more accurate, a pattern of African agency constrained by an oppressive colonial society. In an individual memoir, tales of medical treatment of local people read as an unusual occurrence, yet comparative readings of many memoirs establish that amateur treatment was a fundamental and distinctive element of colonial healthcare.

\footnotetext{
${ }^{103}$ Whitlock, 131.

104 Tilley; Vaughan, Curing their Ills; Vaughan, 'Healing and Curing'.
} 
Conclusion

For white settlers in late nineteenth and early twentieth-century rural Kenya, Rhodesia, Tanganyika, and Nyasaland, a knowledge of medicine was essential. Reflecting the widespread fears within Britain of the African disease environment, settlers supplemented their preexisting knowledge of medicine with information specific to the tropics. They did so via tropical outfitters, advice books for the tropics, advertising from firms such as BWC, short medical courses, and - after arriving in the colonies - from other settlers and their own experience. Often living far from medical professionals, cut off in wet weather, and with limited means of communication, responsibility for day-to-day healthcare fell to settlers themselves. In serious illnesses, most rural settlers supplemented home care with professional medical aid, if it could be summoned in time. While African communities generally included a range of healers, almost no settlers sought medical treatment from local practitioners. Although rural settlers' medical isolation did decrease between 1890 and 1939, substantial delays in summoning medical professionals was a common theme across the half century.

When called upon to carry out treatments, settlers did not simply replicate professional medical advice and ideas, although they did rely upon some professionally produced products. They typically used a small number of well-known medicines (such as quinine and aspirin), disinfectants (combined with bandages), and a range of home remedies to treat Europeans and Africans. Many amateur doctors were skilled at simple wound treatments and become adept at nursing malaria attacks. Alcohol played a central role in amateur treatment that far exceeded its position within medical handbooks, with alcohol utilised to clean, sustain, anaesthetise, cure, and prevent disease. While some techniques grew more popular between 1890 and 1939 (for example, popular awareness of disinfectant increased), the core methods and medicines remained fairly constant. Furthermore, settlers throughout the period embraced a model of disease causation that merged miasmatic traditions and modern germ/vector transmission theories to suit their experiences of health in Africa.

Settlers' management of their bodies reveals further examples of amateur negotiation and reconceptualisation of expert advice. In British Africa, a faith in the power of scientific and medical discoveries coexisted with an intense sense of physical vulnerability to the tropical climate. Guidebooks and medical handbooks laid out detailed regimes of dress, segregation, and 'moderate' moral behaviour that would allow Europeans to protect their bodies and minds from degeneration in the African environment. Although influenced by recommended hygienic 
measures, settlers managed their bodies in far more dynamic and variable ways. Individuals adopted, ignored, compromised, and adapted the advice they encountered, balancing medical recommendations against conflicting needs and producing individualised body management regimes. Their bodies were both discursively produced and regulated, and also unique, malleable places of living and experience. ${ }^{1}$ Settlers' management of their bodies in the African climate is an example of the complex construction of colonial bodies, and the importance of moving beyond prescriptive sources to try to reach settlers' lived experience, even if the records are fragmentary.

As well as treating themselves, settlers also carried out first aid and medical treatment within African communities. Mission hospitals and state healthcare for Africans were insufficient for the vast rural areas (state healthcare did not expand significantly until the 1940s), situating settlers as important medical actors. ${ }^{2}$ The medical encounters between Europeans and their African patients provided many white settlers with their most intimate moments of contact with people whose lands they had occupied. European women tended to record their experiences with ambivalence. They found satisfaction together with sadness and stress, and avoided claiming too much medical authority while still asserting their own medical skill and cementing their position and popularity. Gaining any kind of insight into the motivations and perspectives of Africans who sought treatment from Europeans is extremely difficult through colonial sources: the authors are simply too uninterested, culturally remote, and prejudiced to provide usable evidence. Oppositional reading, however, reveals a pattern of African agency within amateur medical encounters. Yet such agency should not be overstated, as it was constrained by the inherently oppressive colonial system in which amateur treatment took place.

Women's extensive amateur medical practice highlights the important, and often overlooked, role that white women played in British colonialism. While men built roads, women established schools and bandaged wounds. ${ }^{3}$ Women's literary representations of their activities also fed into the narrative of benevolent colonialism. Recorded instances of European sickness and suffering offered a penance for colonial invasion, claiming land through hardship. At the same time, it would be wrong to read settlers' descriptions of amateur treatment simply as pro-imperial propaganda. Medical anecdotes provided drama for memoirs, offering readers tantalising glimpses and graphic descriptions of exotic injuries and illness. Accounts are also

\footnotetext{
${ }^{1}$ Bynum, 5; Canning, 503, 506.

${ }^{2}$ Vaughan, 'Healing and Curing', 288; Cooper, 26.

${ }^{3}$ Forbes, 516.
} 
deeply personal, revealing settlers' sense of vulnerability after migration and distress when faced with sickness or injuries beyond their ability to treat. As well as texts of colonialism, settlers' narratives are also accounts of globally mobile individuals, recording and shaping the experience of migration and life in new and challenging environments.

Settlers' narratives from British East and South-Central Africa were part of a distinctive print culture and a strong literary tradition of colonial memoirs and travelogues. Amateur medical treatment was a process directed, shaped, and narrated through text. Guidebooks and handbooks inspired and influenced settler practice, and settlers told their stories through memoirs, letters, and diaries. Books are physical objects as well as collections of information, and those objects moved throughout the Empire with their owners. Settlers carried guidebooks into Africa, and they sent letters home to Britain and manuscripts to publishers in Cape Town and London. The audiences and genre conventions of memoirs shaped the records of amateur treatment. As well as a medical phenomenon, amateur medicine was a literary phenomenon, and the printed book stands as an important mediator between amateur and professional, and settler and audience.

Historians have long viewed medicine in both colonial and non-colonial settings as a source of power - a collection of objects, ideas, and techniques that can be deployed to enhance the authority of individuals, organisations, or governments. In tropical colonies, medicine's hegemonic role was particularly overt, tied closely and explicitly to colonial control and suppressing/regulating local populations. Western science, and in particular 'modern' tropical medicine, became in British Africa a powerful symbol of authority and colonial superiority. Although historians usually associate such authority with medical professionals, states, and institutions, the importance of amateur medicine highlights the fact that untrained individuals in colonial settings could also draw upon medical authority despite existing outside the colonial medical establishment. Unlike the travelogues studied by Hassan, settler memoirs do not include enough medical detail to consider them as part of a medical dialogue, and were often published long after the events described. ${ }^{4}$ Even so, authors' depictions of medical treatment in the absence of professionals allowed them to adopt - within the particular context of tropical Africa - a portion of professional medical/Western scientific authority.

Although historians of medicine in Africa broadly agree as to the hegemonic intentions of colonial medicine, the degree to which professional colonial medicine achieved those aims is still debated. Vaughan, for example, argues that "the study of colonial medicine has been

\footnotetext{
${ }^{4}$ Hassan, 25.
} 
one of those areas which has illuminated most clearly the limits of colonial power" and states that "in Africa, at least, colonial medics were simply too thin on the ground and their instruments too blunt to be viewed either as agents of oppression or as liberators from disease". 5 An appreciation of the extent of amateur practice in East and South-Central Africa offers another element to this debate. European settlers, although still a tiny proportion of the overall population of the region, were vastly more numerous than colonial doctors. If we widen the view of colonial medicine to include the practice of settlers, rather than just professional doctors and nurses, then the prevalence and influence of colonial medicine in East and SouthCentral Africa is far more extensive.

A further question that emerges from this study is the significance of amateur practice for extending European life in the tropics. Curtin's work quantitatively correlated the medical and sanitary advances of the nineteenth century with declining mortality and morbidity among British troops through the tropical empire. ${ }^{6}$ Could the same be said for amateur treatment? Did settlers' knowledge and practice have an appreciable impact upon their life-span and health? Given the very limited information authors provide and the substantial difficulties of determining accurate diagnoses and prognoses for century-old illnesses, it is impossible to state authoritatively the influence that any individual act of amateur treatment had on the health of the patient. Yet viewing the amateur treatment in general, it seems very probable that settlers' medical aid did extend the life-spans and health of at least some of their patients. If so, then amateur treatment must be viewed alongside colonial medicine as one of the measures that buttressed colonial control by sustaining European settler life and health in the tropics.

Incorporating amateur treatment into the picture of colonial medicine disrupts the traditional narrative of medical progress. Tropical medicine was viewed by its practitioners as a thoroughly modern discipline, intimately tied to a discourse of modernity, medical and scientific progress, and Western superiority. Scholars have increasingly identified the many fundamentally unmodern tendencies in professional tropical medicine - lingering miasmatic thinking, slow percolation of research, the persistence of nineteenth century hygiene advice, and of older medicines and techniques. ${ }^{7}$ Viewing amateur treatment as part of colonial medicine further highlights the continuities rather than advances. Although settlers did utilise some medical developments, they retained climatic etiologies of disease long after germ theory

\footnotetext{
${ }^{5}$ Vaughan, 'Healing and Curing', 288.

${ }^{6}$ Curtin, Death by Migration.

${ }^{7}$ Crozier, 'Sensationalising Africa'; Endfield and Nash; Worboys; Anderson, The Cultivation of Whiteness; Anderson, Colonial Pathologies; Kennedy, 'Diagnosing the Colonial Dilemma'; Johnson, 'Tabloid Brand Medicine Chests'.
} 
was widely accepted by the medical establishment and continued to rely upon long-used home remedies and alcohol for treatment. Ultimately, however, amateur medicine did not attempt to supplant professional medicine, and only operated in the absence of trained doctors and nurses. Despite its prevalence, amateur medicine made no real challenge to professional medicine's authority and expansion.

Was the amateur practice of settlers in Africa unique? In many ways, settler practice in Africa mirrored that around the Empire, and even within Britain. Throughout the Empire it was common for settlers to live in isolated conditions, forcing them to rely upon their own medical skill. In Britain, home remedies persisted into the twentieth century and doctors remained unaffordable for many. At the same time, settlers in East and South-Central Africa acted within a medical and social environment different to any other throughout the Empire, highlighting (as scholars have stressed) the specificity of colonial medicine. The prevalence of falciparum malaria distinguished the African experience from that of British settlers in India, where the less deadly vivax was the primary cause of hospitalisation around $1900 .{ }^{8}$ More importantly, as white settler colonies in a tropical region, Kenya and Rhodesia were extremely unusual. The constant uncertainty about the viability white settlement, fears of physical and mental degeneration, and the small (and consequently vulnerable) white populations created societies in which disease and health were particularly potent issues. The scarcity of professional doctors and large distances between rural settlers and sites of professional medicine further increased the importance of medical self-reliance for rural settlers.

This project exclusively examined British colonies, raising the question of how settlers' experiences compared to those in the African colonies of other European empires. Europeans in colonies such as German East Africa, French West Africa, the Belgian Congo, Italian Somaliland, and Portuguese Mozambique also lived at times in isolation from doctors, and it seems likely that many of the British experiences were shared by Europeans living within other African territories. Within British East and South-Central Africa, other aspects of healthcare also offer intriguing comparisons. Just as settlers carried out medical treatments on one another, they also did so on domestic and farm animals. Amateur veterinary medicine appears throughout memoirs, and even at times features similar techniques used for the amateur treatment of humans. Mental health, although touched on briefly in chapter three, invites far more substantial study. Women's memoirs typically include lengthy discussions of anxiety,

\footnotetext{
${ }^{8}$ Lenore Manderson, Sickness and the State: Health and Illness in Colonial Malaya, 1870-1940 (Cambridge: Cambridge University Press, 2002), 135; Headrick, 64.
} 
depression, loneliness, and worry. Like physical health, settlers believed that their emotional health and wellbeing was at risk from the tropical environment. Maintaining a healthy mind was the subject of frequent discussion in guidebooks.

Amateur practice is hard to locate in sources. Memoirs are seldom indexed and even when examples are discovered, crucial details are often frustratingly absent or glossed over. They are constructed and partial sources, with medical anecdotes selected to fill dramatic roles in memoirs and make particular political statements about Europeans in British Africa. To assemble the examples of amateur practice and medical advice given here required more than seventy memoirs, advice books, novels, letters, diaries, periodicals, and reports. A comprehensive study of amateur medical practice would necessitate a far larger number of sources and many more hours of laborious searching for brief mentions of health and disease. But with a sufficiently large number of sources, enough of those elusive details of the process of amateur treatment could be assembled to draw wider conclusions around the patterns and statistical importance of amateur practice.

Although time consuming, it would be worthwhile, because amateur medical treatment in British Africa mattered. It mattered for those who practiced it, for those whom it treated, and for those who were directly harmed by the strength it gave to white settlement in the region. It was an essential element of colonial medicine in British East and South-Central Africa, both in European and African communities. Examining only professional medicine vanishes a large proportion of individuals' every-day healthcare, and gives but a partial view of European medicine in the region. 
Bibliography

Primary Sources - Unpublished

\section{Manuscripts and Archives}

Barbour, Isobel, Journal Letters of Isobel E. Barbour: Uganda and Kenya, 1927, available through Adam Matthew, Marlborough, Empire Online, www.empire.amdigital.co.uk.

Buxton, Cara, Letters from Cara Buxton to Desmond Buxton, 1913-1924, GB 0162 Micr. Afr.585, Rhodes House Library, Oxford.

Clachan, William James, Letters and Other Papers, 1917, MS-Papers-0503-3 in Clachan, William James, 1892-1918: Papers, MS-Paper-0503, Alexander Turnbull Library, Wellington.

Cook, J. H., Annual Letter from Dr. J. H. Cook, Mengo, 1909, available through Adam Matthew, Marlborough, Empire Online, www.empire.amdigital.co.uk.

CMS Mengo Hospital Report, 1912-1913, available through Adam Matthew, Marlborough, Empire Online, www.empire.amdigital.co.uk.

Hart, Herbert, Diary, 1926, MSX-3897 in Hart Family Papers, MS-Group-0322, Alexander Turnbull Library, Wellington.

Kempthorne, William Oke, William Oke Kempthorne's Ledger Notes, Compiled by B. J. Carruthers, 1870-1919 (Compiled 2002), MS-Papers-11200-36 in Stone Family: Papers, MS-Group-2023, Alexander Turnbull Library, Wellington.

Kirker, James, Travel Diary, 1900-1901, MS-Papers-10821-02 in Kirker, James, 1857-1911:

Papers, MS-Group-1978, Alexander Turnbull Library, Wellington.

Maseno School Report and Related Letter, 1928, available through Adam Matthew, Marlborough, Empire Online, www.empire.amdigital.co.uk.

Mombassa [sic] Medical Officer's Report, 1922, available through Adam Matthew, Marlborough, Empire Online, www.empire.amdigital.co.uk.

Owen, W. E., Letter from Archdeacon Kavirondo W. E. Owen, 1932, available through Adam Matthew, Marlborough, Empire Online, www.empire.amdigital.co.uk.

Report on Mission Stations by Bishop of Mombasa, 1901, available through Adam Matthew, Marlborough, Empire Online, www.empire.amdigital.co.uk. 
St. Hill, George, Letters from Africa, 1893-1904 in Tripp, L. O. H., Histories and Reminiscences, 'Some Notes by L. O. H. Tripp about his friend George H. St. Hill,' 79925 in Acland Family Papers, 44, MacMillan Brown Special Collections, University of Canterbury Library, Christchurch.

$$
\text { Primary Sources - Published }
$$

\section{Books}

Baden-Powell, Robert, Scouting for Boys, Boehmer, Elleke (ed.) (Oxford: Oxford University Press, 2004).

Barnes, A. R, Where the Lion Roars: An 1890 African Colonial Cookery Book, Saffery, David (ed.) (London: Jeppestown Press, 2006).

Blixen, Karen, Letters from Africa, 1914-1931 (Chicago: Chicago University Press, 1981).

- Out of Africa and Shadows on the Grass (London: Penguin, 1985), first published 1937 and 1961.

Boy Scouts of America, Boy Scouts Handbook: The Original 1911 Edition (New York: Skyhorse Publishing, 2012).

Bradley, Emily, Dearest Priscilla: Letters to the Wife of a Colonial Civil Servant (London: Max Parrish, 1950).

— A Household Book for Africa (Oxford: Oxford University Press, 1939).

Bradley, Kenneth, The Diary of a District Officer (Edinburgh: Thomas Nelson and Sons, 1947).

_ Once a District Officer (London: Macmillan, 1966).

Bushman, Hints and Tips for New-Comers to West Africa (London: John Bale, Sons \& Danielsson, 1924).

Caddick, Helen, A White Woman in Central Africa (London: T. Fisher Unwin, 1900).

Cairns, John, Bush and Boma (London: John Murray, 1959).

Cameron, Donald, My Tanganyika Service and Some Nigeria (London: George Allen, 1939).

Church of Scotland Women's Guild, The Kenya Settlers' Cookery Book and Household Guide Fourth edn. (Nairobi: The East African Standard, Ltd., c.1930s).

Cole, Eleanor, Random Recollections of a Pioneer Kenya Settler (Woodbridge: Baron Publishing, 1975). 
Considine, Joan and Rawlins, John (eds.), Childhood Memories of East Africa, 1920-1963 (Slyne-with-Hest: Bongo Books, 2002).

Cross, David Kerr, Health in Africa: A Medical Handbook for European Travellers and Residents (London: James Nisbet \& Co., 1897).

Currie, Jessie, The Hill of Good-Bye: The Story of a Solitary White Woman's Life in Central Africa (London: George Routledge \& Sons, 1920).

Fisher, Ruth, On the Borders of Pigmy Land (London: Marshall Brothers, 1904).

— Twilight Tales of the Black Baganda (London: Frank Cass Publishers, 1970), first published 1911.

Giles, George, Climate and Health in Hot Countries and the Outlines of Tropical Climatology (London: J. Bale, Sons \& Danielsson, 1904).

Goy, Mathilde, Alone in Africa; Or, Seven Years on the Zambesi (London: James Nisbet \& Co., 1901).

Heald, Madeline (ed.), Down Memory Lane with Some Early Rhodesian Women, 1897-1923 (Bulawayo: Books of Rhodesia, 1979).

Hints on the Preservation of Health in Tropical Africa (London: The Crown Agents for the Colonies, 1943).

Hore, Annie, To Lake Tanganyika in a Bath Chair (London: Sampson Low, Marston, Searle \& Rivington, 1886).

Hunt, S. Leigh and Kenny, Alexander S., On Duty Under A Tropical Sun (London: W.H. Allen, 1882).

_Tropical Trials: A Handbook for Women in the Tropics (London: W. H. Allen, 1883).

Huxley, Elspeth, The African Poison Murders (New York: Penguin, 1989), first published as Death of an Aryan, 1939.

- The Flame Trees of Thika: Memories of an African Childhood (London: Chatto \& Windus, 1959).

— Murder at Government House (Oxford: Clio Press, 1990), first published 1937.

— Murder on Safari (New York: Viking, 1989) first published 1938.

- Out in the Midday Sun: My Kenya (New York: Viking, 1987).

The 'Leader' Annual and Gazetter of British East Africa, 1914 (Nairobi and Mombasa: Caxton Publishing, 1914).

Leys, Norman and Oldham, Joseph, By Kenya Possessed: The Correspondence of Norman Leys and J.H. Oldham, 1918-1926, Cell, John (ed.) (Chicago: University of Chicago Press, 1976). 
Mansfield, Charlotte, Via Rhodesia: A Journey through Southern Africa (London: S. Paul, 1911).

Markham, Beryl, West with the Night (London: Virago Press, 1988), first published 1942.

Moir, Jane, A Lady's Letters from Central Africa (Glasgow: James MacLehose, 1891).

Murray, John, How to Live in Tropical Africa: A Guide to Tropical Hygiene (London: George Philip \& Son, 1895).

— How to Live in Tropical Africa: A Guide to Tropical Hygiene (London: The African World Ltd., 1912).

Murray, Stephen Samuel, A Handbook of Nyasaland (London: Crown Agents for the Colonies, 1922).

Page, Gertrude, Jill on a Ranch (London: Cassell and Company, 1921).

Parke, Thomas, Guide to Health in Africa: With Notes on the Country and Its Inhabitants (London: Sampson Low, Marston, 1893).

Reports to the Malaria Committee of the Royal Society (London: Harrison, 1903).

Richards, Hylda, Next Year Will Be Better (Lincoln: University of Nebraska Press, 1985), first published 1952.

Romilly, Hugh and Romilly, Samuel, Letters from the Western Pacific and Mashonaland, 1878-1891 (London: D. Nutt, 1893).

Sellick, Will, The Imperial African Cookery Book: Recipes from English-Speaking Africa (London: Jeppestown Press, 2010).

Simpson, Alyse, The Land That Never Was (Lincoln: University of Nebraska Press, 1985), first published 1937.

Simpson, William, The Maintenance of Health in the Tropics (London: Bale \& Danielsson, 1916).

Smith, Julia, Sunshine and Shade in Central Africa (London: Edwin Dalton, 1908).

Southern Rhodesia: Handbook for the Use of Prospective Settlers on the Land (Cape Town: Minister for Agriculture and Lands, 1924).

Strange, Nora, Kenya Today (London: Stanley Paul, 1934).

Strickrodt, Sike (ed.), Women Writing Home, 1700-1920: Female Correspondence Across the British Empire Vol. 1 (London: Pickering \& Chatto, 2006).

Ward, Harry and Milligan, John, Handbook of British East Africa (London and Nairobi: Sifton Praed and Caxton, 1913).

Waugh, Evelyn, Black Mischief (Harmondsworth: Penguin, 1961), first published 1932. 
Waugh, Evelyn, The Diaries of Evelyn Waugh, Davie, Michael (ed.) (Harmondsworth: Penguin, 1979).

\section{Periodicals}

The African Times and Orient Review (1912-1913)

The African World (1906-1914)

Church Missionary Outlook (1926)

The Lightbearer (1932)

Mercy and Truth (1897)

Secondary Sources

\section{Books}

Anderson, Warwick, Colonial Pathologies: American Tropical Medicine, Race, and Hygiene in the Philippines (Durham: Duke University Press, 2006).

— The Cultivation of Whiteness: Science, Health, and Racial Destiny in Australia (Melbourne: Melbourne University Press, 2002).

Arnold, David (ed.), Imperial Medicine and Indigenous Societies (Manchester: Manchester University Press, 1988).

Beck, Ann, A History of the British Medical Administration of East Africa, 1900-1950 (Cambridge: Harvard University Press, 1970).

Best, Nicholas, Happy Valley (London: Thistle Publishing, 2013).

Bhattacharya, Nandini, Contagion and Enclaves: Tropical Medicine in Colonial India (Liverpool: Liverpool University Press, 2012).

Boddy, Janice, Civilizing Women: British Crusades in Colonial Sudan (Princeton: Princeton University Press, 2007).

Boehmer, Elleke, Colonial and Postcolonial Literature: Migrant Metaphors (Oxford: Oxford University Press, 1995). 
Brelsford, W. V., Generation of Men: The European Pioneers of Northern Rhodesia (Salisbury: Stuart Manning, 1965).

Bristow, Joseph, Empire Boys: Adventures in a Man's World (New York: Harper Collins Academic, 1991).

Burnett, John, Liquid Pleasures: A Social History of Drinks in Modern Britain (London and New York: Routledge, 2012).

Campbell, Chloe, Race and Empire: Eugenics in Colonial Kenya (Manchester: Manchester University Press, 2007).

Collingham, Elizabeth, Imperial Bodies: The Physical Experience of the Raj, c.1800-1947 (Cambridge: Polity, 2001).

Cooper, Frederick, Africa in the World (Cambridge: Harvard University Press, 2014).

Crellin, John, A Social History of Medicines in the Twentieth Century(New York: Pharmaceutical Products Press, 2004).

Crosby, Alfred, Ecological Imperialism: The Biological Expansion of Europe, 900-1900 (Cambridge: Cambridge University Press, 2004), first published 1986.

Crozier, Anna, Practising Colonial Medicine: The Colonial Medical Service in British East Africa (London and New York: I. B. Tauris, 2007).

Curtin, Philip, Death by Migration: Europe's Encounter with the Tropical World in the Nineteenth Century (Cambridge: Cambridge University Press, 1989).

The Image of Africa: British Ideas and Action, 1780-1850 (London: MacMillan, 1965).

Day, Barry, The Essential Noël Coward Compendium: The Very Best of His Work, Life and Times (London: Methuen Drama, 2009).

Fabian, Johannes, Out of Our Minds: Reason and Madness in the Exploration of Central Africa (Berkeley: University of California Press, 2000).

Fraser, Gertrude, African American Midwifery in the South: Dialogues of Birth, Race, and Memory (Cambridge: Harvard University Press, 2009).

Frawley, Maria, A Wider Range: Travel Writing by Women in Victorian England (Madison: Fairleigh Dickinson University Press, 1994).

Gann, Lewis and Duignan, Peter, White Settlers in Tropical Africa (Westport: Greenwood Press, 1977).

Gelfand, Michael, Tropical Victory: An Account of the Influence of Medicine on the History of Southern Rhodesia, 1890-1923 (Cape Town: Juta, 1953).

Ghose, Indira, Women Travellers in Colonial India (Delhi: Oxford University Press, 1999). 
Golant, William, Image of Empire: The Early History of the Imperial Institute, 1887-1925 (Exeter: University of Exeter, 1984).

Haley, Bruce, The Healthy Body and Victorian Culture (Cambridge: Harvard University Press, 1978).

Hansen, Karen, Distant Companions: Servants and Employers in Zambia, 1900-1985 (Ithaca: Cornell University Press, 1989).

Harrison, Mark, Disease and the Modern World: 1500 to the Present Day (Hoboken: John Wiley \& Sons, 2013).

Hassan, Narin, Diagnosing Empire: Women, Medical Knowledge, and Colonial Mobility (Farnham: Ashgate, 2013).

Headrick, Daniel, The Tools of Empire: Technology and European Imperialism in the Nineteenth Century (Oxford: Oxford University Press, 1981).

Iliffe, John, East African Doctors: A History of the Modern Profession (Cambridge: Cambridge University Press, 1998).

Inglis, Andrea Scott, Summer in the Hills: The Nineteenth-Century Mountain Resort in Australia (Melbourne: Australian Scholarly Publishing, 2007).

Johansson, Ingegard, and Somasundaran, P., Handbook for Cleaning/Decontamination of Surfaces (Cambridge: Elsevier, 2007).

Kennedy, Dane, Islands of White: Settler Society and Culture in Kenya and Southern Rhodesia, 1890-1939 (Durham: Duke University Press, 1987).

Kennedy, Rosie, The Children's War: Britain, 1914-1918 (London: Palgrave Macmillan, 2014).

King, Anthony, The Bungalow: The Production of a Global Culture (London: Routledge and Kegan Paul, 1984).

Kirk-Greene, Anthony, On Crown Service: A History of HM Colonial and Overseas Civil Services, 1837-1997 (London: Tauris, 1999).

— Symbol of Authority: The British District Officer in Africa (London and New York: Tauris, 2006).

Klein, Martin, Slavery and Colonial Rule in French West Africa (Cambridge: Cambridge University Press, 1998).

Kuklick, Henrika, The Imperial Bureaucrat: The Colonial Administrative Service in the Gold Coast, 1920-1939 (Stanford: Hoover Institute Press, 1979).

Lake, Marilyn and Reynolds, Henry, Drawing the Global Colour Line: White Men's Countries and the Question of Racial Equality (Melbourne: Melbourne University Press, 2008). 
Li, Jie Jack, Laughing Gas, Viagra, and Lipitor: The Human Stories behind the Drugs We Use (Oxford: Oxford University Press, 2006).

Lorcin, Patricia, Historicizing Colonial Nostalgia: European Women's Narratives of Algeria and Kenya 1900-Present (London: Palgrave Macmillan, 2011).

Lyons, Maryinez, The Colonial Disease: A Social History of Sleeping Sickness in Northern Zaire, 1900-1940 (Cambridge: Cambridge University Press, 1992).

MacLeod, Roy and Lewis, Milton (eds.), Disease, Medicine, and Empire: Perspectives on Western Medicine and the Experience of European Expansion (London: Routledge, 1988).

MacMillan, Margaret, Women of the Raj (London: Thames and Hudson, 1988).

Magner, Lois, A History of Medicine (Boca Raton: CRC Press, 1992).

Manderson, Lenore, Sickness and the State: Health and Illness in Colonial Malaya, 1870-1940 (Cambridge: Cambridge University Press, 2002).

Marland, Hilary, Health and Girlhood in Britain, 1874-1920 (London: Macmillan, 2013).

McClintock, Anne, Imperial Leather: Race, Gender, and Sexuality in the Colonial Contest (London: Routledge, 1995).

McEwan, Cheryl, Gender, Geography and Empire: Victorian Women Travellers in West Africa (Farnham: Ashgate, 2000).

Mills, Sara, Gender and Colonial Space (Manchester: Manchester University Press, 2005).

Mitchell, Sally, Daily Life in Victorian England (Westport: Greenwood, 1996).

Moreau, A. Scott, Corwin, Gary, and McGee, Gary, Introducing World Missions: A Biblical, Historical, and Practical Survey (Grand Rapids: Baker Academic, 2004).

Myers, Garth, Verandahs of Power: Colonialism and Space in Urban Africa (New York: Syracuse University Press, 2003).

Neill, Deborah, Networks in Tropical Medicine: Internationalism, Colonialism, and the Rise of a Medical Specialty, 1890-1930 (Redwood City: Stanford University Press, 2012).

Padwa, Howard, Social Poison: The Culture and Politics of Opiate Control in Britain and France, 1821-1926 (Baltimore: Johns Hopkins University Press, 2012).

Poser, Charles and Bruyn, George, An Illustrated History of Malaria (New York and London: Parthenon Publishing Group, 1999).

Pratt, Mary Louise, Imperial Eyes: Travel Writing and Transculturation (London: Routledge, 1992).

Pulford, Cedric, Casualty of Empire: Britain's Unpaid Debt to an African Kingdom (Woodford Halse: Ituri Publications, 2007). 
Ramsey, Matthew, Professional and Popular Medicine in France 1770-1830: The Social World of Medical Practice (Cambridge: Cambridge University Press, 2002).

Roscoe, Adrian, The Columbia Guide to Central African Literature in English since 1945 (New York: Columbia University Press, 2008).

Scott, Peter, The Making of the Modern British Home: The Suburban Semi and Family Life Between the Wars (Oxford: Oxford University Press, 2013).

Stevenson, Catherine Barnes, Victorian Women Travel Writers in Africa (Farmington Hills: Twayne Publishers, 1982).

Storey, William, Guns, Race, and Power in Colonial South Africa (Cambridge: Cambridge University Press, 2012).

Tilley, Helen, Africa as a Living Laboratory: Empire, Development, and the Problem of Scientific Knowledge, 1870-1950 (Chicago: University of Chicago Press, 2011).

Valenčius, Conevery, The Health of the Country (New York: Basic Books, 2002).

Vaughan, Megan, Curing Their Ills: Colonial Power and African Illness (Redwood City: Stanford University Press, 1991).

Walsh, Judith, Domesticity in Colonial India: What Women Learned when Men gave them Advice (Lanham: Rowman and Littlefield, 2004).

Weisz, George, Divide and Conquer: A Comparative History of Medical Specialization (Oxford: Oxford University Press, 2005).

White, Luise, Speaking with Vampires: Rumor and History in Colonial Africa (Berkeley: University of California Press, 2000).

Whitlock, Gillian, The Intimate Empire: Reading Women's Autobiography (London: Cassell, 2000).

Woollacott, Angela, Gender and Empire (London: Macmillan, 2006).

\section{Articles, Chapters, Conference Papers, and Reports}

Adamson, George, “"The Languor of the Hot Weather": Everyday Perspectives on Weather and Climate in Colonial Bombay, 1819-1828', Journal of Historical Geography 38.2 (2012), 143-154.

Alexander, Kristine, 'The Girl Guide Movement and Imperial Internationalism during the 1920s and 1930s', The Journal of the History of Childhood and Youth 2.1 (2009), 3763. 
Amster, Matthew, 'The Diary of a District Officer: Alastair Morrison's 1953 Trip to the Kelabit Highlands', Borneo Research Bulletin 36 (2005), 91-107.

Anderson, Warwick, 'Immunities of Empire: Race, Disease, and the New Tropical Medicine, 1900-1920', Bulletin of the History of Medicine 70.1 (1996), 94-118.

Arnold, David, 'Disease and Imperialism' in Arnold, David (ed.), Warm Climates and Western Medicine: The Emergence of Tropical Medicine, 1500-1900 (Amsterdam: Rodopi, 1996), 99-107.

—_ 'Introduction: Tropical Medicine Before Manson' in Arnold, David (ed.), Warm Climates and Western Medicine: The Emergence of Tropical Medicine, 1500-1900 (Amsterdam: Rodopi, 1996), 1-19.

Blake, Susan, 'A Woman's Trek: What Difference does Gender Make?' in Chaudhuri, Nupur and Strobel, Margaret (eds.), Western Women and Imperialism: Complicity and Resistance (Indianapolis: Indiana University Press, 1992), 19-34.

Bledsoe, Caroline and Goubaud, Monica, 'The Reinterpretation of Western Pharmaceuticals among the Mende of Sierra Leone', Social Science \& Medicine 21.3 (1985), 275-282.

Brooks, Barbara, 'In Search of Verandahs', Island 112 (2008), 32-37.

Burton, Antoinette, 'The White Woman's Burden: British Feminists and “The Indian Woman”, 1865-1915' in Chaudhuri, Nupur and Strobel, Margaret (eds.), Western Women and Imperialism: Complicity and Resistance (Indianapolis: Indiana University Press, 1992), 137-157.

Bynum, Caroline, 'Why All the Fuss about the Body? A Medievalist's Perspective', Critical Inquiry 22.1 (1995), 1-33.

Callaway, Helen, 'Dressing for Dinner in the Bush: Rituals of Self-Definition and British Imperial Authority' in Barnes, Ruth and Eicher, Joanne (eds.), Dress and Gender: Making and Meaning in Cultural Contexts (Oxford: Berg, 1992), 232-247.

Canning, Kathleen, 'The Body as Method? Reflections on the Place of the Body in Gender History', Gender \& History 11.3 (November 1999), 499-513.

Charumbira, Ruramisai, 'Administering Medicine Without a License: Missionary Women in Rhodesia's Nursing History, 1890-1901', Historian 68.2 (2006), 241-266.

Chattopadhyay, Swati, "Blurring Boundaries: The Limits of "White Town" in Colonial Calcutta', The Journal of the Society of Architectural Historians 59.2 (2000), 154-179.

Crozier, Anna, 'Sensationalising Africa: British Medical Impressions of Sub-Saharan Africa, 1890-1939', Journal of Imperial and Commonwealth History 35.3 (2007), 393-415. 
Curtin, Philip, 'Medical Knowledge and Urban Planning in Tropical Africa', The American Historical Review 90.3 (1985), 594-613.

Dalton, Heather, 'The Gold Coast: The Wives' Experience', Oxford Development Records Project Report No. 15 (Oxford: Rhodes House Library, 1985).

David, Deirdre, 'Imperial Chintz: Domesticity and Empire', Victorian Literature and Culture 27.2 (1999), 569-577.

De Caro, Francis and Jordan, Rosan, 'The Wrong Topi: Personal Narratives, Ritual, and the Sun Helmet as a Symbol', Western Folklore 43.4 (1984), 233-248.

Driver, Felix and Martins, Luciana, 'Introduction' in Driver, Felix and Martins, Luciana (eds.), Tropical Visions in an Age of Empire (Chicago: Chicago University Press, 2005), 320.

Duder, C. J. D., 'Love and the Lions: The Image of White Settlement in Kenya in Popular Fiction, 1919-1939', African Affairs 90.360 (1991), 427-438.

Edmond, Rod, 'Returning Fears: Tropical Disease and the Metropolis' in Driver, Felix and Martins, Luciana (eds.), Tropical Visions in an Age of Empire (Chicago: Chicago University Press, 2005), 175-194.

Endfield, Georgina and Nash, David, “"Happy Is the Bride the Rain Falls On”: Climate, Health and "the Woman Question" in Nineteenth-Century Missionary Documentation', Transactions of the Institute of British Geographers 30.3 (2005), 368-386.

Fassin, Didier, 'Embodied History: Uniqueness and Exemplarity of South African AIDS', African Journal of AIDS Research 1.1 (2002), 63-68.

Forbes, Geraldine, 'Medical Careers and Health Care for Indian Women: Patterns of Control', Women's History Review 3.4 (1994), 515-530.

Freed, Libbie, “"Every European Becomes a Chief': Travel Guides to Colonial Equatorial Africa, 1900-1958', Journal of Colonialism and Colonial History, 12.2 (Fall 2011).

Gariepy, Thomas, 'Antisepsis' in Heilbron, John (ed.), The Oxford Companion to the History of Modern Science (Oxford: Oxford University Press, 2003), 41-42.

George, C. R., 'Blackwater Fever: The Rise and Fall of an Exotic Disease', Journal of Nephrology 22 (2008), 120-128.

Gutzke, David, "The Cry of the Children": The Edwardian Medical Campaign Against Maternal Drinking', British Journal of Addiction 79.1 (1984), 71-84.

Hill, Jude, 'Globe-Trotting Medicine Chests: Tracing Geographies of Collecting and Pharmaceuticals', Social and Cultural Geography 7.3 (2006), 365-384. 
Hunter, Kate, 'More than an Archive of War: Intimacy and Manliness in the Letters of a Great War Soldier to the Woman He Loved, 1915-1919', Gender \& History 25.2 (2013), $339-354$.

Jennings, Michael, "'Healing of Bodies, Salvation of Souls": Missionary Medicine in Colonial Tanganyika, 1870s-1939', Journal of Religion in Africa 38 (2008), 27-56.

— “This Mysterious and Intangible Enemy": Health and Disease Amongst the Early UMCA Missionaries, 1860-1918', Social History of Medicine 15.1 (2002), 65-87.

Johnson, Ryan, 'Colonial Mission and Imperial Tropical Medicine: Livingstone College, London, 1893-1914', Social History of Medicine 23.3 (2010), 549-566.

— 'Commodity Culture: Tropical Health and Hygiene in the British Empire', Endeavour 32.2 (2008), 70-74.

_ European Cloth and "Tropical” Skin: Clothing Material and British Ideas of Health and Hygiene in Tropical Climates', Bulletin of the History of Medicine 83.3 (2009), 530560.

_ 'Tabloid Brand Medicine Chests: Selling Health and Hygiene for the British Tropical Colonies', Science as Culture 17.3 (2008), 249-268.

Jones, Margaret, 'The Ceylon Malaria Epidemic of 1934-35: A Case Study in Colonial Medicine', Social History of Medicine 13.1 (2000), 87-110.

Kennedy, Dane, 'Diagnosing the Colonial Dilemma: Tropical Neurasthenia and the Alienated Briton' in Ghosh, Durba and Kennedy, Dane (eds.), Decentring Empire: Britain, India, and the Transcolonial World (Hyderabad: Orient Longman, 2006), 157-181.

— 'Introduction' in Simpson, Alyse, The Land That Never Was (Lincoln: University of Nebraska Press, 1985), v-X.

Kirk-Greene, Anthony, 'The Colonial Service in the Novel' in Smith, John (ed.) Administering Empire: The British Colonial Service in Retrospect (London: University of London Press, 1999), 19-48.

Kirkwood, Deborah, 'Settler Wives in Southern Rhodesia: A Case Study' in Callan, Hilary and Ardener, Shirley (eds.), The Incorporated Wife (London: Croom Helm, 1984), 143164.

Landau, Paul, 'Explaining Surgical Evangelism in Colonial Southern Africa: Teeth, Pain and Faith', The Journal of African History 37.2 (1996), 261-281.

Livingstone, David, 'Tropical Climate and Moral Hygiene: The Anatomy of a Victorian Debate', The British Journal for the History of Science 32.1 (1999), 93-110. 
Locher-Scholten, Elsbeth, 'So Close and Yet so Far: The Ambivalence of Dutch Colonial Rhetoric on Javanese Servants in Indonesia, 1900-1942' in Clancy-Smith, Julia and Gouda, Frances (eds.), Domesticating the Empire: Race, Gender, and Family Life in French and Dutch Colonialism (Charlottesville: University of Virginia Press, 1998), $131-153$.

MacKenzie, John, 'Empires of Travel: British Guide Books and Cultural Imperialism in the $19^{\text {th }}$ and $20^{\text {th }}$ Centuries' in Walton, John (ed.), Histories of Tourism: Representation, Identity and Conflict (Clevedon: Channel View Publications, 2005), 19-38.

MacLeod, Roy, 'Introduction' in MacLeod, Roy and Lewis, Milton (eds.), Disease, Medicine and Empire: Perspectives on Western Medicine and the Experiences of European Expansion (London and New York: Routledge, 1988), 1-18.

Marks, Lara and Worboys, Michael, 'Introduction' in Marks, Lara and Worboys, Michael (eds.), Migrants, Minorities and Health: Historical and Contemporary Studies (London and New York: Routledge, 1997), 1-21.

Marks, Shula, 'What is Colonial about Colonial Medicine? And What has Happened to Imperialism and Health?' Social History of Medicine 10.2 (1997), 205-219.

Máthé-Shires, László, 'Imperial Nightmares: The British Image of "the Deadly Climate" of West Africa, c.1840-74', European Review of History 8.2 (2001), 137-156.

Michel, J. M., 'Why Do People like Medicines? A Perspective from Africa', The Lancet 325.8422 (1985), 210-211.

Mills, Sarah, 'Knowledge, Gender, and Empire' in Blunt, Alison and Rose, Gillian (eds.), Writing Women and Space: Colonial and Postcolonial Geographies (New York and London: The Guilford Press, 1994), 26-50.

Mitman, Gregg and Numbers, Ronald, 'From Miasma to Asthma: The Changing Fortunes of Medical Geography in America', History and Philosophy of the Life Sciences 25.3 (2003), 391-412.

Nelson, Megan, 'The landscape of disease: Swamps and medical discourse in the American Southeast, 1800-1880', The Mississippi Quarterly 55.4 (2002), 535-568.

Ngoshi, Hazel, 'Mapping the Contours of an Imperial and Domestic Settler Subjectivity: Hylda Richards and the Heteroglossia of Her Epoch', Imbizo 1 (2012), 34-46.

Olsen, Gerald, "'Physician Heal Thyself”: Drink, Temperance and the Medical Question in the Victorian and Edwardian Church of England, 1830-1914', Addiction 89.9 (1994), $1167-1176$. 
Purser, Margaret, 'The View from the Verandah: Levuka Bungalows and the Transformation of Settler Identities in Later Colonialism', International Journal of Historical Archaeology 7.4 (2003), 293-314.

Ranger, Terence, 'Godly Medicine: The Ambiguities of Medical Mission in South-East Tanzania, 1900-1945', Social Science and Medicine 15.3 (1981), 261-277.

Reed, Liz, “"Mrs Bon's Verandah Full of Aboriginals”: Race, Class, Gender and Friendship', History Australia 2.2 (2011), 39.1-39.15.

Renbourn, E. T., 'The History of the Flannel Binder and Cholera Belt', Medical History 1 (1957), 211-225.

_ 'Life and Death of the Solar Topi: A Chapter in the History of Sunstroke', paper presented at the Seventh Commonwealth Defence Conference on Clothing and General Store, London, 1961.

Roberts, Andrew, 'Introduction' in Roberts, Andrew (ed.), The Colonial Moment in Africa: Essays on the Movement of Minds and Materials, 1900-1940 (Cambridge: Cambridge University Press, 1990), 3-23.

Tomes, Nancy, 'The Private Side of Public Health: Sanitary Science, Domestic Hygiene, and the Germ Theory, 1870-1900', Bulletin of the History of Medicine 64.4 (1990), 509539.

Tough, Alistair, 'Oral Culture, Written Records and Understanding the Twentieth-Century Colonial Archive: The Significance of Understanding from Within', Archival Science 12.3 (2012), 245-265.

Vaughan, Megan, 'Healing and Curing: Issues in the Social History and Anthropology of Medicine in Africa', Social History of Medicine 7.2 (1994), 283-295.

_ 'Health and Hegemony: Representation of Disease and the Creation of the Colonial Subject in Nyasaland' in Engles, Dagmar and Marks, Shula (ed.), Contesting Colonial Hegemony: State and Society in Africa and India (London and New York: British Academic Press, 1994), 173-201.

Warren, Allen, 'Popular Manliness: Baden-Powell, Scouting, and the Development of Manly Character' in Mangan, J. A. and Walvin, James (eds.), Manliness and Morality: Middle-class Masculinity in Britain and America 1800-1940 (New York: St Martin's Press, 1987), 199-219.

Wolf, James, 'A Woman Passing Through: Helen Caddick and the Maturation of the Empire in British central Africa', Journal of Popular Culture 30.3 (1996) 35-55. 
Worboys, Michael, 'Germs, Malaria and the Invention of Mansonian Tropical Medicine: From "Diseases in the Tropics" to "Tropical Diseases" in Arnold, David (ed.), Warm Climates and Western Medicine: The Emergence of Tropical Medicine, 1500-1900 (Amsterdam: Rodopi, 1996), 181-207.

\section{Theses}

Freeman, Staci, 'Medicine and Morality: The Use of Rhetoric in Victorian Marriage and Child Rearing Manuals', MA Thesis, East Central University, 2012.

Rankin, John, 'Healing the "African Body" in the Age of Abolition? British Medicine in West Africa, c.1800-1860', Ph.D. Thesis, McMaster University, 2010. 